\title{
Transverse Migration of Chemotactic Bacteria Toward \\ Chemical Attractants in a Two Dimensional Microcosm with \\ Convective Flow
}

\author{
A Thesis \\ Presented to
}

The Faculty of the School of Engineering and Applied Science

University of Virginia

In Partial Fulfillment

of the Requirements for the Degree

Master of Science (Chemical Engineering)

by

Brittany Boser

August 2012 
APPROVAL SHEET

The thesis

is submitted in partial fulfillment of the requirements for the degree of

Master of Science

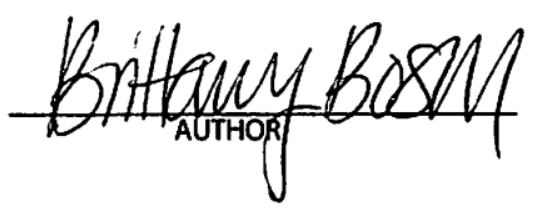

The thesis has been read and approved by the examining committee:
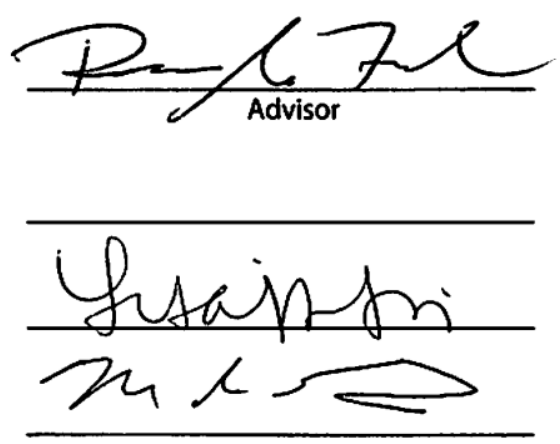

Accepted for the School of Engineering and Applied Science:

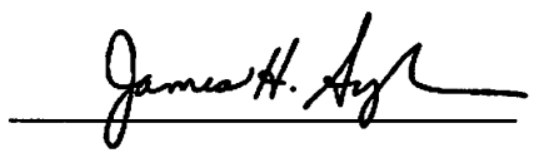

Dean, School of Engineering and Applied Science

August

2012

ii 


\section{Abstract}

Bioremediation is often limited by the inability to bring populations of bacteria capable of degradation into contact with groundwater contaminants. Chemotaxis, the ability of bacteria to sense a chemical gradient and swim preferentially towards locations of high concentration, can enhance the biased transport of bacteria. Improving bacterial transport to contaminant sources in groundwater aquifers offers a way to potentially improve the overall effectiveness of in situ bioremediation. A two-dimensional microcosm packed with quartz sand was used to quantify the effect of chemotaxis on the migration of bacteria in porous media. Aqueous media was pumped across the microcosm at approximately $1 \mathrm{~m}$ /day to simulate the conditions found naturally in a groundwater aquifer. A plume of sodium benzoate was continuously injected into the microcosm to create an attractant gradient transverse to flow. The chemotactic bacteria, Pseudomonas putida F1, or the nonchemotactic mutant, Pseudomonas putida F1 CheA, were injected with a fluorescent tracer above or below the attractant. A moment analysis was implemented to estimate the center of mass, variance, and skewness of the concentration profiles. The transverse dispersion coefficient and the transverse dispersivity transport parameters were also determined.

Results show that the center of mass for the chemotactic bacteria was closer to the attractant source on average than the nonchemotactic control when compared to the uranine tracer for experiments using a pulse injection of bacteria. Experiments were also performed using a continuous injection of bacteria and the center of mass for chemotactic bacteria was closer to the attractant source on average than the nonchemotactic control when compared to the uranine tracer. These results showed that chemotaxis can increase bacterial transport toward 
contaminants, potentially enhancing in situ bioremediation. Experiments with $3 \mathrm{~cm}$ and $2 \mathrm{~cm}$ spacing between bacteria and attractant were performed to explore the relationship between the exposure time of the bacteria to attractant and the transverse migration of bacteria due to chemotaxis. A difference was not found between the experimental results for $3 \mathrm{~cm}$ spacing and $2 \mathrm{~cm}$ spacing.

Experimentally determined transport parameters were used as input to a two-dimensional mathematical model. Modeling was used to test the effects of changing the chemotactic sensitivity coefficient and the chemotaxis receptor constant at three different bacteria and attractant separation distances: $4 \mathrm{~cm}, 3 \mathrm{~cm}$, and $2 \mathrm{~cm}$. A chemotactic sensitivity coefficient of $10^{-4} \mathrm{~cm}^{2} / \mathrm{s}$ was found to match the change in center of mass determined experimentally for $3 \mathrm{~cm}$ and $2 \mathrm{~cm}$ separation distances. Model results showed the center of mass shift for chemotactic bacteria was greater for $3 \mathrm{~cm}$ and $2 \mathrm{~cm}$ spacing than $4 \mathrm{~cm}$ spacing at constant chemotactic sensitivity coefficient values, which shows that increasing the exposure time of the bacteria to the attractant can increase the transverse migration of bacteria. Mathematical modeling is a valuable tool that can be used to predict which values of chemotactic sensitivity coefficient, chemotaxis receptor constant, and injection spacing will provide the greatest transverse migration of chemotactic bacteria. 


\section{Table of Contents}

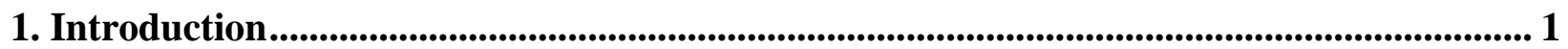

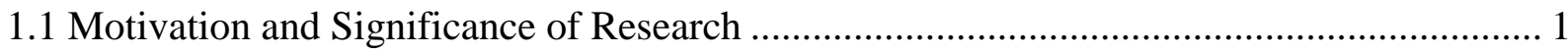

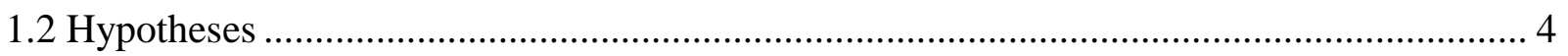

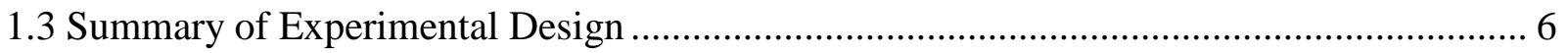

2. Background ............................................................................................................................................... 9

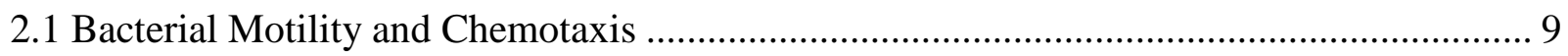

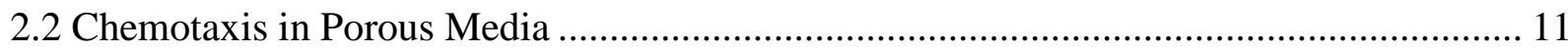

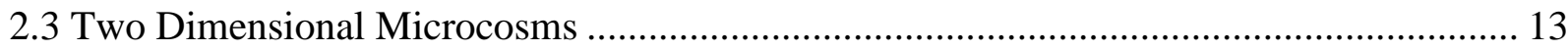

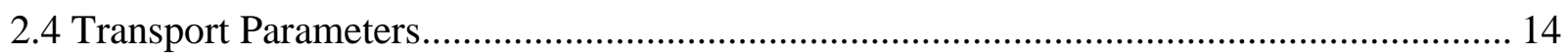

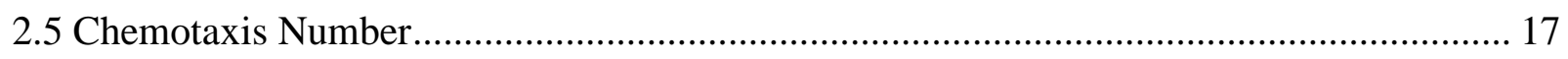

2.6 Two-Dimensional Mathematical Model ....................................................................... 18

3. Materials and Methods........................................................................................................................... 20

3.1 Two- Dimensional Microcosm Configuration …………………................................. 20

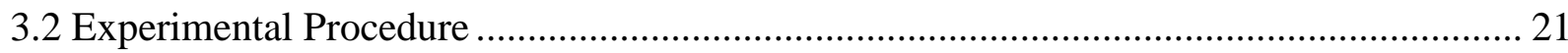

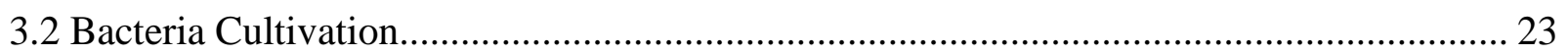

3.3 Injections and Sampling ………………………….............................................. 24

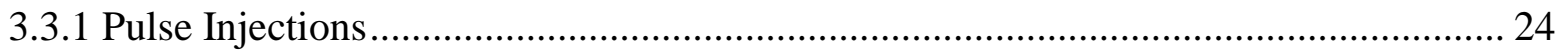

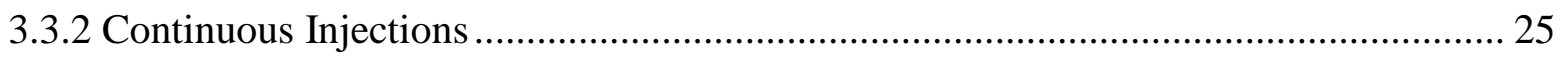

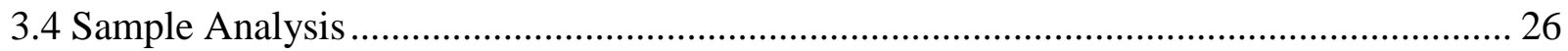

3.5 Estimation of Transport Parameters ......................................................................... 28

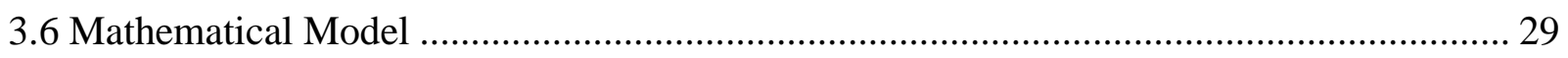

4. Results for Pulse Injection Experiments........................................................................................ 32

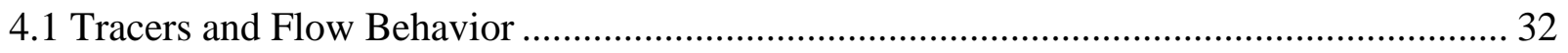

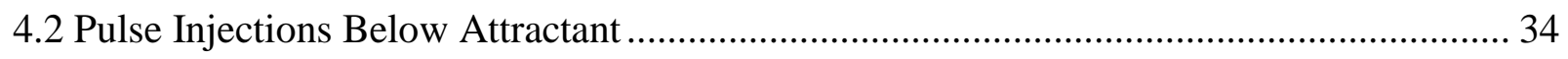

4.2 Pulse Injections Without Attractant ................................................................................ 40

4.3 Pulse Injections Above Attractant ................................................................................ 41

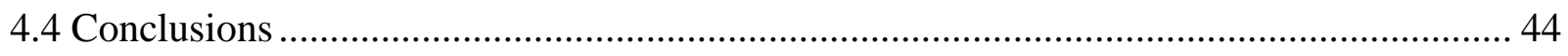

5. Results for Continuous Injection Experiments ................................................................................. 46

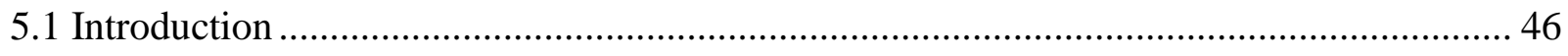


5.2 Continuous Injections Below Attractant at $3 \mathrm{~cm}$ Spacing......................................... 47

5.3 Continuous Injections Below Attractant at $2 \mathrm{~cm}$ Spacing......................................... 52

5.4 Continuous Injections Above Attractant ................................................................... 59

5.5 Continuous Injections Below Attractant Using Denser Media ..................................... 60

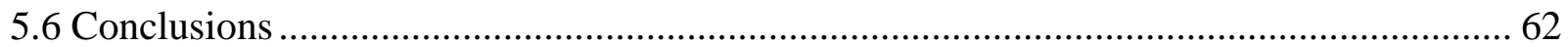

6. Results of Mathematical Modeling..................................................................................6 63

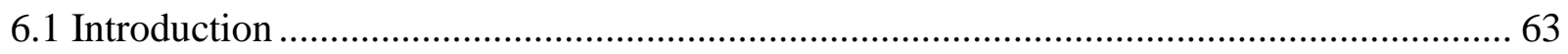

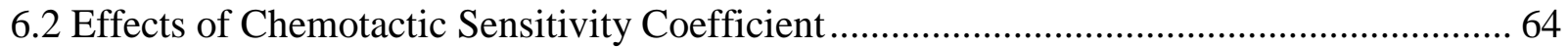

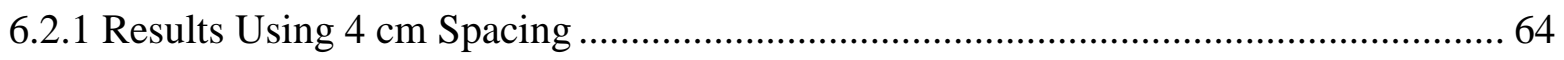

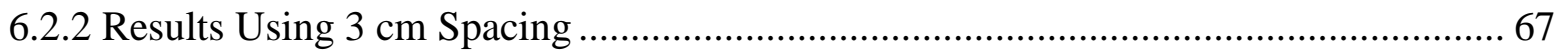

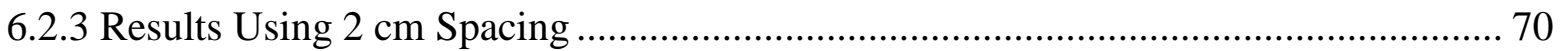

6.3 Effects of Chemotactic Receptor Constant ............................................................. 73

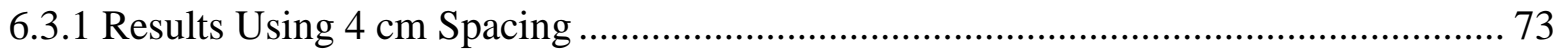

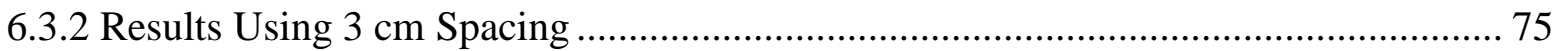

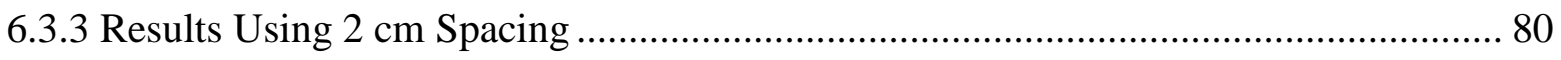

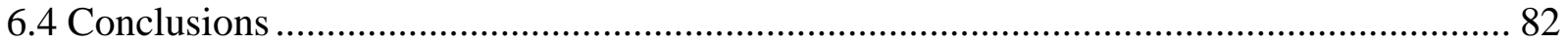

7. Conclusions and Recommendations ............................................................................ 84

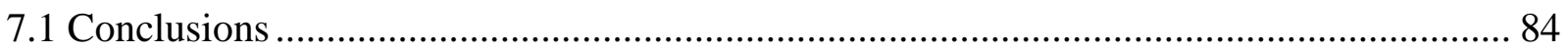

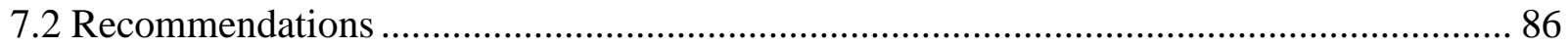

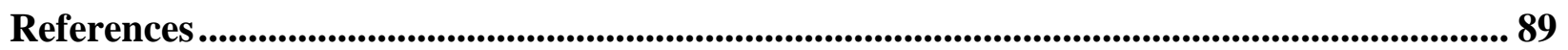

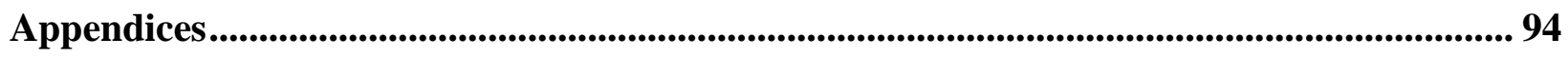

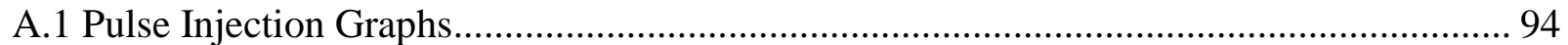

A.2 Effect of Background Bacteria Selection on Moment Analysis.................................... 97

A.3 Comparison of Methods to Calculate Transverse Dispersion ........................................ 99

A.4 Images from Mathematical Modeling .................................................................... 102 


\section{List of Figures}

Figure 1.1 Chemotactic bacteria migrating transverse to flow out of a coarse sand region to reach contaminants trapped in a fine grain clay lens, image adapted from (Kusy 2005; X. Wang 2010).

Figure 2.1 Bacterial random motility and chemotaxis. (a) In an isotropic solution, individual bacterium swims randomly in a series of runs and tumbles. The straight lines indicate runs, and the line vertices indicate tumbles. (b) This random motion appears as an even distribution on the macroscopic scale. In the bottom two figures, the shading represents areas of increasing attractant concentration. (c) Chemotaxis increases the run length as the bacteria is swimming toward regions of higher attractant concentration. (d) This biased run and tumble pattern results in a bulk movement toward areas of higher attractant concentration, and a chemotaxis band forms at regions of higher attractant concentration. Image modified from (Lanning 2004; X. Wang 2010).

Figure 3.1 Images of two-dimensional microcosm configuration. (a) Inlet aqueous media, attractant plume, and pump. (b) Outlet capillaries, tubing, and pump. (c) Microcosm with a steady state attractant plume.

Figure 3.2 Images of microcosm injections of bacteria (yellow) and attractant (blue). (a) Pulse injection of bacteria below attractant plume. (b) Continuous injection of bacteria above attractant plume.

Figure 4.1 Images of transverse velocity gradients due to flow inconsistencies. (a) Pulse injection of colorful tracer in each port. (b) Pulse injection in each port after travelling about $3 / 4$ of the way through the microcosm. Tracer that has travelled furthest indicates regions of high velocity, tracer that has lagged behind indicates regions of low velocity. 33

Figure 4.2 Shapes of pulse injection in the two dimensional microcosm. The small circular inlet pulse shape is shown on the bottom left. The final outlet shape of the pulse injection is shown on the bottom right. The direction of flow is left to right in this image.. 34

Figure 4.3 Transverse population distributions from 2-D microcosm experiments with bacteria pulse injections below attractant plume. Chemotactic bacteria $P$. putida F1 are represented as red squares, $\mathbf{\square}$, (a, c) and nonchemotactic bacteria $P$. putida $\mathrm{F} 1 \mathrm{CheA}$ are represented as red squares, $\boldsymbol{\square},(\mathrm{b}, \mathrm{d})$. Concentration distributions for the uranine tracer are represented by blue diamonds, $\diamond$, and benzoate attractant concentration represented by green triangles, All bacteria, uranine and benzoate distributions have been normalized by the sum of concentrations from each individual port. Normalized distribution curves have been fit to the nonchemotactic bacteria, uranine, and benzoate data using Equation 3.5.

Figure 4.4 Transverse population distributions from 2-D microcosm experiments without an attractant source for chemotactic bacteria P. putida F1 ( $\square$, a) and non chemotactic bacteria $P$. putida F1 CheA $(\boldsymbol{\square}, \mathrm{b})$ normalized by the sum of bacteria concentrations from each individual port. Uranine tracer distributions, $\diamond$, have been normalized by the sum or uranine concentrations from each port. All bacteria and tracer curves have been fit to a normalized distribution curve using Equation 3.5 ..................................................................... 41 
Figure 4.5 Transverse population distributions from 2-D microcosm experiments with bacteria pulse injections above attractant plume. Chemotactic bacteria $P$. putida $\mathrm{F} 1$ are represented as red squares, $\mathbf{\square}$, (a) and nonchemotactic bacteria $P$. putida $\mathrm{F} 1 \mathrm{CheA}$ are represented as red squares, $\mathbf{\square}$, (b). Concentration distributions for the uranine tracer are represented by blue diamonds, $\boldsymbol{\nabla}$, and benzoate attractant concentration represented by green triangles, $\boldsymbol{\Delta}$. All bacteria, uranine and benzoate distributions have been normalized by the sum of concentrations from each individual port. Normalized distribution curves have been fit to the nonchemotactic bacteria, uranine, and benzoate data using Equation 3.5.

Figure 5.1 Transverse population distributions from 2-D microcosm experiments with continuous bacteria injections $3 \mathrm{~cm}$ below attractant plume. Chemotactic bacteria $P$. putida F1 are represented as red squares, $\mathbf{\square},(\mathrm{a}, \mathrm{c})$ and nonchemotactic bacteria $P$. putida $\mathrm{F} 1 \mathrm{CheA}$ are represented as red squares, $\mathbf{\square},(\mathrm{b}, \mathrm{d})$. Concentration distributions for the uranine tracer are represented by blue diamonds, $\diamond$, and benzoate attractant concentration represented by green triangles, $\boldsymbol{\Delta}$. All bacteria, uranine and benzoate distributions have been normalized by the sum of concentrations from each individual port. Normalized distribution curves have been fit to the nonchemotactic bacteria, uranine, and benzoate data using Equation 3.5 ...... 48

Figure 5.2 Transverse population distributions from 2-D microcosm experiments with continuous bacteria injections $2 \mathrm{~cm}$ below attractant plume. Chemotactic bacteria $P$. putida F1 are represented as red squares, $\mathbf{\square},(\mathrm{a}, \mathrm{c})$ and nonchemotactic bacteria $P$. putida F1 CheA are represented as red squares, $\mathbf{\square},(\mathrm{b}, \mathrm{d})$. Concentration distributions for the uranine tracer are represented by blue diamonds, $\diamond$, and benzoate attractant concentration represented by green triangles, $\boldsymbol{\Lambda}$. All bacteria, uranine and benzoate distributions have been normalized by the sum of concentrations from each individual port. Normalized distribution curves have been fit to the nonchemotactic bacteria, uranine, and benzoate data using Equation 3.5...... 53

Figure 5.3 Transverse population distributions from 2-D microcosm experiments with continuous bacteria injections (a) $3 \mathrm{~cm}$ and (b) $2 \mathrm{~cm}$ below attractant plume. All bacteria distributions have been adjusted so that the $\mathrm{x}$-axis represents the center of mass location for the uranine tracer. Chemotactic bacteria $P$. putida $\mathrm{F} 1$ are represented as blue diamonds, $\diamond$, and nonchemotactic bacteria P. putida F1 CheA are represented as red circles, $\bullet$. A normalized distribution curve has been fit to the nonchemotactic data points. Background bacteria data points have been subtracted out.

Figure 5.4 Transverse population distributions from 2-D microcosm experiments with continuous bacteria injections $3 \mathrm{~cm}$ above attractant plume. Chemotactic bacteria $P$. putida F1 are represented as red squares, $\mathbf{\square}$, (a,) and nonchemotactic bacteria $P$. putida F1 CheA are represented as red squares, $\mathbf{\square}$, (b). Concentration distributions for the uranine tracer are represented by blue diamonds, $\diamond$, and benzoate attractant concentration represented by green triangles, $\boldsymbol{\Delta}$. All bacteria, uranine and benzoate distributions have been normalized by the sum of concentrations from each individual port. Normalized distribution curves have been fit to the nonchemotactic bacteria, uranine, and benzoate data using Equation 3.5. 
Figure 5.5 Transverse population distributions from 2-D microcosm experiments with continuous bacteria injections $3 \mathrm{~cm}$ below attractant plume using 10\% glycerol in AGW to increase media density. Chemotactic bacteria $P$. putida F1 are represented as red squares, $\mathbf{\square}$, (a,) and nonchemotactic bacteria $P$. putida F1 CheA are represented as red squares, $\mathbf{\square}$, (b). Concentration distributions for the uranine tracer are represented by blue diamonds, $\diamond$, and benzoate attractant concentration represented by green triangles, $\boldsymbol{\Lambda}$. All bacteria, uranine and benzoate distributions have been normalized by the sum of concentrations from each individual port. Normalized distribution curves have been fit to the nonchemotactic bacteria,

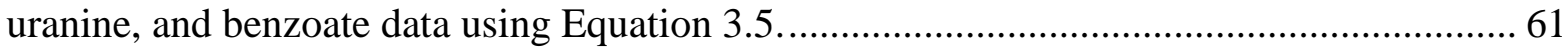

Figure 6.1 Transverse population distributions from two-dimensional mathematical modeling using different values of the chemotactic sensitivity coefficient with continuous bacteria injections $4 \mathrm{~cm}$ below attractant plume.

Figure 6.2 Transverse population distributions from two-dimensional mathematical modeling using different values of the chemotactic sensitivity coefficient with continuous bacteria injections $3 \mathrm{~cm}$ below attractant plume.

Figure 6.3 Transverse population distributions from two-dimensional mathematical modeling using different values of the chemotactic sensitivity coefficient with continuous bacteria injections $2 \mathrm{~cm}$ below attractant plume.

Figure 6.4 Transverse population distributions from two-dimensional mathematical modeling using different values of the chemotaxis receptor constant and constant $\chi_{0}$ of $2 \times 10^{-4} \mathrm{~cm}^{2} / \mathrm{s}$ with continuous bacteria injections $4 \mathrm{~cm}$ below attractant plume.

Figure 6.5 Transverse population distributions from two-dimensional mathematical modeling using different values of the chemotaxis receptor constant and constant $\chi_{0}$ of $10^{-4} \mathrm{~cm}^{2} / \mathrm{s}$ with continuous bacteria injections $3 \mathrm{~cm}$ below attractant plume.

Figure 6.6 Transverse population distributions from two-dimensional mathematical modeling using different values of the chemotaxis receptor constant and constant $\chi_{0}$ of $10^{-3} \mathrm{~cm}^{2} / \mathrm{s}$ with continuous bacteria injections $3 \mathrm{~cm}$ below attractant plume.

Figure 6.7 Transverse population distributions from two-dimensional mathematical modeling using different values of the chemotaxis receptor constant and constant $\chi_{0}$ of $10^{-4} \mathrm{~cm}^{2} / \mathrm{s}$ with continuous bacteria injections $2 \mathrm{~cm}$ below attractant plume.

Figure A.1 Transverse population distributions from 2-D microcosm experiments with bacteria pulse injections below attractant plume in port 10. Chemotactic bacteria P. putida $\mathrm{F} 1$ are represented as red squares, $\mathbf{\square}$, (a) and nonchemotactic bacteria $P$. putida F1 CheA are represented as red squares, $\mathbf{\square}$, (b). Concentration distributions for the uranine tracer are represented by blue diamonds, $\diamond$, and benzoate attractant concentration represented by green triangles, $\boldsymbol{\Lambda}$. All bacteria, uranine and benzoate distributions have been normalized by the sum of concentrations from each individual port. Normalized distribution curves have been fit to the nonchemotactic bacteria, uranine, and benzoate data using Equation 3.5. 94

Figure A.2 Transverse population distributions from 2-D microcosm experiments with bacteria pulse injections below attractant plume in port 9. Chemotactic bacteria $P$. putida F1 are 
represented as red squares, $\square$, (a) and nonchemotactic bacteria $P$. putida F1 CheA are represented as red squares, $\mathbf{\square}$, (b). Concentration distributions for the uranine tracer are represented by blue diamonds, $\diamond$, and benzoate attractant concentration represented by green triangles, $\boldsymbol{\Lambda}$. Bacteria, uranine and benzoate distributions have been normalized by the sum of concentrations from each individual port. Normalized distribution curves have been fit to the nonchemotactic bacteria, uranine, and benzoate data using Equation 3.5. 94

Figure A.3 Transverse population distributions from 2-D microcosm experiments with bacteria pulse injections below attractant plume in port 8 . Chemotactic bacteria $P$. putida F1 are represented as red squares, $\mathbf{\square}$, (a) and nonchemotactic bacteria $P$. putida F1 CheA are represented as red squares, $\mathbf{\square}$, (b). Concentration distributions for the uranine tracer are represented by blue diamonds, $\diamond$, and benzoate attractant concentration represented by green triangles, $\boldsymbol{\Delta}$. All bacteria, uranine and benzoate distributions have been normalized by the sum of concentrations from each individual port. Normalized distribution curves have been fit to the nonchemotactic bacteria, uranine, and benzoate data using Equation 3.5.

Figure A.4 Transverse population distributions from 2-D microcosm experiments with bacteria pulse injections above attractant plume. Chemotactic bacteria $P$. putida $\mathrm{F} 1$ are represented as red squares, $\square$, (a,c) and nonchemotactic bacteria $P$. putida $\mathrm{F} 1 \mathrm{CheA}$ are represented as red squares, $\mathbf{\square}$, (b). Concentration distributions for the uranine tracer are represented by blue diamonds, $\boldsymbol{\nabla}$, and benzoate attractant concentration represented by green triangles, Benzoate attractant was not present in (c). All bacteria, uranine and benzoate distributions have been normalized by the sum of concentrations from each individual port. Normalized distribution curves have been fit to the nonchemotactic bacteria, uranine, and benzoate data using Equation 3.5.

Figure A.5 Transverse population distributions from 2-D microcosm experiments with bacteria pulse injections below attractant plume. Nonchemotactic bacteria $P$. putida $\mathrm{F} 1 \mathrm{CheA}$ are represented as red squares, $\mathbf{\square}$. The bacteria distribution has been normalized by the sum of concentrations from each individual port. A normalized distribution curve has been fit to the nonchemotactic bacteria data using Equation 3.5. Bacteria points have been labeled by their location on the y-axis. 98

Figure A.6 Attractant concentration distribution image from COMSOL. Red represents a benzoate concentration of $5 \mathrm{mM}$, yellow represents $3 \mathrm{mM}$, and dark blue represent $0 \mathrm{mM} .102$ Figure A.7 (a) Nonchemotactic and (b) chemotactic bacteria concentration distribution images from COMSOL. Red represents a bacteria concentration of $10^{9}$ cells $/ \mathrm{mL}$, yellow represents $6 \times 10^{8}$ cells $/ \mathrm{mL}$, and dark blue represent 0 cells $/ \mathrm{mL}$ 


\section{List of Tables}

Table 4.1 Moment analysis summary for pulse bacteria injections below attractant plume. ....... 37

Table 4.2 Summary of center of mass and skewness differences for uranine tracer and bacteria data for experiments with pulse bacteria injections below the attractant plume. ................. 38

Table 4.3 Moment analysis summary for pulse bacteria injections above attractant plume. ...... 43

Table 4.4 Summary of center of mass and skewness differences for uranine tracer and bacteria data for experiments with pulse bacteria injections above the attractant plume.................. 44

Table 5.1 Moment analysis summary for continuous bacteria injections below attractant plume at $3 \mathrm{~cm}$ spacing.

Table 5.2 Summary of center of mass and skewness differences for uranine tracer and bacteria data for experiments with continuous bacteria injections below the attractant plume at $3 \mathrm{~cm}$ spacing.

Table 5.3 Moment analysis summary for continuous bacteria injections below attractant plume at $2 \mathrm{~cm}$ spacing. 54

Table 5.4 Summary of center of mass and skewness differences for uranine tracer and bacteria data for experiments with continuous bacteria injections below the attractant plume at $2 \mathrm{~cm}$ spacing.

Table 6.1 Moment analysis summary for mathematical modeling with continuous bacteria injections $4 \mathrm{~cm}$ below attractant plume and varying chemotactic sensitivity coefficient...... 66

Table 6.2 Moment analysis summary for mathematical modeling with continuous bacteria injections $3 \mathrm{~cm}$ below attractant plume and varying chemotactic sensitivity coefficient.

Table 6.3 Moment analysis summary for mathematical modeling with continuous bacteria injections $2 \mathrm{~cm}$ below attractant plume and varying chemotactic sensitivity coefficient....... 72

Table 6.4 Moment analysis summary for mathematical modeling with continuous bacteria injections $4 \mathrm{~cm}$ below attractant plume and varying chemotaxis receptor constant with constant $\chi_{0}$ of $2 \times 10^{-4} \mathrm{~cm}^{2} / \mathrm{s}$.

Table 6.5 Moment analysis summary for mathematical modeling with continuous bacteria injections $3 \mathrm{~cm}$ below attractant plume and varying chemotaxis receptor constant with constant $\chi_{0}$ of $10^{-4} \mathrm{~cm}^{2} / \mathrm{s}$......

Table 6.6 Moment analysis summary for mathematical modeling with continuous bacteria injections $3 \mathrm{~cm}$ below attractant plume and varying chemotaxis receptor constant with constant $\chi_{0}$ of $10^{-3} \mathrm{~cm}^{2} / \mathrm{s}$......

Table 6.7 Moment analysis summary for mathematical modeling with continuous bacteria injections $2 \mathrm{~cm}$ below attractant plume and varying chemotaxis receptor constant with constant $\chi_{0}$ of $10^{-4} \mathrm{~cm}^{2} / \mathrm{s}$.......

Table A.1 Moment Analysis Summary Table for various points selected from the bacteria distribution shown in Figure A.5.

Table A.2 Transverse dispersion coefficient values for chemotactic experiments at $3 \mathrm{~cm}$ spacing. Results have been calculated using two different methods: Equation 2.9 and a moment analysis. 
Table A.3 Transverse dispersion coefficient values for nonchemotactic experiments at $3 \mathrm{~cm}$ spacing. Results have been calculated using two different methods: Equation 2.9 and a moment analysis.

Table A.4 Transverse dispersion coefficient values for chemotactic experiments at $2 \mathrm{~cm}$ spacing. Results have been calculated using two different methods: Equation 2.9 and a moment analysis

Table A.5 Transverse dispersion coefficient values for nonchemotactic experiments at $2 \mathrm{~cm}$ spacing. Results have been calculated using two different methods: Equation 2.9 and a moment analysis. 


\section{List of Symbols}

Symbol

\section{Arabic}

C

$C_{A}$

$C_{B}$

$C_{h}$

$C_{i}$

$C_{t}$

$d_{b}$

$D_{0}$

$D_{A x}$

$D_{A y}$

$D_{B x}$

$D_{B y}$

$D_{\text {eff }}$

$D_{F}$

$D_{L}$

$D_{T}$

$g$

$K_{c}$

$L$

$n$

$N_{b}$

$P$

$R$

$v_{b}$

$V_{C h x}$

$V_{\text {Chy }}$

$V_{f}$

$V_{\text {settling }}$

$t$

$t_{\text {res }}$

w

$x$

$y$

$y_{i}$

$\bar{y}$

$\bar{y}_{B a c}$

$\bar{y}_{U r a}$
Definition

Units

Solute concentration $\quad \mathrm{M}$

Attractant concentration $\quad$ M

Bacteria concentration $\quad M$

Chemotaxis number unitless

Concentration at port $i \quad \mathrm{M}$

Total concentration $\quad \mathrm{M}$

Diameter of bacteria $\quad \mu \mathrm{m}$

Diffusion coefficient in bulk media $\quad \mathrm{cm}^{2} / \mathrm{s}$

Attractant longitudinal dispersion coefficient $\quad \mathrm{cm}^{2} / \mathrm{s}$

Attractant transverse dispersion coefficient $\mathrm{cm}^{2} / \mathrm{s}$

Bacteria longitudinal dispersion coefficient $\quad \mathrm{cm}^{2} / \mathrm{s}$

Bacteria transverse dispersion coefficient $\quad \mathrm{cm}^{2} / \mathrm{s}$

Effective diffusion coefficient $\mathrm{cm}^{2} / \mathrm{s}$

Dilution factor

Longitudinal dispersion coefficient

Transverse dispersion coefficient

Gravitational acceleration

Chemotaxis receptor constant

unitless

$\mathrm{cm}^{2} / \mathrm{s}$

$\mathrm{cm}^{2} / \mathrm{s}$

$\mathrm{cm} / \mathrm{s}^{2}$

$\mathrm{mM}$

Characteristic length scale

$\mathrm{cm}$

Number of ports

Number of bacteria

P-value for statistical analysis

unitless

cells

unitless

unitless

$\mathrm{cm} / \mathrm{s}$

Bacteria swimming speed

$\mathrm{cm} / \mathrm{s}$

Chemotactic velocity in $\mathrm{x}$ direction

Chemotactic velocity in y direction

Linear fluid velocity

$\mathrm{cm} / \mathrm{s}$

$\mathrm{cm} / \mathrm{s}$

$\mathrm{cm} / \mathrm{s}$

$\begin{array}{ll}\text { Settling velocity of bacteria } & \mathrm{cm} / \\ \text { Time } & \mathrm{s}\end{array}$

Residence time in microcosm $\mathrm{s}$

Width of injection zone $\mathrm{cm}$

Direction of fluid flow- longitudinal $\mathrm{cm}$

Direction transverse to fluid flow-vertical $\mathrm{cm}$

Vertical position of port $i \quad \mathrm{~cm}$

Center of mass $\quad \mathrm{cm}$

Center of mass of bacteria $\mathrm{cm}$

Center of mass of uranine $\quad \mathrm{cm}$ 
Symbol

\section{Greek}

$\alpha$

$\alpha_{T}$

$\gamma$

$\lambda$

$\mu_{0}$

$\mu_{\text {eff }}$

$\mu_{f}$

$\rho_{b}$

$\rho_{f}$

$\sigma^{2}$

$\tau$

$\chi_{o}$

$\chi_{o, e f f}$
Definition

Units

Turn angle of bacteria between successive runs

$\operatorname{deg}$

Transverse dispersivity

$\mathrm{cm}$

Skewness

Length of runs between tumbles

Random motility coefficient

Effective random motility coefficient

Fluid viscosity

Bacteria density

Fluid density

Variance

Tortuosity

Chemotactic sensitivity coefficient

Effective chemotactic sensitivity coefficient unitless

$\mu \mathrm{m}$

$\mathrm{cm}^{2} / \mathrm{s}$

$\mathrm{cm}^{2} / \mathrm{s}$

$\mathrm{cp}$

gram $/ \mathrm{cm}^{3}$

$\mathrm{gram} / \mathrm{cm}^{3}$

$\mathrm{cm}^{2}$

unitless

$\mathrm{cm}^{2} / \mathrm{s}$

$\mathrm{cm}^{2} / \mathrm{s}$ 


\section{Introduction}

\subsection{Motivation and Significance of Research}

Sources of clean drinking water are critical to the health of a local community. In 2005, groundwater made up $51 \%$ of all drinking water for the total population and $99 \%$ of drinking water for the rural population (Groundwater Foundation 2011). Groundwater aquifers can often become contaminated by accidental leaks or spills of organic compounds resulting in underground contaminant plumes. The most commonly used technology to treat contaminated aquifers is pump-and-treat, where groundwater is pumped to the surface, organic contaminants are removed through processes such as adsorption or filtration, and clean water is returned to the aquifer. Pump-and-treat is an energy intensive process that can take decades to complete. In a 2001 study the EPA estimated that operation and maintenance costs would be $\$ 790$ million to completely remediate 79 nationwide contaminated sites using pump-and-treat method (Environmental Protection Agency 2001). Pump-and-treat is especially inefficient in groundwater environments with contamination in regions of low permeability, not readily accessible to groundwater flow. Water immiscible contaminants, such as non-aqueous phase liquids (NAPLs), can become trapped in areas of low hydraulic conductivity for years, slowly leaching out into the surrounding environment (Liu and Ball 2002).

An alternative method to clean contaminated aquifers is to take advantage of indigenous organisms that are capable of chemically transforming organics into less toxic byproducts through biodegradation. Technologies that utilize this method are monitored natural attenuation and bioremediation. Monitored natural attenuation is the least invasive method, which allows the indigenous organisms to degrade contaminants in a controlled and monitored environment. Bioremediation methods include biostimulation, where nutrients are added to the groundwater to 
encourage degradation from indigenous species, and bioaugmentation, where non-native organisms are added to the groundwater to assist with degradation. One reason these technologies are not selected to be used more frequently is that the processes governing their success are not well characterized in mathematical models that can be used in feasibility studies, risk analysis, and design of processes. Improving the accuracy of these models will encourage the use of less invasive and less energy intensive approaches to remediation.

Biodegradation requires that the electron donor (contaminant), the electron acceptor (oxygen), and the bacteria (catalyst) are all brought into contact. A major challenge of groundwater remediation is mixing in the subsurface environment, and bioremediation in porous media is often times limited by the ability of degrading populations of bacteria to reach the contaminant (Boopathy 2000; Head 1998). The principal mechanisms for mixing are advection and dispersion. Advective flow is often limited by low flow rates typical of groundwater of about $1 \mathrm{~m} /$ day. Dispersion accounts for increased spreading of components due to variation in the flow from the averaged linear velocity and tends to increase with scale and heterogeneity of grain sizes. For example, dispersion will have more of an impact in larger grained sand layers and less of an impact in finer grained clay layers. Advection and dispersion processes are not very effective at delivering bacteria to regions of low hydraulic conductivity, such as clay lenses, where contaminants tend to accumulate.

Chemotaxis, the ability of bacteria to sense a chemical attractant gradient and swim preferentially towards it, offers a way to potentially enhance bioremediation by improving the bioavailability of the contaminant to the degrading bacteria (Marx \& Aitken 2000; Pandey \& Jain 2002). Chemotactic bacteria have receptors on their surface which allow them to detect micromolar concentrations of organic compounds, including many contaminants (Harwood et al. 
1989). They are able to swim to regions of higher attractant concentration to benefit their survival. Figure 1 below shows a contaminant trapped in a low permeable region of sediment. Nonchemotactic bacteria carried along with the groundwater by-pass the contaminant, thereby reducing the degradation efficiency. On the other hand, chemotactic bacteria sense the contaminant slowly diffusing out into the surrounding groundwater, allowing them to respond to the concentration gradient and swim transverse to convective flow toward the contaminant source.

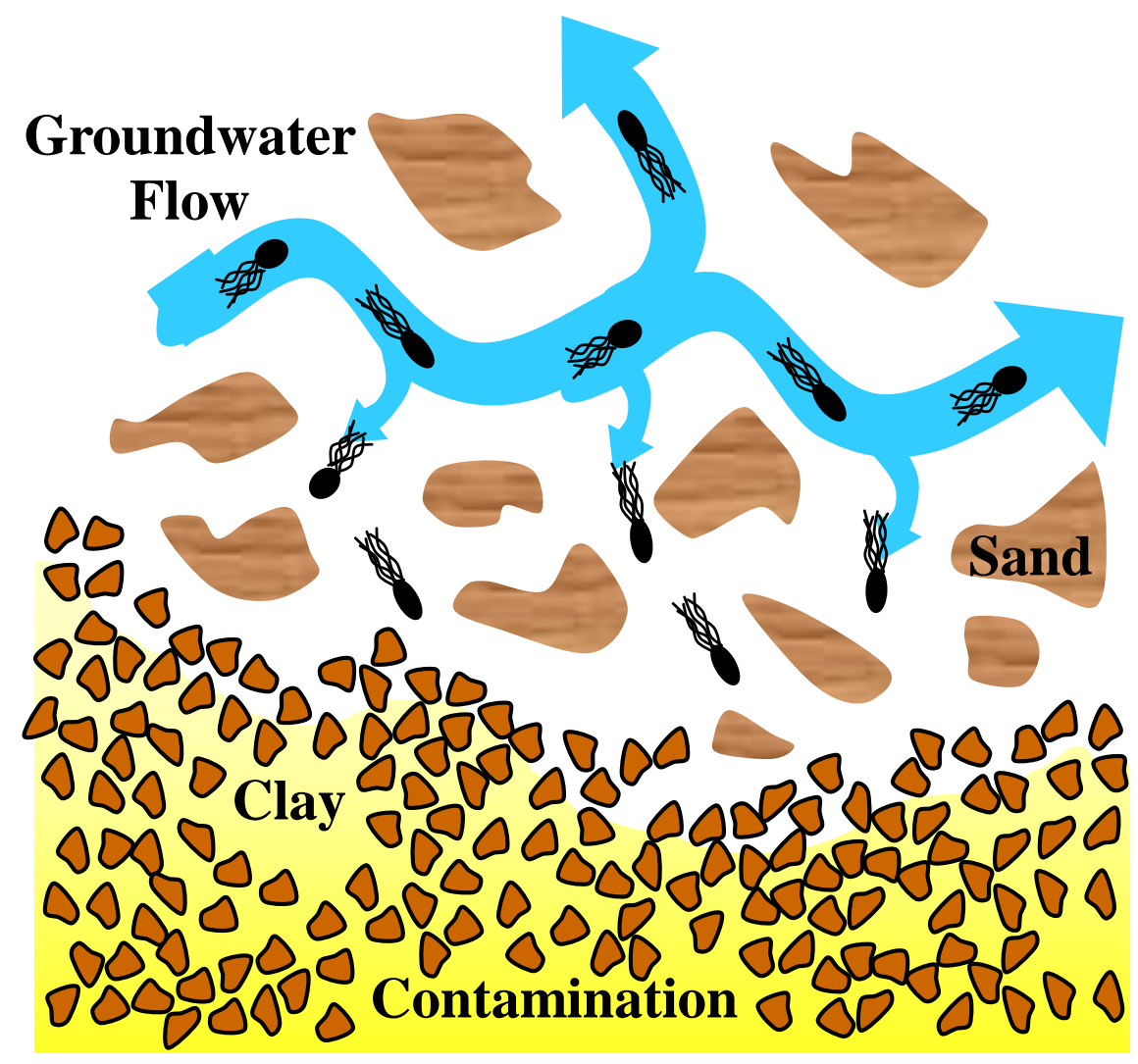

Figure 1.1 Chemotactic bacteria migrating transverse to flow out of a coarse sand region to reach contaminants trapped in a fine grain clay lens, image adapted from (Kusy 2005; Wang 2010).

The goal of this research is to examine how chemotaxis can enhance bioremediation of groundwater contaminants. In order to determine whether chemotaxis will impact 
bioremediation, the magnitude of the chemotactic response must be quantified under typical groundwater conditions. Previous work has studied chemotactic behavior in open aqueous systems or static porous environments (Berg \& Brown 1972; Harwood et al. 1990; Barton \& Ford 1995). This study evaluates the ability of chemotaxis to improve bacterial transport to groundwater contaminants in a bench scale two-dimensional microcosm packed with quartz sand. To measure the chemotactic response a steady state attractant plume was maintained within the microcosm and bacteria was injected either above or below the attractant plume. Chemotactic bacteria were expected to migrate toward the attractant plume with increased transverse dispersion compared to the nonchemotactic bacteria and tracer controls. The use of a two-dimensional microcosm is advantageous because it simulates conditions found naturally in porous aquifers, while still allowing for small scale measurements to be taken in a well controlled laboratory setting. Additionally, transport parameters such as fluid velocity, grain size of the sediment, and transverse dispersion coefficients determined from microcosm experiments can be used to evaluate mathematical models of bacteria transport and dispersion in the microcosm. These models can then be used to predict what will happen at the field scale, which can aid in design of field-scale experiments and in the decision making process for clean-up of contaminated sites.

\subsection{Hypotheses}

Hypothesis 1 - Chemotactic bacteria will migrate transverse to convective flow towards an attractant plume in a two dimensional microcosm to a greater extent than the nonchemotactic control.

To evaluate this hypothesis we contstructed a bench scale two-dimensional microcosm packed with homogeneous sediment. A contaminant plume was generated by continuously 
injecting the contaminant through one of the microcosm inlet ports, resulting in a vertical attractant gradient transverse to flow. Bacteria were then injected either above or below the attractant plume. Pseudomonas putida F1 was used as the chemotactic bacteria and Pseudomonas putida F1 CheA was used as the nonchemotactic mutant. Outlet concentrations of bacteria, attractant, and tracers were used to analyze the migration of bacteria. The concentration distributions for the chemotactic bacteria were expected to have a center of mass closer the attractant and an asymmetry biased towards the attractant when compared to the nonchemotactic control.

Hypothesis 2- Injecting the bacteria closer to the attractant plume will increase the exposure time of the bacteria to the attractant gradient, resulting in a migration of the chemotactic bacteria toward the attractant plume.

Experiments in the two-dimensional microcosm were performed over a range of bacteriaattractant separation distances, with a focus on comparing a $3 \mathrm{~cm}$ injection distance to a $2 \mathrm{~cm}$ injection distance.

Hypothesis 3- Transport parameters estimated from microcosm experiments and used as input to a mathematical model of chemotactic bacteria, nonchemotactic bacteria, and attractant transport will generate effluent distributions that are consistent with experimental observations.

To evaluate this hypothesis transport parameters such as fluid velocity and transverse dispersion coefficients determined from microcosm experiments were used to evaluate a mathematical model that was solved using the computer program COMSOL. The mathematical models were compared to experimental results to assess their accuracy. 


\subsection{Summary of Experimental Design}

This thesis focuses on a variety of experiments that have been performed to observe the effects of chemotaxis in a bench scale model aquifer, also called a two-dimensional microcosm. Many factors have affected the sensitivity of the experimental results. These factors have impeded the ability to measure the bacteria signal through the noise associated with the experimental design, which makes it difficult to assess the difference between the chemotactic and nonchemotactic bacteria breakthrough curves. Factors contributing to experimental inaccuracy include:

- Sinking of the bacteria due to density differences between the aqueous media and the cells.

- Flow variations within the microcosm.

- Forced dispersion due to the injection method.

- Background levels of bacteria present in all experiments, due to bacteria retained from previous experiments that attached to the sand.

In order to control for these factors, many experimental changes were made. A list of major experimental design changes includes:

- Vertical location of the bacteria injection relative to the bottom of the microcosm.

- Pulse bacteria injection versus continuous bacteria injection.

- Distance between bacteria injection source and attractant injection source.

The first change was moving the vertical location of the bacteria injection. Chapter 4 focuses on a series of pulse injection experiments where the bacteria injection location is varied. Injections both above and below the attractant source were tested, with different distances between the 
bacteria and attractant, and also at different distances from the bottom of the microcosm, where flow variations were most pronounced. Additionally, a fluorescent tracer was injected with the bacteria to provide a baseline for the bacteria movement. This baseline helped with accounting for flow variations and also allowed the sinking of bacteria to be quantified. One problem with the pulse injection experiments was that the injection method caused forced dispersion of the bacteria, which contributed to less reproducible results and inaccurate transport parameters. Additionally, the pulse shape was easily distorted due to flow variations, and the bacteria signal in effluent samples was weak, which made it difficult to distinguish between injected bacteria and background bacteria.

Chapter 5 focuses on experiments where the bacteria were continuously injected into the microcosm. These experiments helped to increase the strength of the bacteria signal, which eliminated errors due to background bacteria. The continuous injections also helped to stabilize the bacteria injection, which reduced errors due to flow variations. Continuous bacteria injections allowed for more accurate measurements of transport parameters and also provided more reproducible results to determine the difference between the migration of the chemotactic bacteria and the nonchemotactic bacteria. Preliminary experiments were conducted using a more dense aqueous media to reduce the sinking of bacteria, however these experiments were not successful and sinking was still present in all continuously injected experiments. The primary experimental variable that was adjusted for the continuously injected experiments was the distance between the bacteria injection, which tests the exposure time argument addressed in Hypothesis 2. Transport parameters determined experimentally were used to evaluate a mathematical model, which is discussed in Chapter 6. 
The biggest challenge for the experiments discussed in this thesis was overcoming the amount of noise that occurs when using the two-dimensional microcosm. The chemotactic response was small when compared to the noise inherent in microcosm experiments, which made it difficult to assess the effects of chemotaxis in a more complex system. Statistical analysis of experimental results was performed to determine if there was a difference between the response of chemotactic bacteria and nonchemotactic bacteria. Chapter 7 presents conclusions from experimental results and recommendations for future work. 


\section{Background}

\subsection{Bacterial Motility and Chemotaxis}

Individual motile bacteria move about in a random three dimensional walk described by a series of runs and tumbles. The bacteria are propelled through solution when their flagella bundle together and rotary motors turn them in a counterclockwise motion, resulting in a smooth forward motion. When one or more of the motors reverses direction, the flagella bundle unravels and the cell body tumbles, before reorienting itself and beginning a new run. This random walk can be seen in Figure 2.1a. A mathematical relationship can be used to relate the swimming pattern of individual cells to bulk diffusion of the population described by the random motility coefficient, $\mu_{0}$, derived by Lovely and Dahlquist (Lovely \& Dahlquist 1975),

$$
\mu_{0}=\frac{\lambda v_{b}}{3} \frac{1}{1-\cos \alpha}
$$

where $v_{b}$ is the individual cell swimming speed, $\lambda$ is the length of runs between tumbles, and $\alpha$ is the turn angle between successive runs.

Chemotaxis is the ability of certain types of bacteria to sense a chemical gradient and swim preferentially towards locations of higher concentration. Chemotactic bacteria have receptors embedded on their cell membrane which allow them to detect chemical gradients. As the bacteria are swimming up chemoattractant gradients towards regions of favorable concentration, they can detect the changes in concentration, suppress tumbles, and extend their run time. This results in a biased random walk towards areas of high concentration, as seen in Figure 2.1c. On the population scale this results in an accumulation of bacteria in areas of higher chemoattractant concentration, as seen in Figure 2.1d. 


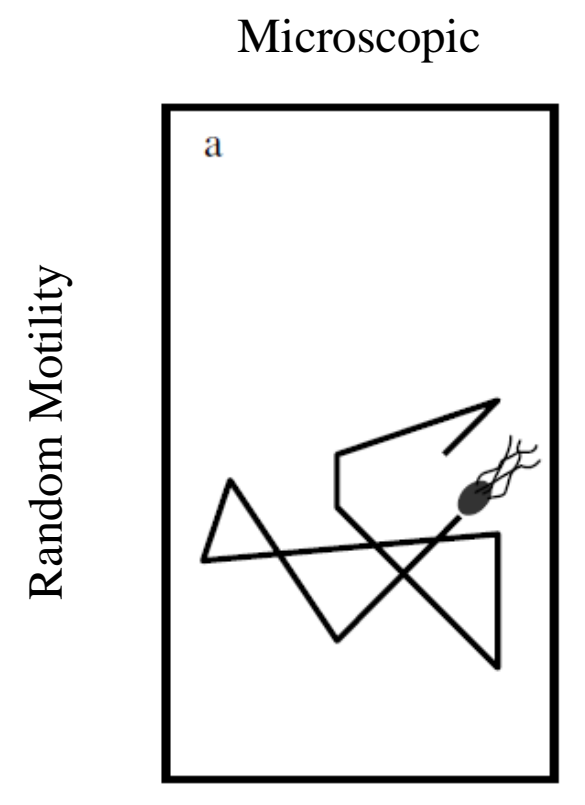

\section{Macroscopic}
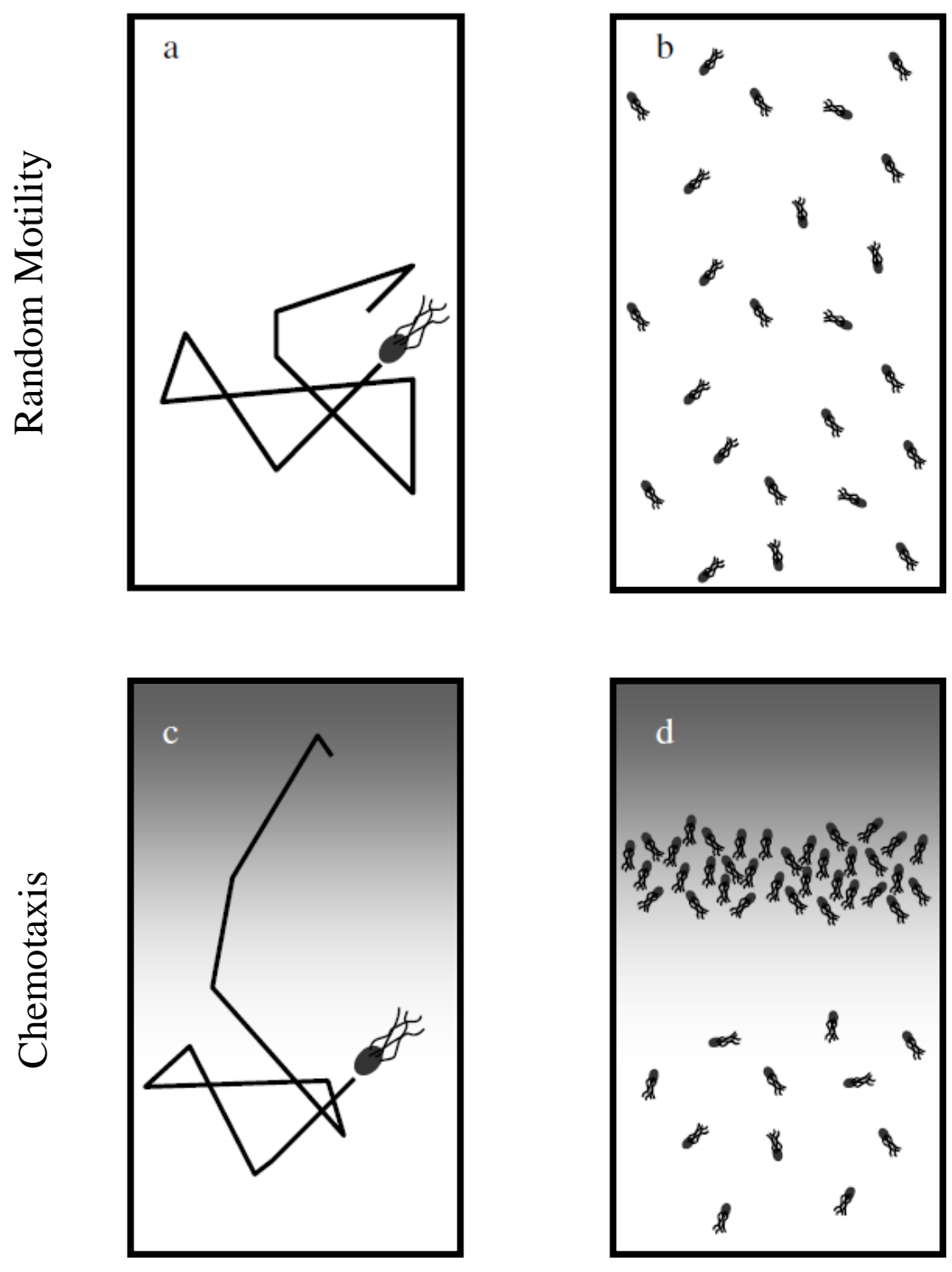

Figure 2.1 Bacterial random motility and chemotaxis. (a) In an isotropic solution, individual bacterium swims randomly in a series of runs and tumbles. The straight lines indicate runs, and the line vertices indicate tumbles. (b) This random motion appears as an even distribution on the macroscopic scale. In the bottom two figures, the shading represents areas of increasing attractant concentration. (c) Chemotaxis increases the run length as the bacteria is swimming toward regions of higher attractant concentration. (d) This biased run and tumble pattern results in a bulk movement toward areas of higher attractant concentration, and a chemotaxis band forms at regions of higher attractant concentration. Image modified from (Lanning 2004; Wang 2010). 


\subsection{Chemotaxis in Porous Media}

Chemotaxis could increase bacterial transport in porous media, which can lead to increased degradation of contaminant plumes where transverse dispersion is the limiting factor. In order to assess the ability of chemotaxis to increase biodegradation, the effect of chemotaxis on bacterial transport in porous media must be determined. Chemotaxis has been well characterized in open systems (Ford et al. 1991), but less is known about chemotaxis in porous media. Chemotaxis was found to enhance degradation of naphthalene, supplied from a glass capillary tube, in both a homogenenous and a heterogeneous static aqueous environment (Marx \& Aitken 2000; Pedit et al. 2002). In another study, swarm plate migration experiments with Pseudomonas stutzeri $\mathrm{KC}$ showed that the chemotactic response was enhanced within heterogeneous porous medium (Roush et al. 2006). The enhancement was hypothesized to be due to steep attractant gradients present in the pores, which were formed by nitrate consumption. Wang and Ford used a column packed with a coarse grain core surrounded by fine grain to measure chemotactic migration (Wang \& Ford 2009). This study revealed that chemotactic bacteria were able to migrate transverse to convective flow out of a region of low conductivity toward the attractant in region of high conductivity. Long and Ford used a microfluidic porous T-sensor to directly observe and measure chemotactic migration transverse to flow at the pore

scale. Chemotaxis enhanced bacterial migration toward a model contaminant under low flow rates comparable to groundwater flow. Greater than $50 \%$ of the chemotactic bacteria population accumulated in the half of the T-sensor with the chemical attractant (Long \& Ford 2009). The results of this experiment were successfully modeled in a paper by Porter et al. (Porter et al. 2010) 
Two recent studies have investigated chemotactic migration transverse to convective flow in two-dimensional microcosms. Strobel et al. used a two-dimensional microcosm to measure the chemotactic response to both an attractant plume and an attractant pulse injection in homogeneous model aquifer. Bacteria and attractant distributions showed that chemotaxis caused a shift in the center of mass of the bacteria toward the attractant and also an increased transverse dispersivity compared with the nonchemotactic control. The chemotactic response was more pronounced in the experiments conducted at lower velocity with an attractant plume (Strobel et al. 2011). Liu conducted a similar study measuring effluent distributions for the bacteria and a fluorescent tracer injected with the bacteria. Chemotaxis was found to increase vertical migration of the bacteria toward an attractant plume. Liu also found that the chemotactic response was greater at low velocity. A two-dimensional transport model was successfully implemented to interpret experimental results from the microcosm (Liu 2011).

The study conducted in this paper uses the same two-dimensional microcosm and homogeneous sediment packing that was used by Strobel at al. and Liu, however there are many differences between these two previous experiments and the experiments performed in this study. Stobel et al. and Liu used pulse injections of bacteria, whereas this study focuses on continuous injections of bacteria. Continuous injections of bacteria provided a stronger bacteria signal in effluent samples and more stable bacteria injections, which increased the reproducibility of results and accuracy of transport parameters. This study included a fluorescent tracer injected with the bacteria, which was included in study by Liu but not in the study by Strobel et al. This study also included effluent concentration distributions for the attractant, which were not included in the study by Liu. Strobel et al and Liu studied the effects of changing the interstitial velocity within the microcosm. This study used a constant velocity, and 
looked at the effects of changing the distance between the attractant injection source and the bacteria injection source. Moving the bacteria injection closer to the attractant source increases the exposure time of the bacteria to the attractant gradient. Finally, the mathematical modeling performed in this study was evaluated assuming steady-state conditions with a continuous bacteria injection. The mathematical model in this study was used to determine a chemotactic sensitivity coefficient to match experimental results, perform a sensitivity analysis in the chemotactic sensitivity coefficient and chemotaxis receptor constant, and determine optimal experimental conditions. Mathematical modeling performed by Liu assumed transient conditions, and only looked at determining the chemotactic sensitivity coefficient to match experimental results. This study has expanded on previous work focused on chemotactic migration transverse to convective flow in two-dimensional microcosms. Quantification of chemotaxis in model aquifers is an important step toward determining the effect of chemotaxis at the field scale.

\subsection{Two Dimensional Microcosms}

Field experiments often utilize nonreactive tracers injected underground to estimate aquifer transport parameters, sediment heterogeneity, and contaminant pathways (Ptak et al. 2004). However, it is difficult to adequately quantify the location and mechanism by which bioremediation occurs in groundwater because of limited accessibility of the plumes as well as the inability to collect data at a high enough resolution (Prommer et al. 2009). One tool used to investigate biodegradation of contaminant plumes and transverse mixing in porous media is twodimensional bench scale microcosms. Two-dimensional microcosms offer a way to bridge the gap between field and lab scale experiments by simulating conditions found naturally in porous aquifers in a well controlled laboratory setting. Various studies have used two-dimensional 
microcosms to determine the hydrodynamic properties of porous media such as transverse dispersivity (Cirpka et al. 2006; Olsson \& Grathwohl 2007; Rahman et al. 2005), biodegradation in contaminant plumes (Bauer et al. 2008; Bauer, Rolle, Bauer, et al. 2009; Bauer, Rolle, Kürzinger, et al. 2009; Huang et al. 2003; Thullner et al. 2004), and the migration of chemotactic bacteria (Liu 2011; Strobel et al. 2011). Recent two-dimensional microcosm experiments have corroborated that degradation occurs at the plume fringe where mixing is largely controlled by transverse dispersion of the contaminant, electron acceptor and bacteria from the bulk groundwater across the contaminant plume (Bauer et al. 2008; Bauer, Rolle, Bauer, et al. 2009; Bauer, Rolle, Kürzinger, et al. 2009; Cirpka et al. 2006; Rahman et al. 2005; Thornton et al. 2001). It is important to understand both the processes limiting degradation and the physical regions of increased degradation in order to efficiently clean up in situ contaminant plumes.

\subsection{Transport Parameters}

The structure of porous media affects the swimming trajectory of bacteria, therefore in order to account for the effects of porous media, an effective motility coefficient is used (Olson et al. 2005),

$$
\mu_{e f f}=\frac{\mu_{0}}{\tau}
$$

where $\mu_{0}$ is the random motility coefficient in bulk media, and $\tau$ is the tortuosity factor. Tortuosity accounts for the increased diffusional path length that is associated with moving around impenetrable solids, such as sand.

For species that are not bacteria, the effective diffusion coefficient, $D_{\text {eff, }}$ accounts for diffusion porous media, 


$$
D_{e f f}=\frac{D_{0}}{\tau}
$$

where $\mathrm{D}_{0}$ is the diffusion coefficient in bulk media.

In static porous systems diffusion accounts for the movement of species, however in systems with fluid flow, dispersion becomes important. The transverse dispersion coefficient can be expressed as the sum of contributions from diffusion and flow:

$$
D_{T}=D_{\text {eff }}+\alpha_{T} V_{f}
$$

where $D_{T}$ is the dispersion coefficient, $V_{f}$ is the linear velocity in the direction of flow, and $\alpha_{T}$ is the transverse dispersivity. Dispersion accounts for increased spreading of components due to variation in the flow from the averaged linear velocity and tends to increase with scale and heterogeneity of grain sizes. The transverse dispersivity parameter captures the contribution of the mechanical mixing due to the structure of the porous media.

One way to find dispersion coefficients from a concentration distribution is through the Einstein relationship for one dimensional dispersion (Cussler 1997):

$$
D_{T}=\frac{\sigma^{2}}{2 t_{r e s}}
$$

where $\sigma^{2}$ is the variance in a concentration distribution, and $t_{r e s}$ is the residence time over which the concentration disperses. This relationship assumes a point source that spreads out over time.

There is alternate method to find dispersion coefficients for species continuously injected into a two-dimensional microcosm, which takes into account both two-dimensional dispersion in porous media and the width if the injection zone in the microcosm. This equation is derived from the equation for two-dimensional mass transfer, 


$$
\frac{\partial C}{\partial t}=D_{L} \frac{\partial^{2} C}{\partial x^{2}}+D_{T} \frac{\partial^{2} C}{\partial y^{2}}-V_{f} \frac{\partial C}{\partial x}
$$

where $C$ is the solute concentration, $V_{f}$ is the average velocity of the water, $t$ is time, $D_{T}$ is the transverse dispersion coefficient, $D_{L}$ is the longitudinal dispersion coefficient, $x$ is the distance longitudinally in the direction of water flow along the microcosm, and $y$ is the transverse distance to the $x$ axis with $x=0$ located at the center of the injection zone. For the steady state case, assuming that longitudinal dispersion is much smaller than transverse dispersion and can therefore be neglected, the transport equation becomes

$$
D_{T} \frac{\partial^{2} C}{\partial y^{2}}-V_{f} \frac{\partial C}{\partial x}=0
$$

This remaining partial differential equation was solved for the initial condition described the Heaviside function, $H(y)$,

$$
C x=0, y=C_{0}\left[\begin{array}{lll}
H & y+\frac{w}{2}-H & y-\frac{w}{2}
\end{array}\right]
$$

where $C_{0}$ is the inlet concentration of solute, and $w$ is the injection zone width on the $y$ axis. The solution is the following equation for concentration in the microcosm.

$$
\frac{C(x, y)}{C_{0}}=\frac{1}{2} \operatorname{erf} \frac{y+w / 2}{\frac{4 x D_{T}}{V_{f}}}-\operatorname{erf} \frac{y-w / 2}{\frac{4 x D_{T}}{V_{f}}}
$$

This equation can be fit to experimental data using the transverse dispersion constant $\left(D_{T}\right)$ and the injection width $(w)$ as fitting parameters. 


\subsection{Chemotaxis Number}

Chemotaxis contributes to both advection and dispersion of bacteria in groundwater. The chemotactic response is mathematically represented in models as an advective term, where the driving force for the velocity is an attractant gradient rather than a hydraulic gradient. Attractant gradients are generally due to contaminants seeping out of regions of accumulation, resulting in gradients transverse to the direction of groundwater flow. Therefore chemotaxis allows the bacteria to migrate transverse to groundwater flow, resulting in an increased spread of bacteria, which is captured in the dispersion term. Thus, chemotaxis impacts the advection and dispersion terms in mathematical modeling. A quantitative analysis to evaluate the impact of chemotaxis in comparison to other mechanisms can be performed to determine the extent to which chemotaxis occurs in natural attenuation, its facilitation of degradation, and the degree to which it can be exploited in bioremediation schemes. As a first approximation, the contribution of chemotaxis relative to dispersion can be estimated in the form of a chemotaxis number (Porter et al. 2010), represented at $C h$ :

$$
C h=\frac{\chi_{0}}{L V_{f}}
$$

where $\chi_{0}$ is the chemotactic sensitivity coefficient and depends on the type of bacteria and attractant, $L$ is a characteristic length scale associated with the system, and $V_{f}$ is the linear velocity in the direction of flow. The length scale is often the most difficult to determine and it can be approximated in many ways. For example in the two-dimensional microcosm the length scale could be the transverse dispersivity coefficient or the distance between the bacteria and attractant injection ports. In this study the length scale is assumed to be the distance between the 
bacteria and attractant injection ports. This number is a valuable tool for evaluating whether chemotaxis will have an impact at a field site.

\subsection{Two-Dimensional Mathematical Model}

The experimentally determined transport parameters were used to mathematically model results from the two-dimensional microcosm. The two-dimensional advection-dispersion transport model for the attractant is described by

$$
R \frac{\partial C_{A}}{\partial t}=D_{A x} \frac{\partial^{2} C_{A}}{\partial x^{2}}+D_{A y} \frac{\partial^{2} C_{A}}{\partial y^{2}}-V_{f} \frac{\partial C_{A}}{\partial x}
$$

where $R$ is the retardation factor, $C_{A}$ is the attractant concentration, $t$ is time, $x$ is in the direction of flow, $y$ is in the direction transverse to flow, $D_{A x}$ is the attractant longitudinal dispersion coefficient, $D_{A y}$ is the attractant transverse dispersion coefficient, and $V_{f}$ is the interstitial fluid velocity.

The two-dimensional transport model for chemotactic bacteria, adapted from Olson et al. (Olson et al. 2004), can be represented as

$$
R \frac{\partial C_{B}}{\partial t}=D_{B x} \frac{\partial^{2} C_{B}}{\partial x^{2}}+D_{B y} \frac{\partial^{2} C_{B}}{\partial y^{2}}-V_{f} \frac{\partial C_{B}}{\partial x}-\frac{\partial\left(V_{C h x} C_{B}\right)}{\partial x}-\frac{\partial\left(V_{C h y} C_{B}\right)}{\partial y}
$$

where $C_{B}$ is the bacteria concentration, $D_{B x}$ is the bacteria longitudinal dispersion coefficient, $D_{B y}$ is the bacteria transverse dispersion coefficient, $V_{C h x}$ is the longitudinal chemotactic velocity, and $V_{C h y}$ is the transverse chemotactic velocity. The chemotactic velocity terms (Chen et al. 1998) are defined by

$$
V_{C h x}=\frac{2}{3} v_{b} \tanh \frac{\chi_{0, e f f}}{2 v_{b}} \frac{K_{c}}{\left(K_{c}+C_{A}\right)^{2}} \frac{\partial C_{A}}{\partial x}
$$




$$
V_{\text {Chy }}=\frac{2}{3} v_{b} \tanh \frac{\chi_{0, e f f}}{2 v_{b}} \frac{K_{c}}{\left(K_{c}+C_{A}\right)^{2}} \frac{\partial C_{A}}{\partial y}
$$

where $v_{b}$ is the bacteria swimming speed, $\chi_{0, \text { eff }}$ is the effective chemotactic sensitivity coefficient, and $K_{c}$ is the chemotaxis receptor constant. Experimentally determined parameters, such as transverse dispersion coefficients and interstitial fluid velocity, can be used to evaluate the twodimensional mathematical models for transport of attractant, chemotactic bacteria, and nonchemotactic bacteria. 


\section{Materials and Methods}

\subsection{Two- Dimensional Microcosm Configuration}

The two-dimensional microcosm, shown in Figure 1, was constructed at the University of Virginia by Ricky Buchanan, and was modeled after a microcosm from the Institute of Groundwater Ecology at the Hemholtz Center in Munich, Germany. The microcosm had a Teflon base on the bottom, Teflon end pieces, an aluminum frame, and two sheets of glass all sealed water-tight with silicone glue. The inner dimensions measured $95 \mathrm{~cm} \times 14 \mathrm{~cm} \times 1 \mathrm{~cm}$ and the apparatus sat on two wooden supports with a spill tray underneath. The inlet (Figure 3.1a) and outlet (Figure 3.1b) ends of the microcosm were equipped with twelve ports with a vertical spacing of $1 \mathrm{~cm}$ numbered 1 through 12 from top to bottom. Two-inch long stainless steel capillaries (1/16 in., Alltech, IL) were fitted through the ports. The inflow capillaries extended $0.5 \mathrm{~cm}$ into the microcosm, with the attractant and bacteria injection ports extending 1 $\mathrm{cm}$ into the microcosm. The outflow capillaries extended $0.5 \mathrm{~cm}$ into the microcosm and were wrapped with $1 \mathrm{~cm} \times 1 \mathrm{~cm}$ piece of steel woven wire fine mesh (180 x 180, McMaster Carr, Atlanta, GA) to the prevent sediment from clogging the capillaries. The outer capillary tips were connected to PVC pump tubing links (0.89 mm ID, Thermo Scientific, Dubuque, IA) which ran through two twelve-channel Carter peristaltic precision pumps (Manostat Carter, Thermo Scientific, Dubuque, IA), one for the inflow and another for outflow. The pump was calibrated so that the flowrate variance from each channel was less than $5 \%$. The inlet ports were used to pump artificial groundwater from a $1 \mathrm{~L}$ storage bottle into the microcosm. The effluent media pumped from the outlet ports was directed into a hazardous waste collection container. 

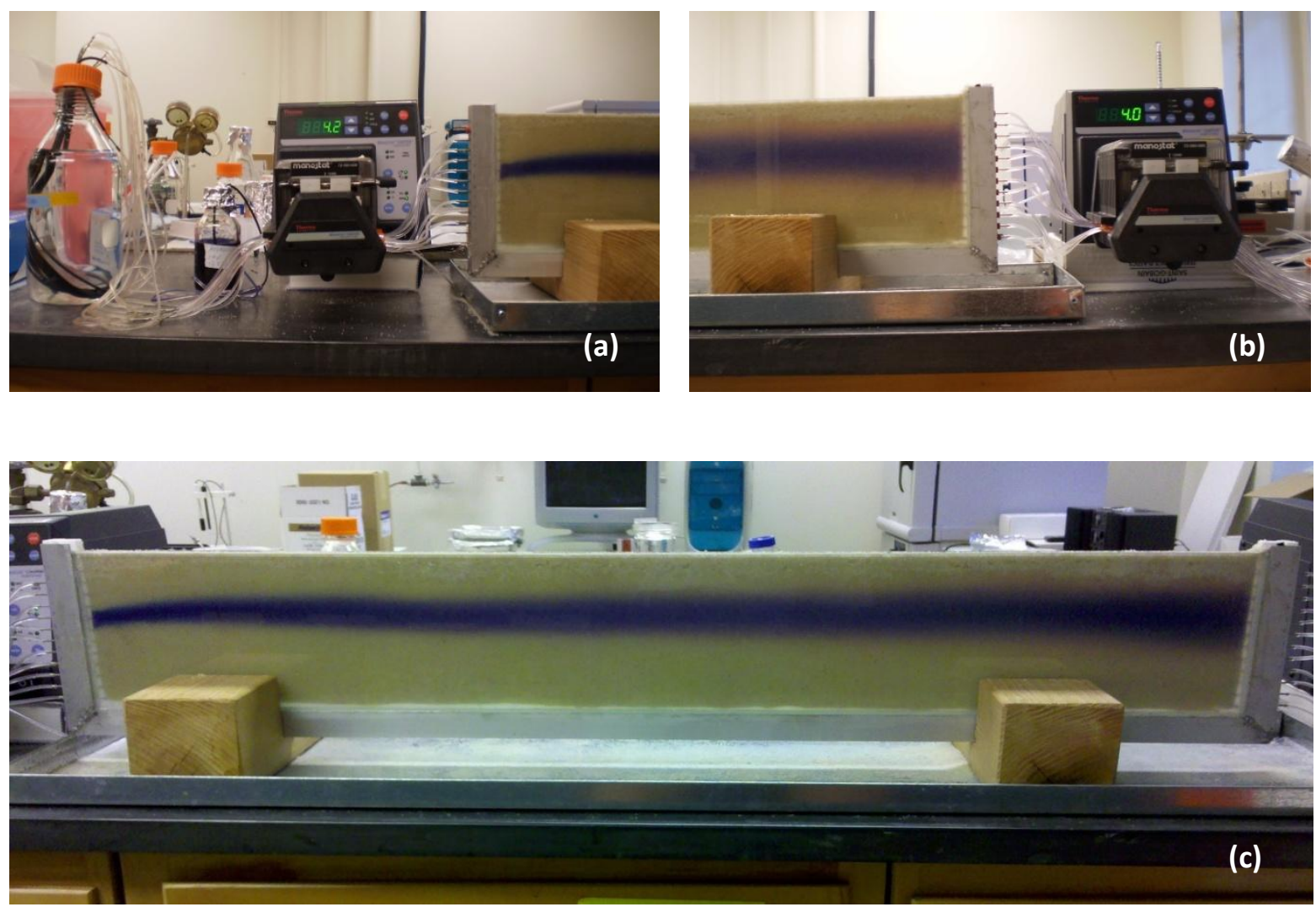

Figure 3.1 Images of two-dimensional microcosm configuration. (a) Inlet aqueous media, attractant plume, and pump. (b) Outlet capillaries, tubing, and pump. (c) Microcosm with a steady state attractant plume.

\subsection{Experimental Procedure}

The microcosm was packed with quartz sand with an average grain diameter of $710 \mu \mathrm{m}$. Artificial groundwater (AGW) $\left(1.0 \mathrm{~g} / \mathrm{L} \mathrm{NaCl}, 0.4 \mathrm{~g} / \mathrm{L} \mathrm{MgCl}{ }_{2} \cdot 6 \mathrm{H}_{2} \mathrm{O}, 0.2 \mathrm{~g} / \mathrm{L} \mathrm{KH}_{2} \mathrm{PO}_{4}, 0.25 \mathrm{~g} / \mathrm{L}\right.$ $\mathrm{NH}_{4} \mathrm{Cl}, 0.5 \mathrm{~g} / \mathrm{L} \mathrm{KCl}$, and $0.15 \mathrm{~g} / \mathrm{L} \mathrm{CaCl}{ }_{2} \cdot 2 \mathrm{H}_{2} \mathrm{O}$ ) was used as the liquid media pumped through the microcosm. Artificial groundwater was autoclaved before each experiment, and approximately $3 \mathrm{~L}$ of media was needed for the duration each experiment. The microcosm was packed using a wet packing method to prevent air pockets being trapped in the porous media. To 
begin, AGW was pumped through the inlet tubing and capillaries. Once AGW had saturated the tubing lines and all of the air bubbles were pumped out, the microcosm was filled one third full with AGW by pouring the media directly in the top opening. The inlet pump was kept running throughout the packing process to prevent sediment clogging the inlet capillaries. A glass funnel was filled with several scoops of sand then the tip of the funnel was submerged below the water line in the microcosm. AGW was then poured into the funnel to flush the wet sand into the microcosm. As the sand flowed out of the funnel, the funnel was moved back and forth over the length of the microcosm to ensure even layers of sand being deposited. After approximately every three funnel fills, a small spatula was used to smooth out the layers and lightly disturb sand to release air bubbles that may have become trapped. When the water level rose to the top of the microcosm a syringe with a small piece of tubing was used to suction out some of the water. When the packed sand reached about 1 inch from the top of the microcosm, sand was scooped directly in using a small spatula to fill the remainder. The top of the microcosm was then covered with foil for the duration of the experiment. In some of the experiments the top of the microcosm was sealed with parafilm, which prevented evaporation of the water in the microcosm more effectively than the foil. The inlet and outlet pumps were then set to the desired flowrate. An inlet setting of $4.2 \mathrm{~mL} / \mathrm{min}$ and an outlet setting of $4.0 \mathrm{~mL} / \mathrm{min}$ produced an interstitial velocity of about $1.1 \mathrm{~m} /$ day. In order to achieve and maintain a $1.5 \mathrm{~cm}$ unsaturated zone at the top of the microcosm, only the bottom 11 inflow ports were connected to the inflow pump. The topmost outlet port collected any overflow and maintained the water level. The inlet and outlet flow rates would have to be slightly adjusted throughout the experiment to maintain an even unsaturated zone. Additionally, the tubing in the pumps wore out over time, therefore over the course of several experiments the pump setting was increased to maintain an interstitial velocity 
of about $1.1 \mathrm{~m} /$ day. When the tubing wore out in one channel the entire set of tubes would have to be replaced to maintain even flowrates from each port. Tubes needed to be changed about every 2-3 months, or after about every 15 experiments. After packing, the microcosm was allowed to reach steady state for approximately 12 hours after packing before experiments began. Specific types of experiments and injection methods are described in section 3.3 below.

After the experiments had been performed, the microcosm was then emptied and cleaned. The sand was carefully scooped out of the top of the microcosm into a metal tray placed underneath the microcosm. The wooden support blocks were turned over one at a time to prop up one end of the microcosm during unpacking to make room for the metal tray. The pumps were kept running throughout unpacking until all of the sand had been removed. The tubing was then disconnected from the capillaries and the microcosm could be gently picked up to pour out the remaining water into a waste container. The microcosm was then rinsed with $70 \%$ ethanol and DI water between all experiments. Ethanol was also pumped through all of the tubing for about 20 minutes followed by DI water for an additional 20 minutes. Capillaries were inspected to remove any sand that may have cause clogging issues. The sand was soaked in $70 \%$ ethanol overnight and rinsed at least three times with DI water, then autoclaved between each experiment.

\subsection{Bacteria Cultivation}

Two bacterial strains were used in the experiments: a motile wild-type chemotactic strain P. putida F1 (Harwood et al. 1989), and a motile non nonchemotactic control P. putida F1 CheA (Liu et al. 2009). A 50-200 $\mu \mathrm{L}$ sample of frozen stock bacteria was used to inoculate $50 \mathrm{~mL}$ of Hutner's Mineral Medium (Barton \& Ford 1995) with $2 \mathrm{mM}$ sodium benzoate in a $250 \mathrm{~mL}$ Erlenmeyer flask. The flasks were then placed on a shaker table (Max Q 400, Thermo 
Scientific) rotating at $150 \mathrm{rpm}$ at $28^{\circ} \mathrm{C}$. The bacteria were harvested during the mid-exponential phase at an optical density $(590 \mathrm{~nm})$ of approximately 0.8 . The bacteria were filtered through a $0.22 \mu \mathrm{m}$ Durapore membrane filter (Millipore, Billerica, MA) and resuspended in 1\% AGW with $5 \times 10^{-4} \mathrm{M}$ sodium uranine as the fluorescent tracer.

\subsection{Injections and Sampling}

\subsubsection{Pulse Injections}

Several different injection methods and locations were tested in these experiments. In all experiments injections did not begin until the microcosm had reached steady state overnight. In the first set of experiments $4 \mathrm{mM}$ sodium benzoate attractant with $0.06 \mathrm{~g} / \mathrm{L}$ sodium resazurin tracer, was continuously injected in port 5. Sodium resazurin was used as a color tracer to visually show the flow path of the attractant plume, which can be seen in blue in Figure 3.4a. After approximately 4-6 hours, bacteria was injected into one of the bottom ports, either port 8 , 9, or 10 depending on the individual experiment. About $1 \mathrm{~mL}$ of bacteria, either chemotactic or nonchemotactic, was slowly injected by hand via a syringe attached to a small piece of tubing over the course of about 20 seconds, resulting in a circular pulse within the microcosm as seen in Figure 3.4a. In the second set of experiments attractant was continuously injected in port 8 . After about 4-6 hours bacteria was pulse injected by hand above the attractant plume in port 5 . Samples were taken from outflow ports $2-12$ when the bacteria injection had reached the opposite end of the microcosm after about 17-22 hours. Samples were collected over about 3 hours until all of the uranine tracer had been visually collected, resulting in 6-7.5 mL samples. Samples were kept on ice until they were analyzed. 

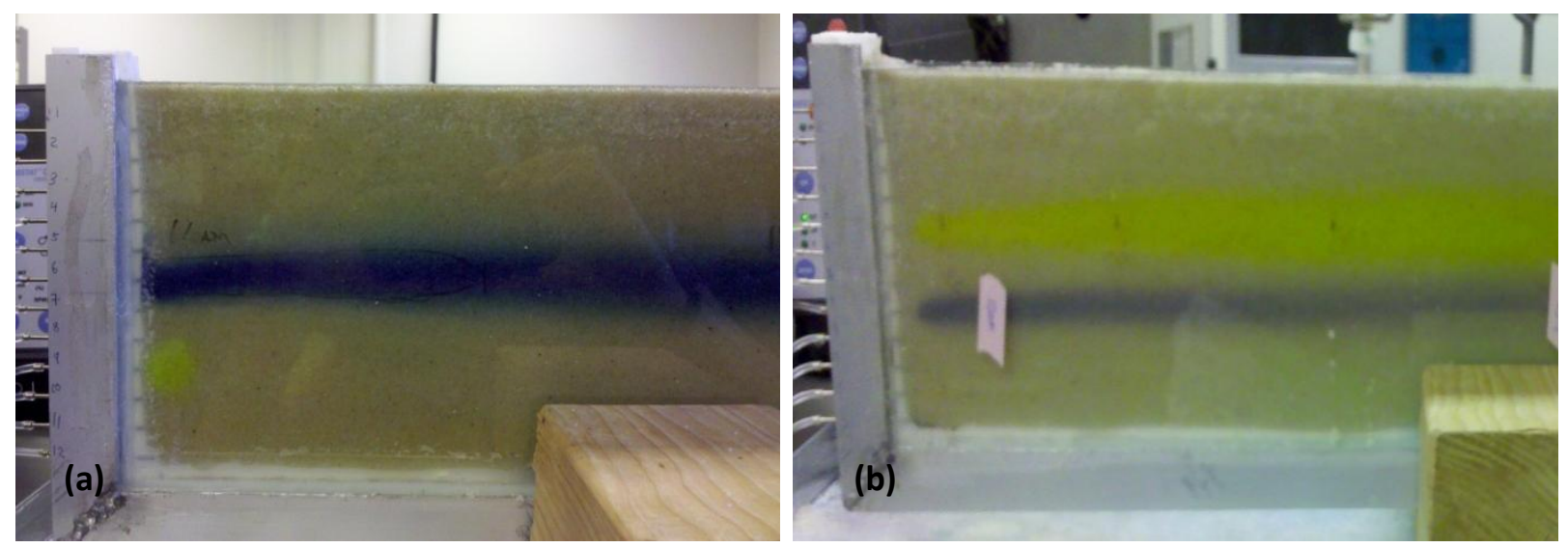

Figure 3.2 Images of microcosm injections of bacteria (yellow) and attractant (blue). (a) Pulse injection of bacteria below attractant plume. (b) Continuous injection of bacteria above attractant plume.

\subsubsection{Continuous Injections}

Experiments were also conducted with both a continuously injected attractant plume and a continuously injected bacteria plume. Chemotactic experiments and nonchemotactic experiments were each run for several different configurations including attractant injected at port 8 and bacteria injected above at port 5, attractant injected at port 5 and bacteria injected below at port 8 , attractant injected in port 8 and bacteria injected in port 6 , and attractant injected in port 7 and bacteria injected in port 5. To begin each experiment the continuous injection of attractant, $5 \mathrm{mM}$ sodium benzoate attractant with $0.06 \mathrm{~g} / \mathrm{L}$ sodium resazurin tracer, was started in its respective injection port. After approximately 1-2 hours bacteria was injected by inserting the tubing connected to the respective injection port into the $50 \mathrm{~mL}$ flask containing the bacteria. The pump was then used to continuously inject the bacteria. About $30 \mathrm{~mL}$ of filtered and resuspended bacteria was required for the duration of the experiment. The bacteria in the flask would be gently agitated every 3-4 hours to prevent settling of the cells in the container. The continuous bacteria injections lasted about 14 hours, and samples were taken from outflow ports 
2-12 after about 17-20 hours. Samples were collected over about 3 hours and captured a portion of the continuous injections that had reached steady state, resulting in 4-6 mL samples. Samples were kept on ice until they were analyzed.

\subsection{Sample Analysis}

Bacteria concentrations in the effluent samples were found using acridine orange (AO) staining (Hobbie et al. 1977). To stain the samples, $40 \mu \mathrm{L}$ of the effluent microcosm sample were mixed with $100 \mu \mathrm{L}$ of AO stain $(5.4 \mathrm{~mL} 37 \%$ formaldehyde stock solution, $93.6 \mathrm{~mL}$ DI water, with $0.1 \mathrm{~g}$ acridine orange, filtered through $0.45 \mu \mathrm{m}$ size syringe filter) and $900 \mu \mathrm{L}$ of filtered DI water. The mixture was then vortexed for $30 \mathrm{~s}$. For pulse injection experiments the $40 \mu \mathrm{L}$ of effluent sample did not need to be diluted, however, for continuous injection, samples corresponding to the bacteria injection port and the port above and below injection were diluted by 10 before preparing the AO stain. The filter was set up with $0.22 \mu \mathrm{m}$ black polycarbonate filters (GE Osmonics, Minnetonka, MN) which were secured into place using two white rings, one placed above and the other below the filter, then the glass filter tower. One minute after vortexing $520 \mu \mathrm{L}$ of filtered $1 \%$ TritonX-100 was pipette into the tower and suctioned dry. The TritonX-100 was used to allow the bacteria to disperse uniformly on the filter. One minute after the TritonX-100 was injected, $1 \mathrm{~mL}$ of the stained microcosm sample was pipetted into the filter tower with the suction on followed by $2 \mathrm{~mL}$ of DI water. Suction was kept on until the filter was removed from the tower. The filter was then allowed to dry completely on a glass microscope slide for about 15 minutes. The complete drying of the filter was extremely important to ensure readability of the final product under the microscope. After the filter was allowed to dry on the glass microscope slide, it was covered with a drop of immersion oil and a cover glass. The slides were then placed under a UV-fluorescent microscope (Zeiss Ph3 F100/1.25 Oil, 160/-) under the 
$100 \times$ lens for enumeration. Five different fields were counted and averaged to find the bacterial concentration using equation 3.1 ,

$$
\text { Concentration }=\frac{\frac{A_{\text {filter }}}{A_{\text {view }}} N_{b}}{V_{\text {sample }} D F}
$$

where $A_{\text {filter }}$ is the area of the filter $\left(283.53 \mathrm{~mm}^{2}\right), A_{\text {view }}$ is the area of the viewing field in the microscope $\left(0.009694 \mathrm{~mm}^{2}\right), N_{b}$ is the average count of bacteria over five viewing fields (between 20-200 cells), $V_{\text {sample }}$ is the sample volume $(40 \mu \mathrm{L})$, and $D F$ is the dilution factor of the sample.

The uranine tracer concentration was determined by measuring its fluorescence intensity. A calibration was made using concentration standards between $0 \mathrm{M}$ and $1 \times 10^{-5} \mathrm{M}$. This range of concentrations produced a linear correlation between concentration and intensity, measured in counts per second (cps). The samples were diluted as needed to ensure that the cps did not exceed 300,000. The final concentration of uranine in the samples could be determined by using linear correlation. Samples were excited at $480 \mathrm{~nm}$ and the emission spectra were collected from $495 \mathrm{~nm}$ through $530 \mathrm{~nm}$, with the peaks appearing at $512 \mathrm{~nm}$. An inlet and outlet slit width of $1.4 \mathrm{~nm}$ was used. Uranine samples were kept wrapped in foil in the refrigerator until they were analyzed to prevent fluorescent decay.

The benzoate concentrations were determined using HPLC (1200 series LC, Agilent, Santa Clara, CA). A Phenomenex Hypersil 5 C18 reverse phase column was used with acidified water (5\% phosphoric acid) and methanol as the carrier phase. A gradient method was used which involved changing the methanol concentration from $30 \%$ to $55 \%$ over the first 3 minutes, holding at 55\% methanol for 6 minutes, and changing the methanol concentration back to $20 \%$ over $1 \mathrm{~min}$. A flow rate of $0.4 \mathrm{~mL} / \mathrm{min}$ was used and the benzoate was detected at a wavelength 
of $240 \mathrm{~nm}$. Benzoate standards between $0 \mathrm{mM}$ and $1 \mathrm{mM}$ were used to create a linear correlation between the area under the emission peak and benzoate concentration.

\subsection{Estimation of Transport Parameters}

The experimental results from the pulse injection experiments were interpreted using a moment analysis. Injections into the porous medium of the microcosm dispersed transversely, resulting in Gaussian concentration distributions. A moment analysis was applied to the bacteria, uranine tracer, and benzoate distributions exiting the microcosm. The vertical center of

mass, $\bar{y}$, variance, $\sigma^{2}$, and skewness, $\gamma$ were determined using the following equations: (Rice 2007)

$$
\begin{gathered}
\bar{y}=\frac{1}{C_{t}} \sum_{i=1}^{n} C_{i} y_{i} \\
\sigma^{2}=\frac{1}{C_{t}} \sum_{i=1}^{n} C_{i}\left(y_{i}-\bar{y}\right)^{2} \\
\gamma=\frac{\frac{1}{C_{t}} \sum_{i=1}^{n} C_{i}\left(y_{i}-\bar{y}\right)^{3}}{\sigma^{2}}
\end{gathered}
$$

where $C_{t}$ is the sum of the outlet concentration collected from each oulet port, $C_{i}$ is the outlet concentration at port $i, y_{i}$ is the vertical position of port $i$, and $n$ is the number of ports used for the analysis. The experimental data often showed low levels of bacteria in the upper ports which were assumed to be background values. The average background bacteria concentrations were 
subtracted from each of the ports before performing the moment analysis, therefore the background did not contribute to the center of mass, variance, or skewness.

The transverse dispersion coefficients for all species in the pulse injection experiments were calculated with Equation 2.5 using the variance found from the moment analysis. For continuously injected experiments the transverse dispersion coefficients were found for all species using two different methods, a moment analysis with Equation 2.5 and also by fitting Equation 2.9 to experimental data. The resulting values were compared and it was found that there was no statistical difference between the two methods (Appendix A.3). Equation 2.4 was then used to find the transverse dispersivity for all experiments. The effective diffusion coefficient was estimated for $P$. putida F1 as $1.5 \pm 0.6 \times 10^{-7} \mathrm{~cm}^{2} / \mathrm{s}$ (Olson et al. 2005), $3.9 \times 10^{-6}$ $\mathrm{cm}^{2} / \mathrm{s}$ for uranine (Liu 2011), and $8.3 \times 10^{-6} \mathrm{~cm}^{2} / \mathrm{s}$ for benzoate (Cussler 1997) assuming a tortuosity factor of 1.2 .

The center of mass and variance values were used to fit the benzoate, uranine, and nonchemotactic bacteria data to normalized curves using the following equation:

$$
f y, y, \sigma^{2}=\frac{C}{C_{t}}=\frac{1}{\overline{2 \pi \sigma^{2}}} e^{-y-y^{2} /\left(2 \sigma^{2}\right)}
$$

where $C$ is the concentration and $y$ is the vertical position. The chemotactic bacteria were not fit to a normalized curve because their preferential swimming toward the attractant tends to cause distributions to be asymmetrical with a bias towards the attractant.

\subsection{Mathematical Model}

To evaluate the mathematical model for two-dimensional transport in the microcosm, the finite element solver COMSOL was used to solve the differential equations for bacteria and 
attractant concentrations (Equations 2.11, 2.12). The simulation was performed with the dimensions $95 \mathrm{~cm}$ (x-axis) X $13 \mathrm{~cm}$ (y -axis). The tank was assumed to be filled with homogeneous porous media with a void fraction of 0.4 . The attractant injection was centered 8.5 $\mathrm{cm}$ above the bottom of the tank and an injection width of $1 \mathrm{~cm}$ was used to simulate the amount of spreading experimentally observed within the microcosm. An inlet attractant concentration of $5 \mathrm{mM}$ sodium benzoate was used to match experimental conditions. The bacteria injection was centered $3.5 \mathrm{~cm}$ from the bottom of the tank to model a $4 \mathrm{~cm}$ experimental spacing between attractant and bacteria. An inlet bacteria concentration of $10^{9}$ cells $/ \mathrm{mL}$ was used to match experimental conditions. Simulations were also performed with the bacteria centered $4.5 \mathrm{~cm}$ from the bottom of the tank, to model $3 \mathrm{~cm}$ spacing, and $5.5 \mathrm{~cm}$ from the bottom of the tank, to model $2 \mathrm{~cm}$ spacing. An injection width of $1 \mathrm{~cm}$ was also used to model the experimentally observed spreading within the tank. Models were evaluated assuming continuous attractant and bacteria plumes and steady-state conditions. No-flux boundary conditions were used for the upper and lower boundaries of the model. A velocity of $1.1 \mathrm{~m} /$ day was used for the simulation. Velocity was assumed to be constant at the inlet and outlet ends of the microcosm, and a slipboundary with constant velocity of $1.1 \mathrm{~m} /$ day at the wall was used for the upper and lower boundaries of the model. Bacteria and attractant were assumed to be injected at a velocity of 1.1 m/day. Transverse dispersion coefficients were calculated from experimental data using Equation 2.9 rather than the moment analysis, because Equation 2.9 takes into account the $1 \mathrm{~cm}$ injection width and the moment analysis assumes a point source (see Appendix A.3 for values). The longitudinal dispersion coefficient was assumed to be the same as the transverse dispersion coefficient. Different values for the chemotactic sensitivity coefficient and chemotaxis receptor constant were used to explore their effect on the shape and location of effluent concentration 
distributions. The built in element size of fluid dynamics controlled "extremely fine mesh" was chosen to evaluate the simulation. This was the smallest mesh size available, and the cell size ranged from $0.87 \mathrm{~mm}$ through $0.026 \mathrm{~mm}$. 


\section{Results for Pulse Injection Experiments}

\subsection{Tracers and Flow Behavior}

Tracer injections were used to provide information about the flow behavior within the microcosm. Resazurin tracer was continuously injected with the benzoate attractant. The tracer showed that the attractant plume was characterized by a slight rise upon entrance to the microcosm followed by steady horizontal flow as seen in Figure 3.1. The slight rise has been documented in previous two-dimensional microcosm experiments and is thought to be due to the hydraulic properties of the experimental setup such as flow rate, initial head, and hydraulic conductivity (Bauer, Rolle, Bauer, et al. 2009). The slight rise did not affect the establishment of a stable attractant gradient across the microcosm. Injections in the upper ports travelled faster than injections in the lower ports. This observation was consistent across all experiments but did not affect the establishment of stable transverse attractant concentration gradients. Uranine was used as a tracer injected with the bacteria to visually characterize the behavior of the bacteria injections and also allowed for samples of the microcosm effluent to be collected at the correct time. The uranine also acted as an inherent control to account for variations in flow that may have affected the bacterial transport. The bacterial distributions could then be compared to the uranine, which had been exposed to the same conditions within the microcosm. Flow variations are illustrated in Figure 4.1 below. Figure 4.1a shows colorful tracer injected in each port at the same time, resulting in a vertical stripe of tracer. Figure $4.1 \mathrm{~b}$ shows the same injection after about 14 hours, or about $3 / 4$ of the way through the microcosm. Tracer that has travelled farthest in Figure 4.1b shows areas of high velocity, and tracer that has lagged behind shows areas of lower velocity. Additionally, flow variations were not consistent in behavior from experiment 
to experiment, making the inclusion of the uranine tracer extremely important for quantifying bacterial transport due to dispersion and motility.
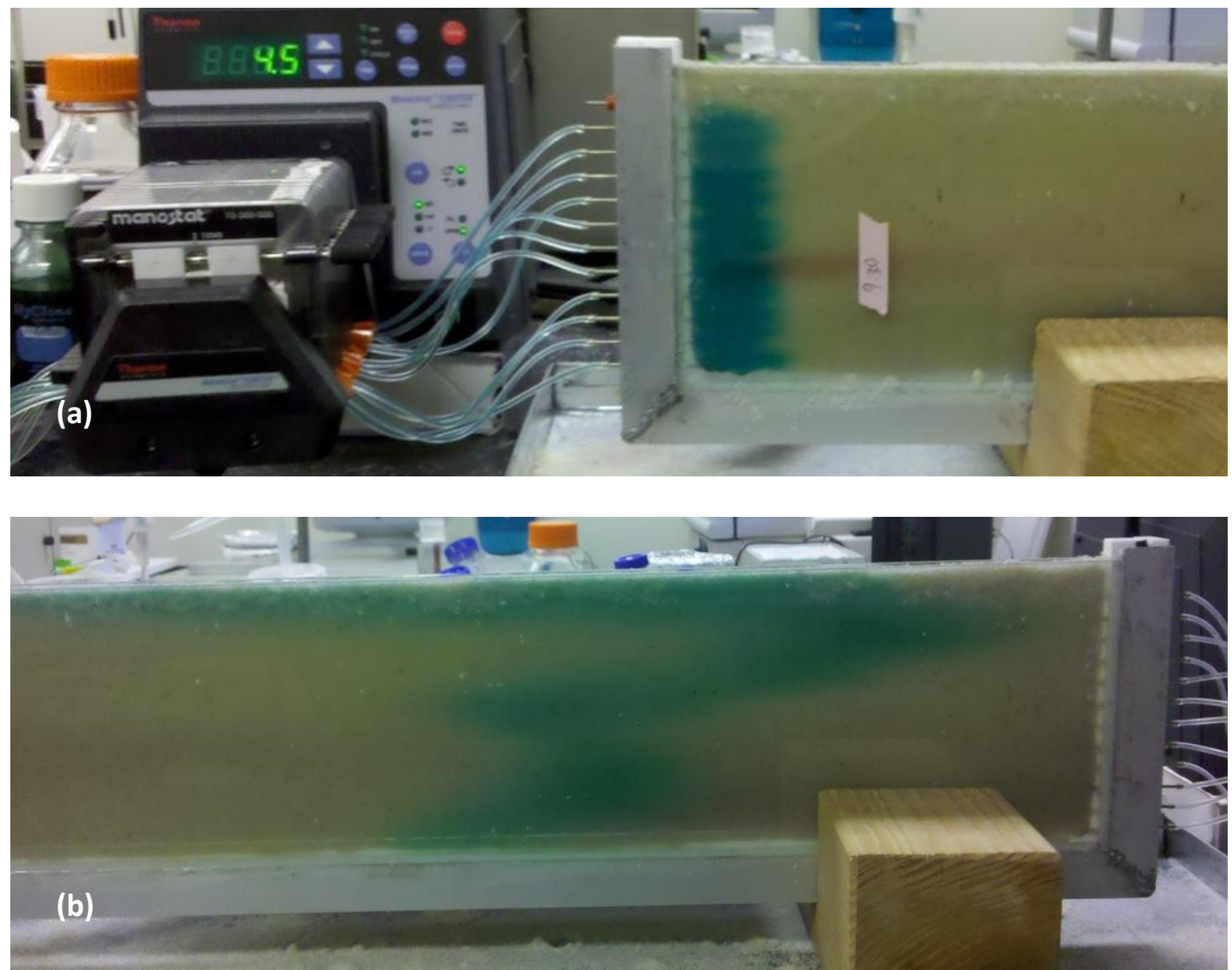

Figure 4.1 Images of transverse velocity gradients due to flow inconsistencies. (a) Pulse injection of colorful tracer in each port. (b) Pulse injection in each port after travelling about $3 / 4$ of the way through the microcosm. Tracer that has travelled furthest indicates regions of high velocity, tracer that has lagged behind indicates regions of low velocity.

Bacteria pulse injections that took place closer to the bottom of the microcosm $(3 \mathrm{~cm}$ from the bottom or less) generally showed more distortion in the shape of the pulse. The pulse would begin in the microcosm as a symmetrical circle, and then as the pulse dispersed in the porous media, transverse velocity gradients would alter the shape to an irregular "s" shape with a long tail (shown in Figure 4.2). This distortion due to velocity gradients impacted the transverse concentration gradients of the bacteria, causing them to be inconsistent over the length of the pulse injection. Shape distortion was less pronounced when the bacteria was injected above port 
9. Initial experiments were run with pulse injection at or below port 9, however the majority of pulse experiments were injected above port 9. The inconsistencies in concentration gradients due to flow variation were only present for pulse injections; continuously injected species maintained stable transverse concentration gradients.

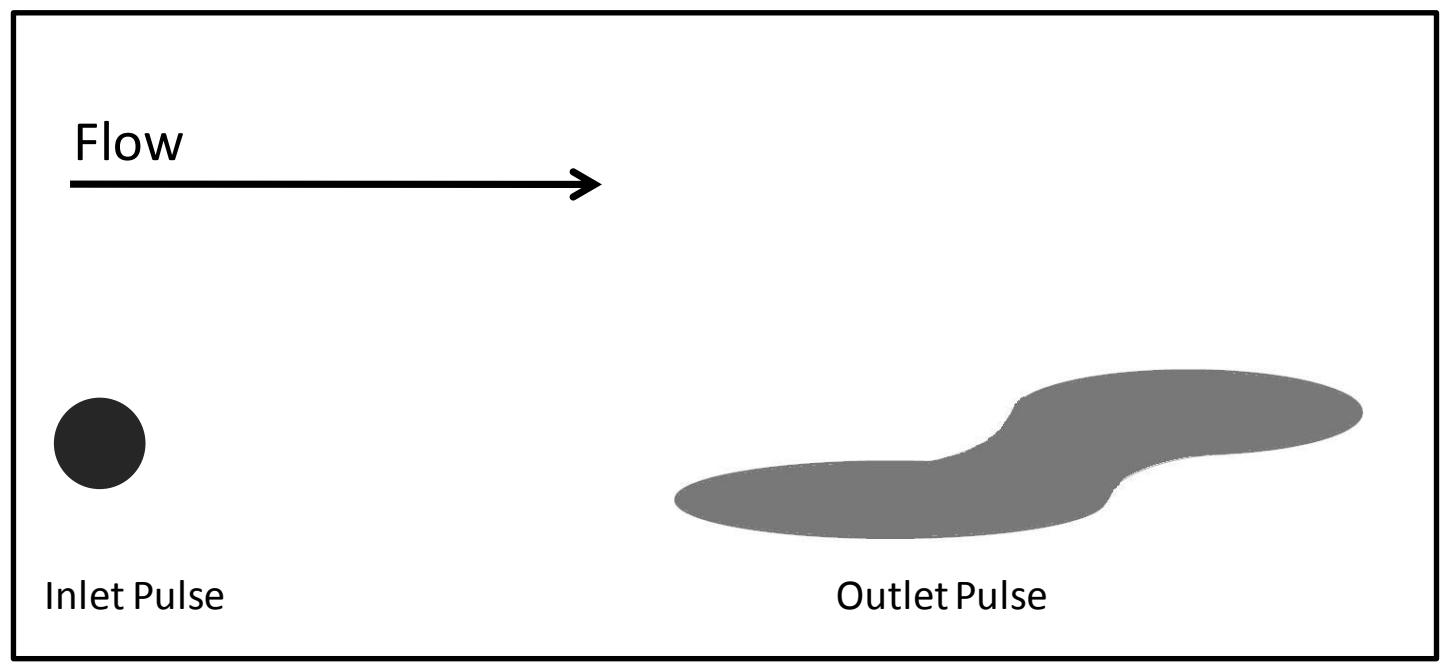

Figure 4.2 Shapes of pulse injection in the two dimensional microcosm. The small circular inlet pulse shape is shown on the bottom left. The final outlet shape of the pulse injection is shown on the bottom right. The direction of flow is left to right in this image.

\subsection{Pulse Injections Below Attractant}

Figure 4.3 below shows the vertical concentration distributions for the bacteria (red squares), benzoate (green triangles), and uranine (blue diamonds) at the microcosm exit for pulse injections of bacteria below the attractant at an average flow velocity of $1.1 \mathrm{~m} / \mathrm{day}$. Bacteria were injected in port 10 for two of the chemotactic runs (not pictured, shown in Appendix A.1), in port 9 for three experiments (Figure 4.3a, 4.3b, one not pictured, shown in Appendix A.1), and port 8 for all other experiments (Figure 4.3c, 4.3d, two not pictured, shown in Appendix A.1). The injections were moved to higher ports to help prevent flow inconsistencies that were more pronounced at the lower ports. Attractant was injected in port 5 for all experiments. The 
bacteria injection port is located at zero on the y-axis in Figure 4.3. In Figure 4.3 it is important to look at the location of the bacteria distribution compared to the uranine tracer distribution, and not injection location.
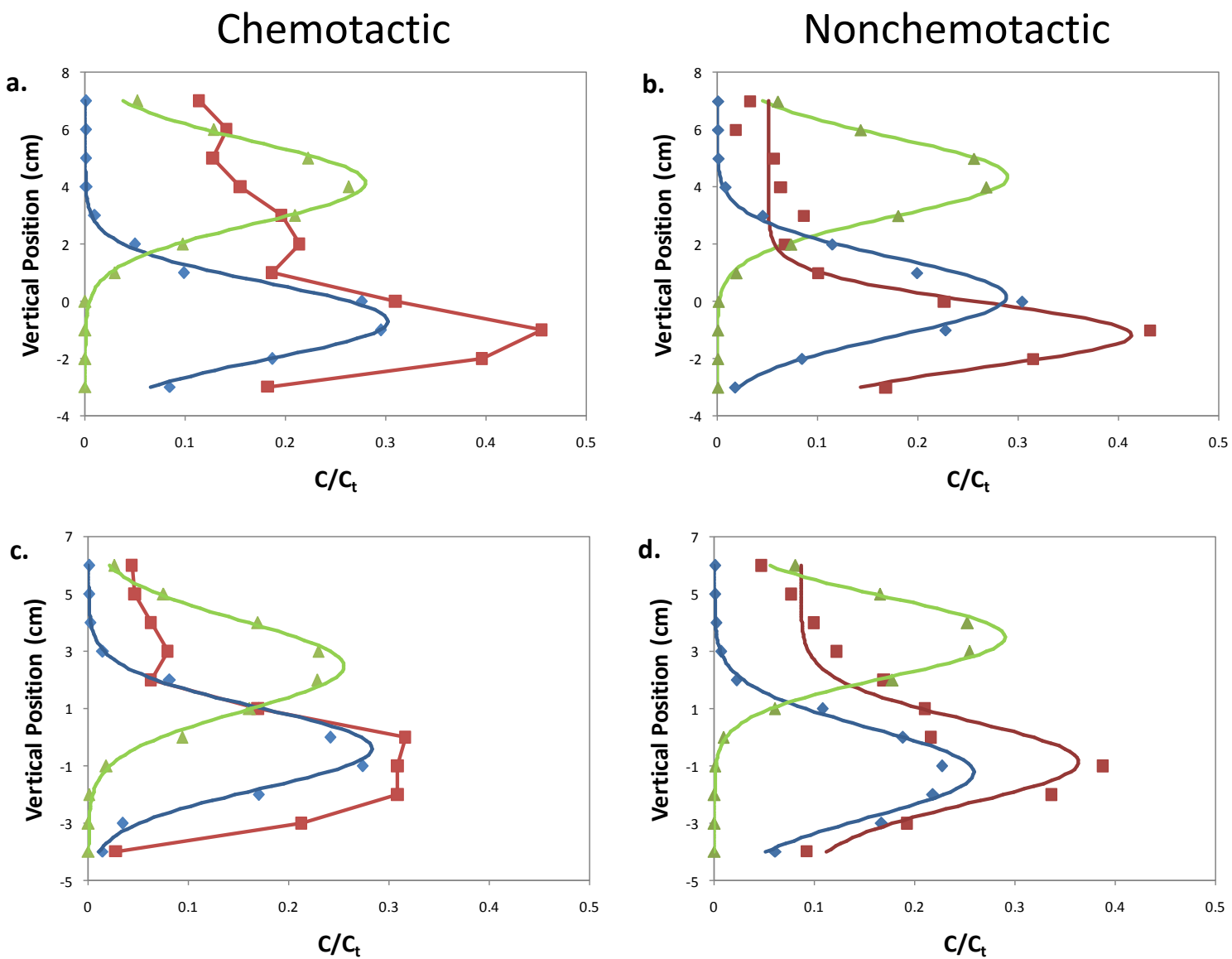

Figure 4.3 Transverse population distributions from 2-D microcosm experiments with bacteria pulse injections below attractant plume. Chemotactic bacteria $P$. putida $\mathrm{F} 1$ are represented as red squares, $\square,(\mathrm{a}, \mathrm{c})$ and nonchemotactic bacteria $P$. putida $\mathrm{F} 1 \mathrm{CheA}$ are represented as red squares, $\square,(b, d)$. Concentration distributions for the uranine tracer are represented by blue diamonds, $\diamond$, and benzoate attractant concentration represented by green triangles, $\triangle$. All bacteria, uranine and benzoate distributions have been normalized by the sum of concentrations from each individual port. Normalized distribution curves have been fit to the nonchemotactic bacteria, uranine, and benzoate data using Equation 3.5.

The normalized distributions fit represented the uranine and the benzoate data well. A noticeable inconsistency in the data is the background bacteria values found in the upper ports. 
Background levels of bacteria were found in all runs and the average background value was subtracted from all ports for the moment analysis calculations. Background bacteria were most likely due to residual bacteria being retained in the sand used to pack the microcosm despite washing and autoclaving the sand between experiments. Mass balances of the bacteria injections and effluent samples show that only about half of the bacteria injected are captured in the effluent samples, therefore a large portion of the bacteria remains in the sand and must be washed out. The amount and distribution of the background bacteria are problematic as it is impossible to distinguish between background data and the injected bacteria, potentially causing the moment analysis to be inaccurate. Benzoate was nearly $100 \%$ recovered for all experiments.

Table 4.1 below summarizes the values for the center of mass, transverse dispersion coefficient, transverse dispersivity, and skewness from the moment analysis. The center of mass for the benzoate plume shows a slight rise on average which was small and most likely due to variations in flow, which was also observed visually with the resazurin tracer. The uranine tracer sank about $0.7 \mathrm{~cm}$, which was consistent with previous microcosm experiments using uranine tracer (J. Liu 2011), and was most likely due to variations in flow within the microcosm. Variations in flow were usually more pronounced at the bottom of the microcosm, which could also be contributing to the larger sinking value for uranine compared to the benzoate. Flow variations also became more pronounced as the tubing through the cassette pump wore out, which caused the individual flow rates through each port to slightly change. The chemotactic bacteria, P. putida F1, and the nonchemotactic control, P. putida F1 CheA, both experienced sinking relative to the injection port location in the experiments. The best way to quantify the center of mass data for the bacteria is to compare it to the uranine tracer, rather than the injection port, to eliminate the effect of the flow variations on the center of mass values. 
Table 4.1 Moment analysis summary for pulse bacteria injections below attractant plume.

\begin{tabular}{|c|cccc|}
\hline Component & $\bar{y}(\mathrm{~cm})$ & $D_{T} \times 10^{5}\left(\mathrm{~cm}^{2} / \mathrm{s}\right)$ & $\alpha_{T} x 10^{2}(\mathrm{~cm})$ & $\gamma$ \\
\hline P. putida $\mathrm{F} 1$ & $-0.4 \pm 0.8$ & $1.6 \pm 0.5$ & $1.2 \pm 0.3$ & $0.4 \pm 0.4$ \\
P. putida F1 CheA & $-1.5 \pm 0.6$ & $1.0 \pm 0.3$ & $0.9 \pm 0.4$ & $0.6 \pm 0.3$ \\
Uranine & $-0.7 \pm 0.7$ & $1.2 \pm 0.3$ & $0.7 \pm 0.2$ & $0.4 \pm 0.4$ \\
Benzoate & $0.2 \pm 0.4$ & $1.4 \pm 0.3$ & $0.4 \pm 0.2$ & $-0.06 \pm 0.07$ \\
\hline
\end{tabular}

Table 4.2 shows the average difference between the bacteria and the uranine tracer. The difference for each run was estimated and the averages of those differences were calculated for both chemotactic and nonchemotactic bacteria. On average the chemotactic bacteria, P. putida F1, sank less than the uranine tracer, which is most likely caused by chemotaxis allowing for the population to migrate upwards toward the attractant plume. The nonchemotactic control sank about $0.6 \mathrm{~cm}$ lower than the uranine tracer. This could be caused by bacterial density causing sinking in addition to that from the flow pattern. The amount of sinking can be estimated from the particle settling velocity according to (Liu 2011):

$$
V_{\text {settling }}=\frac{g d_{b}\left(\rho_{b}-\rho_{f}\right)}{18 \mu_{f}}
$$

where $g$ is the gravitational acceleration, $d_{b}$ is the average bacterial diameter, $\mu_{f}$ is the fluid viscosity, $\rho_{b}$ is the bacterial density, and $\rho_{f}$ is the fluid density. The bacteria density ranges from $1.04 \times 10^{3} \mathrm{~kg} / \mathrm{m}^{3}$ to $1.13 \times 10^{3} \mathrm{~kg} / \mathrm{m}^{3}$ (Bouwer \& Rittmann 1992) corresponding to a settling distance of $0.35 \mathrm{~cm}$ to $1.15 \mathrm{~cm}$ over the course of the experiment, approximately 20 hours. The nonchemotactic bacteria sank on average $0.6 \mathrm{~cm}$ more than the uranine, which is within the expected range of values calculated with Equation 4.1. A T-test was performed on the values for 
center of mass differences, $\bar{y}_{B a c}-\bar{y}_{U r a}$, to compare the chemotactic experiments to the nonchemotactic experiments. The t-test showed that there was a statistically significant difference between the chemotactic and nonchemotactic values for $\mathrm{P}<0.062$.

Table 4.2 Summary of center of mass and skewness differences for uranine tracer and bacteria data for experiments with pulse bacteria injections below the attractant plume.

\begin{tabular}{|l|cc|}
\hline Experiment Type & $\bar{y}_{B a c}-\bar{y}_{U r a}(\mathrm{~cm})$ & $\gamma_{B a c}-\gamma_{U r a}$ \\
\hline Chemotactic & $0.1 \pm 0.4$ & $0.0 \pm 0.4$ \\
Nonchemotactic & $-0.6 \pm 0.7$ & $0.12 \pm 0.06$ \\
\hline
\end{tabular}

The transverse dispersion coefficient, $D_{T}$, and the transverse dispersivity, $\alpha_{T}$, calculated for the chemotactic bacteria were higher than the values calculated for both the nonchemotactic control and the uranine tracer in experiments with pulse bacteria injections below the attractant plume. This suggests that the preferential migration of the chemotactic bacteria transverse to the flow has enhanced the ability of the population to spread out within the porous medium. Ford and Harvey corroborate that chemotaxis can act as a mechanism to increase the transverse dispersion coefficient and transverse dispersivity by diverting bacteria populations from the flow direction towards an attractant gradient (Ford \& Harvey 2007). The transverse dispersion coefficient and transverse dispersivity values for the chemotactic bacteria, nonchemotactic bacteria, benzoate, and uranine are all in close agreement with values determined in previous pulse injection experiments in the same microcosm from the Ford group (Strobel et al. 2011). The values from experiments in this study fall within the range from $0.0035 \mathrm{~cm}$ through $0.015 \mathrm{~cm}$ which is within the range of values predicted by literature sources. Strobel et al. obtained data from the same microcosm and using the same packing that was used for the experiments in this study (Strobel et al. 2011). Two flow rates were used, $1.1 \mathrm{~m} /$ day and $3.9 \mathrm{~m} /$ day. The dispersivity values from the 
$1.1 \mathrm{~m} /$ day experiments ranged from $0.004 \mathrm{~cm}$ through $0.014 \mathrm{~cm}$. Bauer et al. found the transverse dispersivity of a bromide tracer to be $0.006 \mathrm{~cm}$ using a microcosm of the same dimensions with a flow velocity of $1.2 \mathrm{~m}$ /day and a grain size of 200-300 $\mu \mathrm{m}$ (Bauer et al. 2008). Olsson and Grathwohl also used a two-dimensional microcosm setup to investigate the effects of flow velocity and particle size on the transverse dispersivity (Olsson \& Grathwohl 2007). The experiments revealed that higher velocities and smaller grain sizes decrease the transverse dispersivity. Transverse dispersivity values for these experiments ranged from $0.0018 \mathrm{~cm}$ through $0.02 \mathrm{~cm}$. Long and Ford found relatively small transverse dispersivity values in the range of $0.0005 \mathrm{~cm}$ through $0.004 \mathrm{~cm}$ using a homogeneous microfluidic device (Long \& Ford 2009). This was expected as increased heterogeneity of a system increases the transverse dispersivity, and conversely homogeneity decreases dispersivity. The values of transverse dispersivity determined in this study fall within the range of values from literature.

The skewness parameter was used to characterize the asymmetry of the bacteria, uranine, and benzoate distributions about the center of mass. A negatively skewed distribution is characterized by the bulk of the mass present above the mean and a long tail at values below the mean. A negative value was expected for the chemotactic bacteria injected below the attractant plume due to the vertical migration toward the attractant caused by chemotaxis. Mathematical modeling performed by a previous member of the Ford group, using the two-dimensional advection-dispersion equations discussed above, has showed that a negative skewness is expected for chemotactic bacteria when bacteria are injected below the attractant (Liu 2011). For experiments with the bacteria pulse injected below the attractant a positive value of skewness was found for both the chemotactic bacteria and the nonchemotactic control. This is most likely caused by the sinking of the bacteria and flow irregularities affecting the shape of the 
concentration distribution. The uranine tracer also had a positive value which suggests flow irregularities affected the skewness value. The uranine tracer, benzoate, and nonchemotactic bacteria would be expected to have a skewness of zero in an idealized flow without sinking bacteria. The benzoate had a skewness value much closer to the expected value of zero, which suggests that the flow was much more controlled in the upper portion of the microcosm. The difference in the skewness values between the bacteria to those for the uranine tracer, as shown in Table 4.2, shows that the skewness for the chemotactic bacteria is about 0.0 , which is less positive than the difference value of 0.12 for the nonchemotactic control. A t-test shows that there is not a statistically significant difference between these two sets of data $(P=0.300)$. This suggests that for this experimental configuration chemotaxis has impacted the skewness parameter.

\subsection{Pulse Injections Without Attractant}

Microcosm experiments were also run with pulse injections of chemotactic and non chemotactic bacteria without an attractant plume as another control. One chemotactic and one nonchemotactic experiment were run with the bacteria pulse injected in port 8 . The concentration distributions for these control experiments are shown in Figure 4.5. The bacteria sank $0.1 \mathrm{~cm}$ more than the uranine for the chemotactic run and $0.04 \mathrm{~cm}$ more than the uranine for nonchemotactic run. Both of these center of mass differences fall within the expected range of sinking calculated above. Despite the average center of mass values suggesting that chemotaxis is measurable within the microcosm, there is still a large amount of uncertainty reported in these measurements, therefore it is difficult to conclusively determine the contribution of chemotaxis to these values. Sinking of the bacteria is a prominent source of error in all experimental runs, 
affecting the ability to distinguish whether chemotaxis or gravity is contributing to changes in shape and center of mass of bacteria concentration profiles.
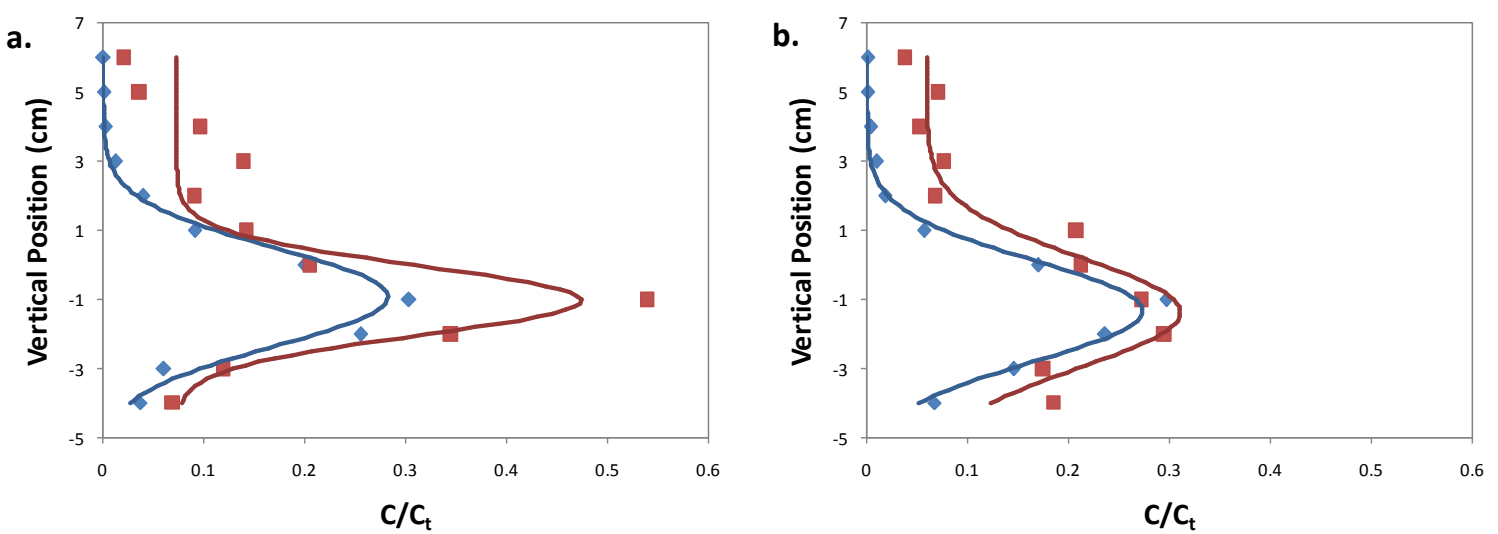

Figure 4.4 Transverse population distributions from 2-D microcosm experiments without an attractant source for chemotactic bacteria $P$. putida F1 $(\square$, a) and non chemotactic bacteria $P$. putida F1 CheA $(a, b)$ normalized by the sum of bacteria concentrations from each individual port. Uranine tracer distributions, $\diamond$, have been normalized by the sum or uranine concentrations from each port. All bacteria and tracer curves have been fit to a normalized distribution curve using Equation 3.5.

\subsection{Pulse Injections Above Attractant}

Experiments were also performed with pulse injections of bacteria above an attractant plume. This configuration was tested to see if transverse migration would be more pronounced when the chemotactic motility of the bacteria was in the same direction as the pull of gravity. Experiments with bacteria injected below the attractant forced the chemotactic bacteria to swim against the pull of gravity. A total of five experiments were run, two chemotactic, two nonchemotactic, and one chemotactic without an attractant plume. A pulse of bacteria was injected in port 5 for all experiments and attractant was injected in port 8 for all experiments using an attractant plume. Concentration distributions of the bacteria, uranine tracer, and benzoate for one chemotactic and one nonchemotactic experiment are shown below in Figure 
4.6. The three remaining graphs for pulse injections above attractant can be found in Appendix A.1. The bacteria injection port is located at zero on the y-axis in Figure 4.6.
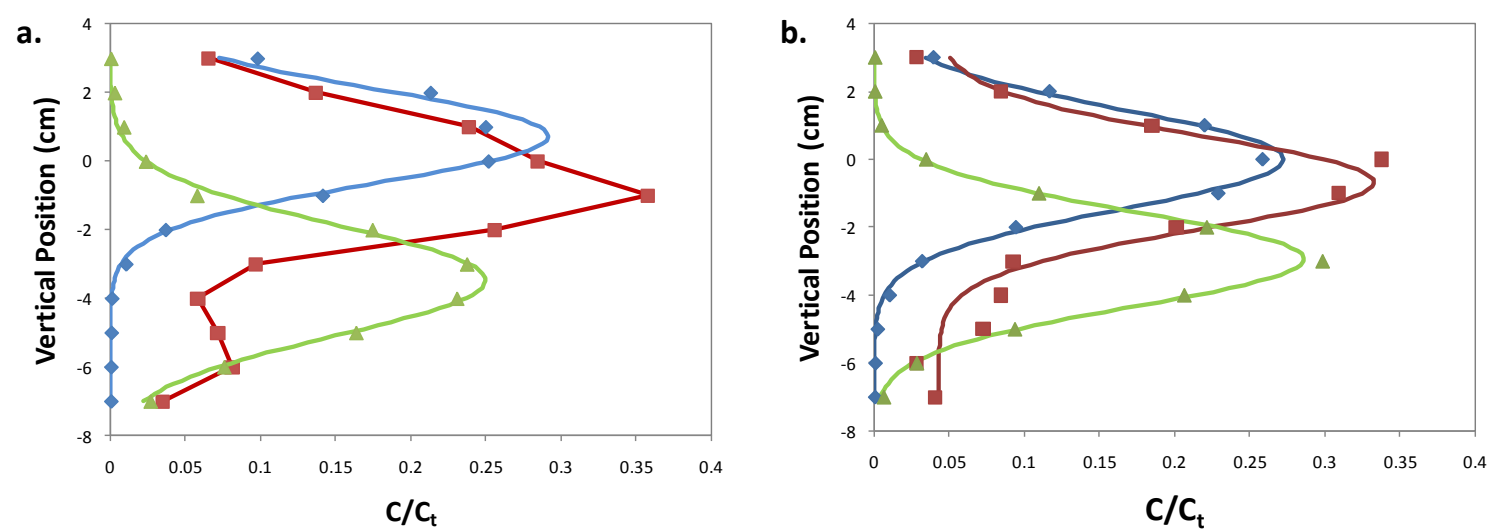

Figure 4.5 Transverse population distributions from 2-D microcosm experiments with bacteria pulse injections above attractant plume. Chemotactic bacteria $P$. putida $\mathrm{F} 1$ are represented as red squares, $\mathbf{a}$, (a) and nonchemotactic bacteria $P$. putida F1 CheA are represented as red squares, , (b). Concentration distributions for the uranine tracer are represented by blue diamonds, and benzoate attractant concentration represented by green triangles, $\triangle$. All bacteria, uranine and benzoate distributions have been normalized by the sum of concentrations from each individual port. Normalized distribution curves have been fit to the nonchemotactic bacteria, uranine, and benzoate data using Equation 3.5.

Table 4.3 below summarizes the values for the center of mass, transverse dispersion coefficient, transverse dispersivity, and skewness from the moment analysis. The parameters for all three control experiments, two nonchemotactic and one chemotactic without attractant, have been compiled together. The center of mass for the uranine tracer shows an average sinking of $1.1 \mathrm{~cm}$, whereas the benzoate plume only sank on average $0.3 \mathrm{~cm}$. This suggests that the nonzero center of mass may be partially due to the injection method and not the location of injection. The shape of pulse injections are much more easily distorted in the microcosm compared to the stability seen with continuously injected species. The chemotactic and nonchemotactic bacteria experienced sinking again for these experiments, with the chemotactic 
bacteria sinking on average $1.5 \mathrm{~cm}$ and the nonchemotactic bacteria sinking on average $1.4 \mathrm{~cm}$. This is due to a combination of variables including injection method, flow variations, and also the higher density of bacteria. Table 4.4 shows the comparison of the average difference in center of mass between the bacteria and the uranine tracer. The difference for each run was estimated and the averages of those differences were calculated for both chemotactic and nonchemotactic bacteria. On average the chemotactic bacteria were found $0.9 \mathrm{~cm}$ closer to the attractant plume compared to the uranine tracer. The nonchemotactic bacteria were found on average $0.1 \mathrm{~cm}$ further away from the attractant plume compared to the uranine tracer. The center of mass averages suggest that chemotaxis has caused the chemotactic bacteria to migrate closer to the attractant plume. There was a large error associated with the center of mass difference for the nonchemotactic bacteria, sinking was only present in one out of three experimental runs. The most likely cause for this discrepancy is the presence of a large amount of background bacteria making it difficult to distinguish injected bacteria from background.

Table 4.3 Moment analysis summary for pulse bacteria injections above attractant plume.

\begin{tabular}{|c|cccc|}
\hline Component & $\bar{y}(\mathrm{~cm})$ & $D_{T} \times 10^{5}\left(\mathrm{~cm}^{2} / \mathrm{s}\right)$ & $\alpha_{T} \times 10^{2}(\mathrm{~cm})$ & $\gamma$ \\
\hline Chemotactic & -1.5 & 1.2 & 0.9 & -0.1 \\
$\begin{array}{c}\text { Nonchemotactic/ } \\
\text { No Attractant }\end{array}$ & $-1.4 \pm 0.9$ & $1.4 \pm 0.3$ & $1.2 \pm 0.4$ & $-0.1 \pm 0.4$ \\
Uranine & $-1.1 \pm 1.5$ & $1.4 \pm 0.3$ & $0.8 \pm 0.3$ & $0.0 \pm 0.2$ \\
Benzoate & $-0.3 \pm 0.3$ & $1.3 \pm 0.2$ & $0.4 \pm 0.2$ & $-0.07 \pm 0.09$ \\
\hline
\end{tabular}

The transverse dispersion coefficient, $D_{T}$, and the transverse dispersivity, $\alpha_{T}$, calculated for the chemotactic bacteria were within the same range of the values calculated for both the nonchemotactic control and the uranine tracer in experiments with pulse bacteria injections below the attractant plume. The dispersion and dispersivity values for all components were 
within the same range as those calculated for experiments with the pulse injection below the attractant plume. These results suggest that chemotaxis has not caused a higher dispersion or dispersivity.

Table 4.4 Summary of center of mass and skewness differences for uranine tracer and bacteria data for experiments with pulse bacteria injections above the attractant plume.

\begin{tabular}{|c|cc|}
\hline Experiment Type & $\bar{y}_{B a c}-\bar{y}_{\text {Ura }}(\mathrm{cm})$ & $\gamma_{B a c}-\gamma_{U r a}$ \\
\hline Chemotactic & -0.9 & 0.1 \\
Nonchemotactic & $0.1 \pm 0.7$ & $0.0 \pm 0.2$ \\
\hline
\end{tabular}

A positively skewed distribution is characterized by the bulk of the mass present below the mean and a long tail at values above the mean. A positive value was expected for the chemotactic bacteria injected above the attractant plume due to the migration toward the attractant caused by chemotaxis. The skewness values on average for the chemotactic and nonchemotactic experiments were indistinguishable within error. The skewness values with the uranine tracer subtracted out were also within range of each other. There was a very pronounced positive skewness value of 0.2 for one chemotactic experiment, shown in Figure 4.6a, however this trend was not reproducible in other experiments.

\subsection{Conclusions}

Two-dimensional microcosm experiments with a bacteria pulse injection below the attractant provided data to suggest that chemotactic bacteria can migrate transversely toward an attractant source. The center of mass value for the chemotactic bacteria was $0.1 \mathrm{~cm}$ closer to the attractant plume that of the uranine tracer whereas the nonchemotactic control was found $0.6 \mathrm{~cm}$ further away from the attractant than the uranine tracer. The transverse dispersion coefficient 
and transverse dispersivity values were larger for the chemotactic bacteria than for the nonchemotactic control or the uranine tracer. This suggests that biased swimming of the chemotactic bacteria has enhanced the ability of the population to spread out within the porous media. Similarly, experiments with a pulse injection of bacteria above the attractant show that chemotactic bacteria was found $0.9 \mathrm{~cm}$ closer to the attractant than the uranine tracer, and nonchemotactic bacteria was found $0.2 \mathrm{~cm}$ further away from the attractant than the tracer. The transverse dispersion coefficient and transverse dispersivity values were found to be the same within uncertainty for chemotactic and nonchemotactic bacteria for this experimental configuration.

The results from these experiments are promising, however, there are still many factors contributing to the error associated with the two-dimensional microcosm. The inability to eradicate background bacteria may affect the moment analysis calculations, as shown in Appendix A.2. It is difficult to differentiate background bacteria from injected bacteria and also the background values are often inconsistent between experiments. Another problem affecting the microcosm experiments is the sinking of the bacteria. The sinking affects the values obtained from the moment analysis, causing the center of mass and the skewness parameters to shift. Finally, the inability to create an idealized flow within the microcosm can affect the accuracy of the results. Flow variations were present throughout the microcosm and were particularly pronounced at the bottom of the microcosm. Additionally, the pulse injection method may also be affecting the accuracy of the results. 


\section{Results for Continuous Injection Experiments}

\subsection{Introduction}

The experiments with continuously injected bacteria used the cassette pumps to inject the bacteria at the same flow rate as the artificial groundwater in the microcosm. One of the benefits of using continuously injected bacteria is the higher concentrations of injected bacteria in the effluent samples. This was advantageous because the concentration of injected bacteria was of a much larger magnitude than the background bacteria, which greatly reduced the effect of background bacteria on the moment analysis. This allows for only injected bacteria to be used for the determination of transport parameters. The continuous bacteria injections visually appeared to be more stabilized than previous pulse injections, where the pulse was often distorted by flow irregularities. In addition, continuously injected bacteria maintained a stable transverse concentration gradient, which could not be maintained with previous pulse injection experiments. These experiments are operated under steady state conditions so samples could be taken from a stable plume, compared to the time-dependent pulse injection experiments where the samples were taken to encompass the whole pulse. The continuously injected experiments reduced scatter in the data used to determine transport parameters, which will subsequently increase the accuracy of the mathematical models. A variety of experimental configurations using continuously injected bacteria are explored in this chapter. Experiments with $3 \mathrm{~cm}$ and 2 $\mathrm{cm}$ spacing between bacteria and attractant have been performed to explore the relationship between the exposure time of the bacteria to attractant and the extent of the chemotactic response. 


\subsection{Continuous Injections Below Attractant at $3 \mathrm{~cm}$ Spacing}

Experiments using continuously injected bacteria were performed with $3 \mathrm{~cm}$ spacing between the attractant and the bacteria. Figure 5.1 below shows the vertical concentration distributions for the bacteria (red squares), benzoate (green triangles), and uranine (blue diamonds) at the microcosm exit for continuous injections of bacteria below the attractant at an average flow velocity of $1.2 \mathrm{~m} /$ day. Bacteria were injected in port 8 and attractant in port 5 . A total of 6 experiments were performed, 3 chemotactic and 3 nonchemotactic.

Chemotactic
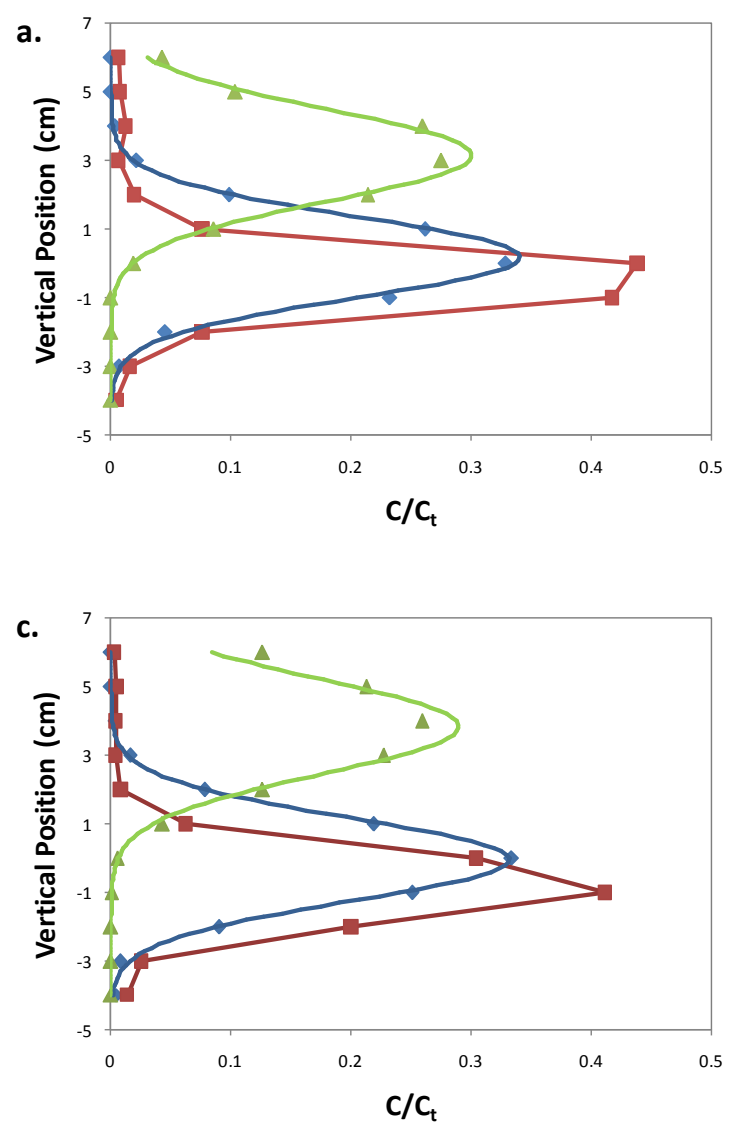

Nonchemotactic
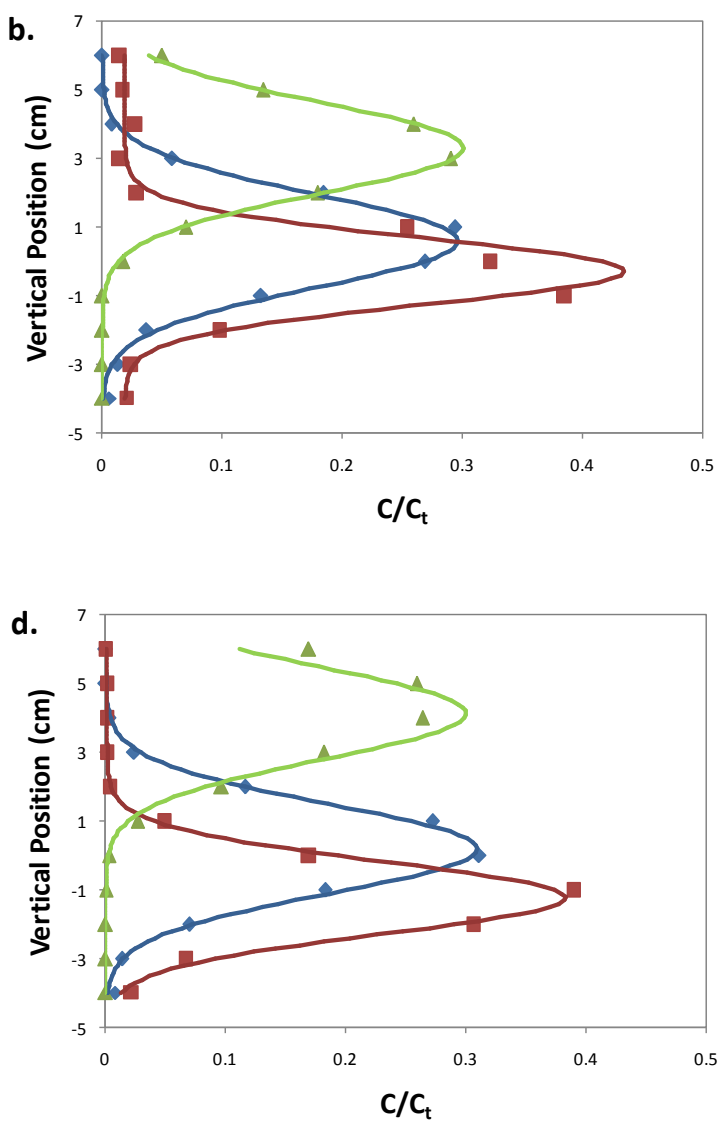

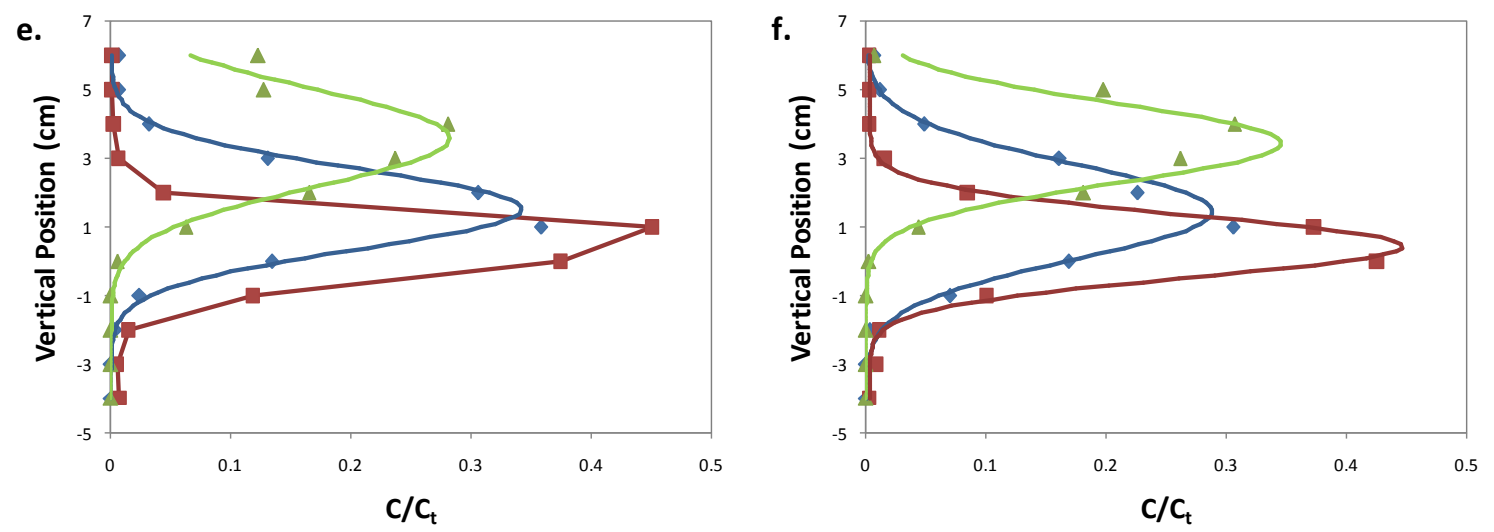

Figure 5.1 Transverse population distributions from 2-D microcosm experiments with continuous bacteria injections $3 \mathrm{~cm}$ below attractant plume. Chemotactic bacteria $P$. putida F1 are represented as red squares, $\square,(\mathrm{a}, \mathrm{c})$ and nonchemotactic bacteria $P$. putida F1 CheA are represented as red squares, $\square,(b, d)$. Concentration distributions for the uranine tracer are represented by blue diamonds, $\diamond$, and benzoate attractant concentration represented by green triangles, $\Delta$. All bacteria, uranine and benzoate distributions have been normalized by the sum of concentrations from each individual port. Normalized distribution curves have been fit to the nonchemotactic bacteria, uranine, and benzoate data using Equation 3.5

The normalized distributions represent both the uranine and the benzoate data well. Background levels of bacteria were found in all runs and the average background value was subtracted from all ports for the moment analysis calculations. Background bacteria concentrations for continuously injected experiments were very small in magnitude, $5 \%$ or less for all runs, when compared to the injected bacteria peaks. Errors due to background bacteria were minimized, and accuracy of the moment analysis was improved.

Table 5.1 below summarizes the values for the center of mass, transverse dispersion coefficient, transverse dispersivity, and skewness from the moment analysis. The center of mass values for uranine and benzoate showed a slight increase on average relative to their respective injection ports, which was most likely due to variations in flow. The chemotactic bacteria, $\mathrm{P}$. putida F1, and the nonchemotactic control, P. putida F1 CheA, both experienced sinking in the 
experiments, which is consistent with pulse injection experiments and most likely due to the higher density of the bacteria.

Table 5.1 Moment analysis summary for continuous bacteria injections below attractant plume at $3 \mathrm{~cm}$ spacing.

\begin{tabular}{|c|cccc|}
\hline Component & $\bar{y}(\mathrm{~cm})$ & $D_{T} \times 10^{5}\left(\mathrm{~cm}^{2} / \mathrm{s}\right)$ & $\alpha_{T} x 10^{2}(\mathrm{~cm})$ & $\gamma$ \\
\hline P. putida $\mathrm{F} 1$ & $-0.3 \pm 0.6$ & $0.7 \pm 0.3$ & $0.5 \pm 0.2$ & $-0.4 \pm 0.5$ \\
P. putida F1 CheA & $-0.4 \pm 0.8$ & $0.6 \pm 0.1$ & $0.4 \pm 0.1$ & $0.0 \pm 0.1$ \\
Uranine & $0.7 \pm 0.7$ & $1.2 \pm 0.2$ & $0.6 \pm 0.2$ & $0.1 \pm 0.3$ \\
Benzoate & $0.6 \pm 0.4$ & $1.3 \pm 0.2$ & $0.3 \pm 0.1$ & $-0.2 \pm 0.2$ \\
\hline
\end{tabular}

A better way to quantify the center of mass data for the bacteria is to compare it to the uranine tracer, rather than the injection port, to eliminate the effect of the flow variations on the center of mass values. Table 5.2 shows the average difference between the bacteria and the uranine tracer. The difference for each run was estimated and the averages of those differences were calculated for both chemotactic and nonchemotactic bacteria. On average the chemotactic bacteria, $P$. putida F1, sank $0.9 \mathrm{~cm}$ below the uranine, and the nonchemotactic control sank about $1.2 \mathrm{~cm}$ below the uranine tracer. The chemotactic bacteria sank less than the nonchemotactic control when compared to the uranine tracer which is most likely caused by chemotaxis allowing for the population to migrate upwards toward the attractant plume. A t-test was performed on the values for center of mass differences, $\bar{y}_{B a c}-\bar{y}_{U r a}$, to compare the chemotactic experiments to the nonchemotactic experiments. The t-test showed that there was a statistically significant difference between the chemotactic and nonchemotactic values using a $90 \%$ confidence interval $(\mathrm{P}<0.097)$. 
Table 5.2 Summary of center of mass and skewness differences for uranine tracer and bacteria data for experiments with continuous bacteria injections below the attractant plume at $3 \mathrm{~cm}$ spacing.

\begin{tabular}{|c|cc|}
\hline Experiment Type & $\bar{y}_{\text {Bac }}-\bar{y}_{\text {Ura }}(\mathrm{cm})$ & $\gamma_{B a c}-\gamma_{U r a}$ \\
\hline P. putida F1 & $-0.9 \pm 0.2$ & $-0.6 \pm 0.7$ \\
P. putida F1 CheA & $-1.2 \pm 0.2$ & $0.1 \pm 0.5$ \\
\hline
\end{tabular}

The transverse dispersion coefficient, $D_{T}$, and the transverse dispersivity, $\alpha_{T}$, calculated for the chemotactic and nonchemotactic bacteria for continuously injected experiments were about half of the value calculated for pulse injection experiments. This is due to the ability to better separate out the background bacteria from injected bacteria. Background bacteria included in the moment analysis can cause a higher transverse dispersion coefficient (see Appendix A.2). The lower transverse dispersion and dispersivity values for continuous injections may also be due to the injection method. Pulse injections in previous experiments force the bacteria into the microcosm faster than the flow rate of the pumps, causing the pulse to spread out immediately upon entrance into the microcosm, corresponding to larger transverse dispersion values than would occur naturally when evaluating a model that assumes a point source. The continuous injections allow the bacteria to enter the microcosm at the same flow rate that has already been established within the tank. Forced spreading of the bacteria at the injection could cause an increase in the spread of the effluent concentration distribution, and therefore a larger variance and transverse dispersion coefficient and dispersivity. The transverse dispersion and dispersivity values are approximately the same for chemotactic and nonchemotactic bacteria which suggests that chemotaxis has not caused a higher dispersion or dispersivity. 
The transverse dispersion coefficient and transverse dispersivity values for the benzoate and uranine are within the same range as previous pulse injection experiments. The uranine was injected into the microcosm with the bacteria for both experiments with pulse injections and experiments with continuous injections; therefore it is surprising that the moment analysis would predict values for the transverse dispersion coefficient to be approximately the same for pulse injection and continuous injection methods. This suggests that the injection method has less of an effect on the calculation of transverse dispersion coefficient than other factors, like flow variations in the microcosm and background bacteria. The transverse dispersion coefficient may be larger for bacteria in pulse injection experiments because of the low mass recovery of the bacteria. Only about half of the bacteria injected are captured in the effluent samples for pulse injection experiments, whereas almost $100 \%$ of the injected bacteria are recovered in continuous injection experiments. This lower recovery rate may be due to bacteria deposition in the sand. Even if a portion of the bacteria was reversibly attached to the sand for a period of time, the bacteria may have been delayed enough in its passage through the microcosm that it was not collected in the effluent samples, which were taken when the uranine was visually exiting the microcosm. Failure to recover all of the bacteria injected may have caused a less steep peak in the effluent distribution, which would result in a larger calculated transverse dispersion coefficient.

The skewness parameter was used to characterize the asymmetry of the bacteria, uranine, and benzoate distributions about the center of mass. A negative value was expected for the chemotactic bacteria injected below the attractant plume due to the vertical migration toward the attractant caused by chemotaxis. For experiments with the bacteria continuously injected $3 \mathrm{~cm}$ below the attractant a negative value of skewness was found for the chemotactic bacteria, and an 
average value of zero was found for the nonchemotactic control. These trends indicate that chemotaxis may be altering the shape of the effluent bacteria concentration distribution. The difference in the skewness values between the bacteria to those for the uranine tracer, as shown in Table 5.2, shows that the skewness for the chemotactic bacteria is about -0.6 , which is again a negative value that would be expected for the chemotactic bacteria. The difference between the uranine and nonchemotactic skewness values is 0.1 on average. A t-test shows that there is a statistically significant difference between these two sets of data for $\mathrm{P}<0.122$. This suggests that chemotaxis has impacted the skewness parameter.

\subsection{Continuous Injections Below Attractant at $2 \mathrm{~cm}$ Spacing}

Experiments using continuously injected bacteria were performed with $2 \mathrm{~cm}$ spacing between the attractant and the bacteria. This experimental configuration was chosen to bring the bacteria and attractant closer together, which would allow the bacteria to be exposed to the attractant for a longer period of time within the microcosm. The increased exposure time of the bacteria is expected to increase the vertical migration due to the chemotactic response. Figure 5.2 below shows the vertical concentration distributions for the bacteria (red squares), benzoate (green triangles), and uranine (blue diamonds) at the microcosm exit for continuous injections of bacteria below the attractant at an average flow velocity of $1.2 \mathrm{~m} /$ day. Bacteria were injected in port 7 and attractant in port 5 for four experiments (Figure 5.2 a,b,c,d), and, bacteria were injected in port 8 and attractant in port 6 for two experiments (Figure 5.2 e,f). 


\section{Chemotactic}
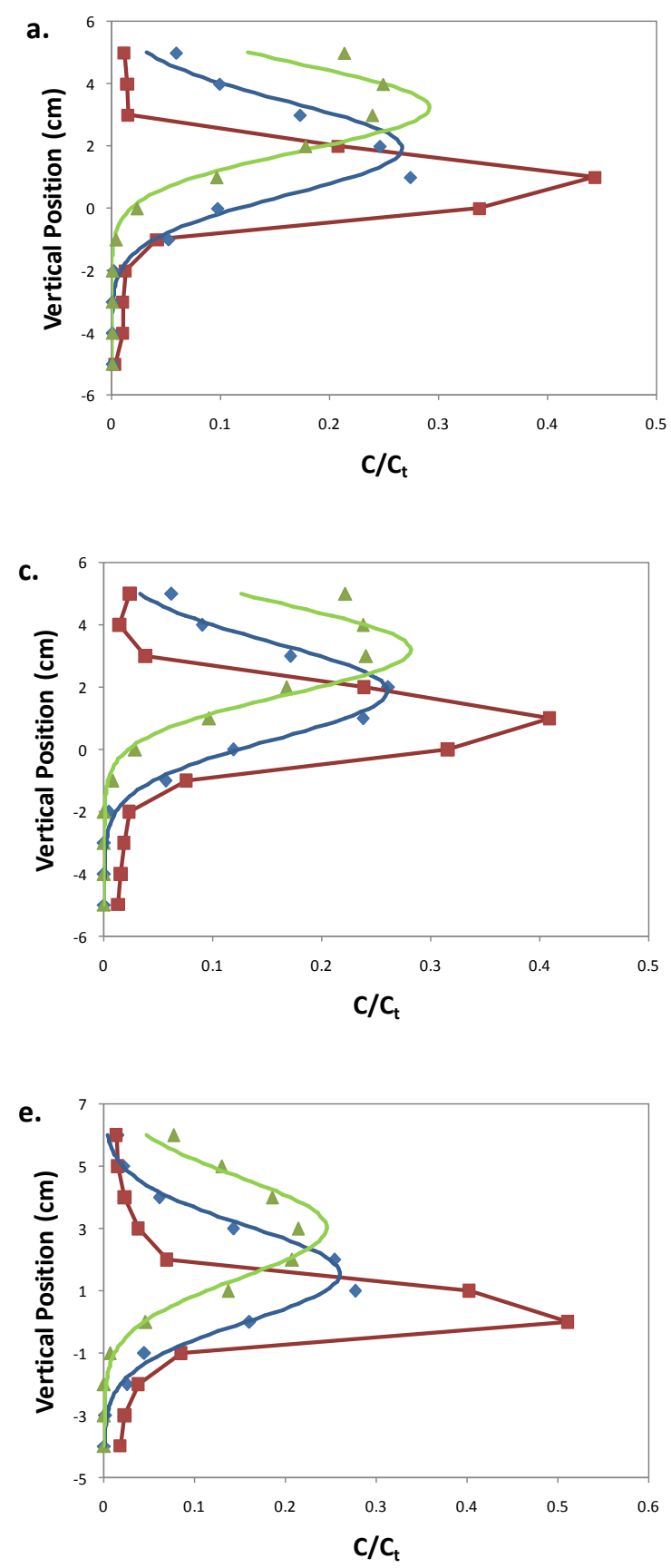

Nonchemotactic
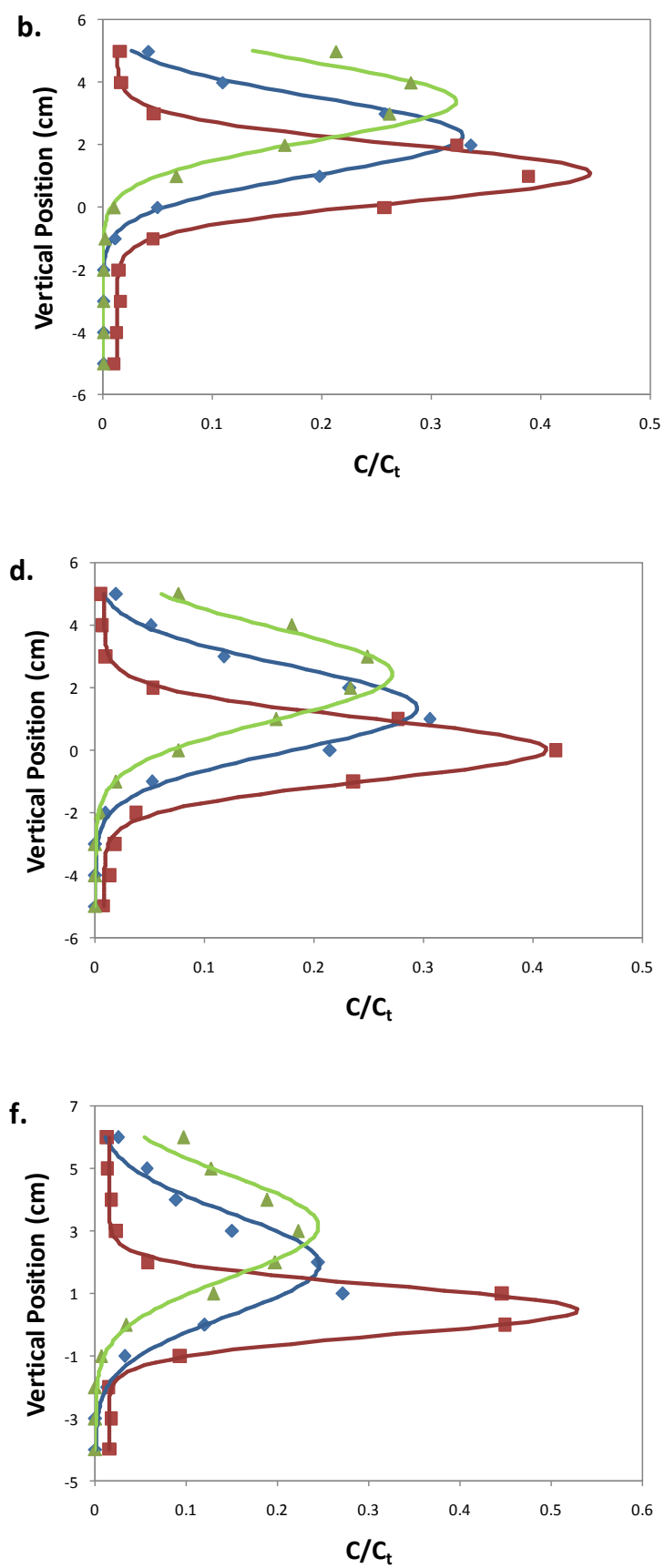

Figure 5.2 Transverse population distributions from 2-D microcosm experiments with continuous bacteria injections $2 \mathrm{~cm}$ below attractant plume. Chemotactic bacteria $P$. putida F1 are represented as red squares, $\square,(\mathrm{a}, \mathrm{c})$ and nonchemotactic bacteria $P$. putida F1 CheA are represented as red squares, $\square,(b, d)$. Concentration distributions for the uranine tracer are represented by blue diamonds, $\diamond$, and benzoate attractant concentration represented by green triangles, $\triangle$. All bacteria, uranine and benzoate distributions have been normalized by the sum 
of concentrations from each individual port. Normalized distribution curves have been fit to the nonchemotactic bacteria, uranine, and benzoate data using Equation 3.5.

The normalized distributions represent both the uranine and the benzoate data well. Background levels of bacteria were found in all runs and the average background value was subtracted from all ports for the moment analysis calculations. Background bacteria concentrations for continuously injected experiments at this spacing were very small in magnitude, $5 \%$ or less for all runs, when compared to the injected bacteria peaks.

Table 5.3 below summarizes the values for the center of mass, transverse dispersion coefficient, transverse dispersivity, and skewness from the moment analysis. The center of mass values for all components show an increase on average which was most likely due to variations in flow and pressure differences within the tank. This rise in center of mass was consistent for all experimental runs and all components. These experiments were performed near the end of the tubing life, which most likely made flow variations more pronounced.

Table 5.3 Moment analysis summary for continuous bacteria injections below attractant plume at $2 \mathrm{~cm}$ spacing.

\begin{tabular}{|c|cccc|}
\hline Component & $\bar{y}(\mathrm{~cm})$ & $D_{T} \times 10^{5}\left(\mathrm{~cm}^{2} / \mathrm{s}\right)$ & $\alpha_{T} \times 10^{2}(\mathrm{~cm})$ & $\gamma$ \\
\hline P. putida $\mathrm{F} 1$ & $0.7 \pm 0.2$ & $0.53 \pm 0.06$ & $0.38 \pm 0.05$ & $0.0 \pm 0.2$ \\
P. putida F1 CheA & $0.5 \pm 0.5$ & $0.6 \pm 0.2$ & $0.4 \pm 0.1$ & $-0.1 \pm 0.4$ \\
Uranine & $1.8 \pm 0.3$ & $1.6 \pm 0.3$ & $0.8 \pm 0.2$ & $0.2 \pm 0.1$ \\
Benzoate & $1.1 \pm 0.3$ & $1.5 \pm 0.3$ & $0.5 \pm 0.2$ & $-0.3 \pm 0.2$ \\
\hline
\end{tabular}

Table 5.2 shows the average difference between the bacteria and the uranine tracer, which is a better way to quantify the center of mass data. The difference for each run was estimated and the 
averages of those differences were calculated for both chemotactic and nonchemotactic bacteria. The chemotactic bacteria, P. putida F1, and the nonchemotactic control, P. putida F1 CheA, both experienced sinking in the experiments, which is consistent with pulse injection experiments and most likely due to the higher density of the bacteria. On average the chemotactic bacteria, $P$. putida $\mathrm{F} 1$, sank $1.1 \mathrm{~cm}$ below the uranine, and the nonchemotactic control sank about $1.3 \mathrm{~cm}$ below the uranine tracer. The amount of sinking for the nonchemotactic bacteria is outside of the range predicted by Equation 4.1, which suggests that flow variations may be impacting the bacteria once it has partially separated out from the uranine tracer. The chemotactic bacteria sank less than the nonchemotactic control when compared to the uranine tracer which is most likely caused by chemotaxis allowing for the population to migrate upwards toward the attractant plume. The chemotactic bacteria sank about $0.2 \mathrm{~cm}$ less than the nonchemotactic control. A ttest was performed on the values for center of mass differences, $\bar{y}_{B a c}-\bar{y}_{\text {Ura }}$, to compare the chemotactic experiments to the nonchemotactic experiments. The t-test showed that there was a statistically significant difference between the chemotactic and nonchemotactic values using a $94 \%$ confidence interval $(\mathrm{P}<0.051)$.

Table 5.4 Summary of center of mass and skewness differences for uranine tracer and bacteria data for experiments with continuous bacteria injections below the attractant plume at $2 \mathrm{~cm}$ spacing.

\begin{tabular}{|c|cc|}
\hline Experiment Type & $\bar{y}_{\text {Bac }}-\bar{y}_{\text {Ura }}(\mathrm{cm})$ & $\gamma_{B a c}-\gamma_{U r a}$ \\
\hline P. putida F1 & $-1.09 \pm 0.04$ & $-0.2 \pm 0.1$ \\
P. putida F1 CheA & $-1.3 \pm 0.1$ & $-0.3 \pm 0.5$ \\
\hline
\end{tabular}

The transverse dispersion and dispersivity values are approximately the same for chemotactic and nonchemotactic bacteria which suggests that chemotaxis has not caused a higher 
dispersion or dispersivity. The transverse dispersion coefficient and transverse dispersivity values for the bacteria, benzoate, and uranine are within the same range as the values for continuously injected experiments at $3 \mathrm{~cm}$ spacing.

For experiments with the bacteria continuously injected $2 \mathrm{~cm}$ below the attractant a value of zero skewness was found for the chemotactic bacteria, and a slightly negative value was found for the nonchemotactic control. This does not follow the expected trend of a negative skewness for chemotactic bacteria. The difference in the skewness values between the bacteria to those for the uranine tracer, as shown in Table 5.4, shows that the skewness for the chemotactic bacteria and nonchemotactic bacteria are approximately the same within the uncertainty in the experimental data. A T-test shows that there is not a statistically significant different between these two sets of data $(\mathrm{P}=0.300)$.

Figure 5.3 below shows the vertical concentration distributions for bacteria that have been normalized so that zero on the y-axis represents the center of mass of the uranine tracer. The chemotactic bacteria are shown in blue and the nonchemotactic bacteria are shown in red with a normalized distribution curve fit for all nonchemotactic points. These graphs allow data to be averaged over all bacteria breakthrough curves and compared on the same graphs, rather evaluating each experiment individually. These graphs show that there are very subtle differences between the distributions of chemotactic and nonchemtactic bacteria. It also shows that differences between experiments with $3 \mathrm{~cm}$ spacing and $2 \mathrm{~cm}$ spacing are very small. In Figure 5.3 a there is an upward bias of the chemotactic peak, towards the attractant, when compared to the nonchemotactic curve. In Figure $5.3 \mathrm{~b}$ it appears that all of the blue chemotactic data points are shifted upward slightly when compared to the nonchemotactic curve. The T-tests for the center of mass differences showed that there is a greater confidence in the difference 
between values at $2 \mathrm{~cm}$ than $3 \mathrm{~cm}$. However, when the numerical values for center of mass differences are compared, the chemotactic bacteria at $3 \mathrm{~cm}$ spacing are on average closer to the attractant source than the chemotactic bacteria at $2 \mathrm{~cm}$ spacing when compared to the uranine tracer. This result does not support the exposure time argument. 

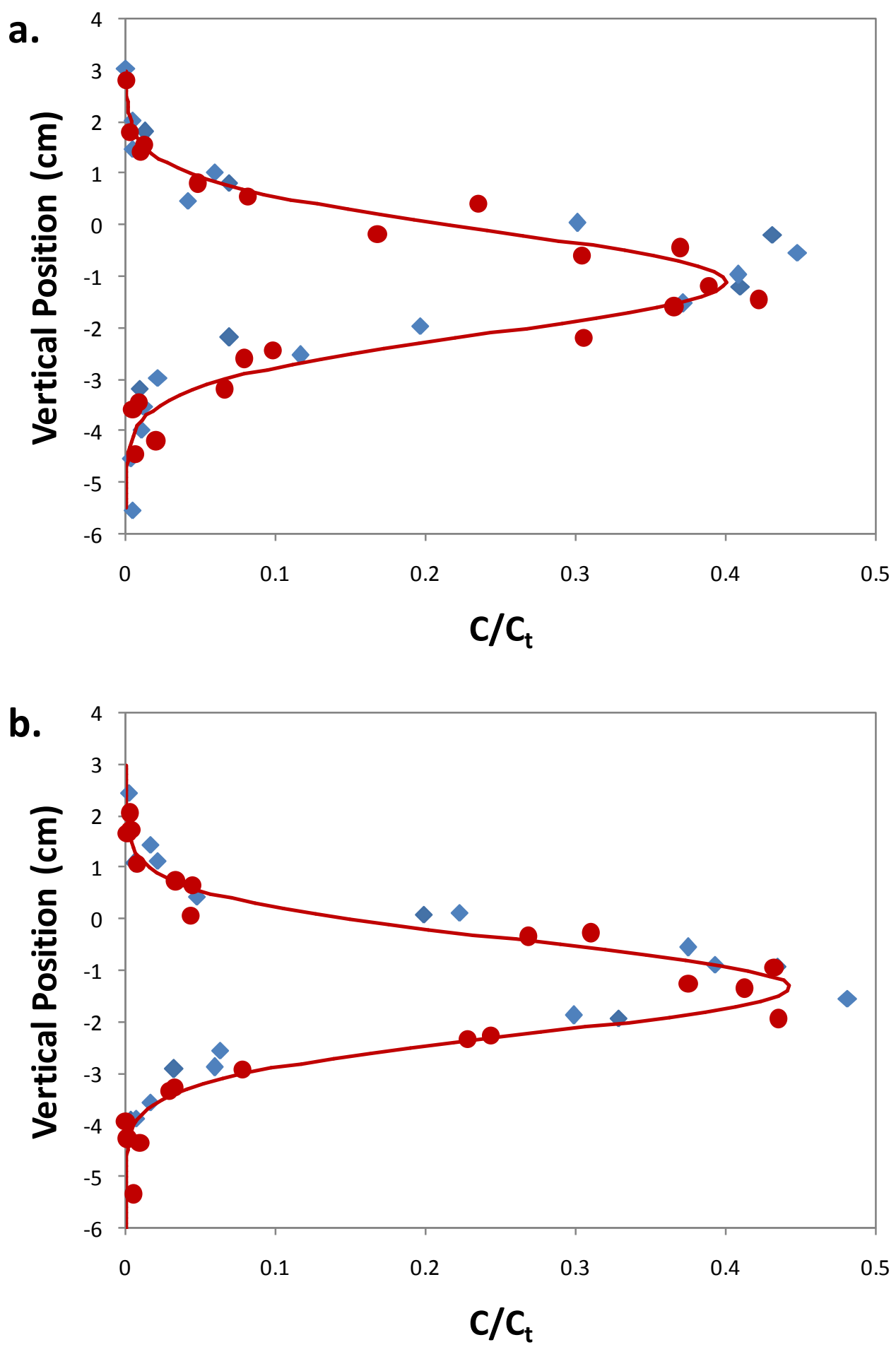

Figure 5.3 Transverse population distributions from 2-D microcosm experiments with continuous bacteria injections (a) $3 \mathrm{~cm}$ and (b) $2 \mathrm{~cm}$ below attractant plume. All bacteria distributions have been adjusted so that the $\mathrm{x}$-axis represents the center of mass location for the uranine tracer. Chemotactic bacteria $P$. putida $\mathrm{F} 1$ are represented as blue diamonds, $\diamond$, and nonchemotactic bacteria $P$. putida $\mathrm{F} 1 \mathrm{CheA}$ are represented as red circles, $\bullet$. A normalized 
distribution curve has been fit to the nonchemotactic data points. Background bacteria data points have been subtracted out.

The differences between chemotactic bacteria and nonchemotactic bacteria breakthrough curves are small, however even small differences in migration can result in larger differences in degradation. Degradation of contaminant plumes takes place at the edge of the plume (i.e. the fringe area) where bacteria, contaminant, and electron donor overlap. In a recent study of biodegradation of a contaminant plume using a two-dimensional microcosm, the plume fringe was found to be in the range of $0-2.4 \mathrm{~cm}$ for various experimental conditions (R. D. Bauer et al. 2008). Chemotaxis may enhance degradation of contaminant plumes when degradation takes place in such a small area. Additionally, degradation of contaminants at the plume fringe may increase the steepness on the contaminant concentration gradient, which would in turn increase the chemotactic velocity.

\subsection{Continuous Injections Above Attractant}

Two preliminary experiments were performed with a continuously injected bacteria plume $3 \mathrm{~cm}$ above the attractant, the results of which are shown in Figure 5.4. For the continuous bacteria injections above the plume, both chemotactic and nonchemotactic bacteria were found $0.8 \mathrm{~cm}$ closer to the attractant than the uranine tracer. The transverse dispersion and transverse dispersivity were on average $4.9 \times 10^{-6} \mathrm{~cm}^{2} / \mathrm{s}$ and $0.0034 \mathrm{~cm}$, respectively, for the chemotactic bacteria, and $7.2 \times 10^{-6} \mathrm{~cm}^{2} / \mathrm{s}$ and $0.0052 \mathrm{~cm}$, respectively, for the nonchemotactic control. These values fall within the range experimental values determined for bacteria continuously injected $3 \mathrm{~cm}$ below the attractant plume. A positive value was expected for the chemotactic bacteria injected above the attractant plume due to the migration toward the attractant caused by chemotaxis. The skewness for the chemotactic bacteria was 0.2 and the 
value for nonchemotactic bacteria was 0.1 . The difference in the skewness values between the bacteria to those for the uranine tracer shows that the skewness for the chemotactic bacteria is about 0.7 , and the value for nonchemotactic bacteria is 0.2 . The higher value of skewness for the chemotactic bacteria suggests that chemotaxis may be altering the shape of the bacteria distribution in this experimental configuration.
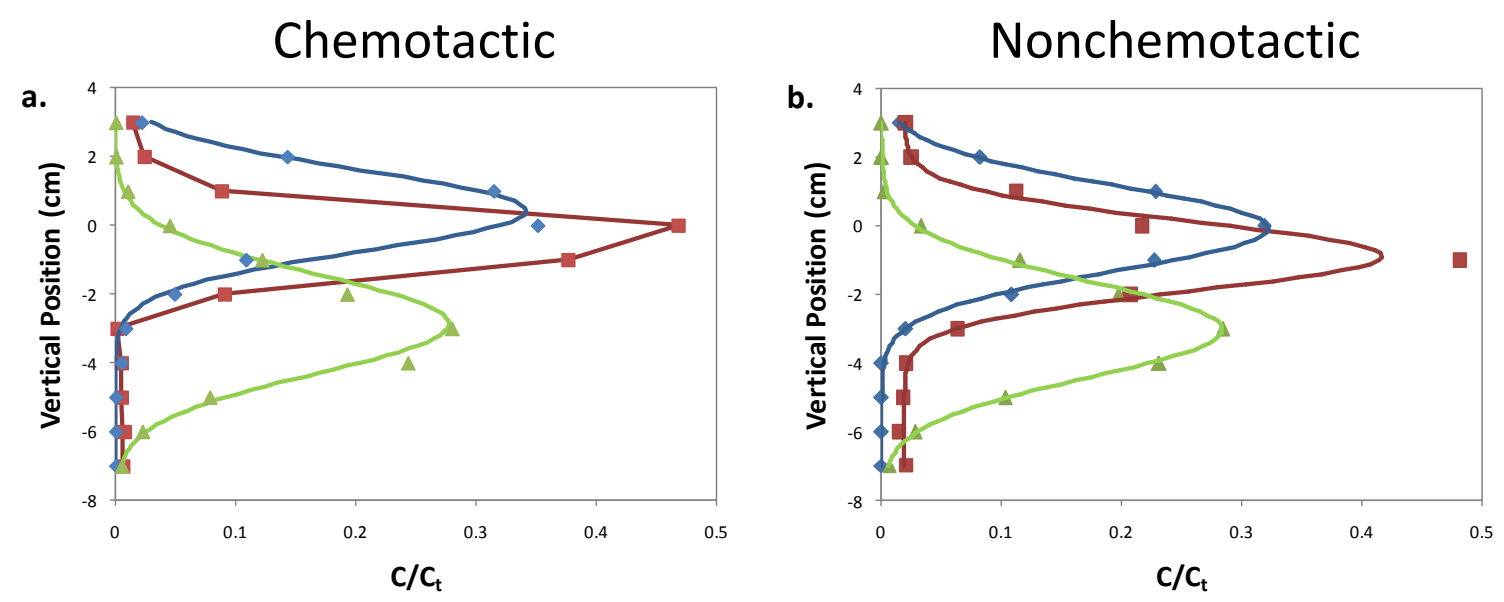

Figure 5.4 Transverse population distributions from 2-D microcosm experiments with continuous bacteria injections $3 \mathrm{~cm}$ above attractant plume. Chemotactic bacteria $P$. putida F1

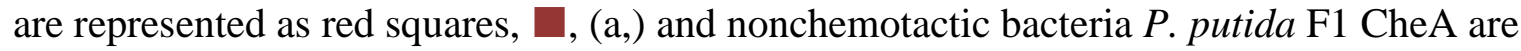
represented as red squares, $\square$, (b). Concentration distributions for the uranine tracer are represented by blue diamonds, $\diamond$, and benzoate attractant concentration represented by green triangles, $\Delta$. All bacteria, uranine and benzoate distributions have been normalized by the sum of concentrations from each individual port. Normalized distribution curves have been fit to the nonchemotactic bacteria, uranine, and benzoate data using Equation 3.5.

\subsection{Continuous Injections Below Attractant Using Denser Media}

Figure 5.5 shows two preliminary experiments that were performed with a continuously injected bacteria plume $3 \mathrm{~cm}$ above the attractant, but using a denser media containing $10 \%$ glycerol. A denser media was used to increase the density and viscosity of the artificial 
groundwater to try and reduce the sinking of bacteria. A previous study by Ford and coworkers which examined bacterial adhesion to a glass surface used glycerol to increase the density of media and reduce sinking of bacteria (McClaine 2001). In this study the addition of glycerol did not disrupt cell motility for $0 \%, 5 \%$, and $10 \%$ glycerol; however motile cells stopped swimming at $20 \%$ glycerol. Therefore, $10 \%$ glycerol was chosen for this experiment to maintain cell motility while still increasing the density of media. The results of these experiments showed that sinking still occurred for both chemotactic and nonchemotactic bacteria. The chemotactic bacteria sank $1.1 \mathrm{~cm}$ below the uranine tracer and the nonchemotactic bacteria sank $1.0 \mathrm{~cm}$ below the uranine tracer. The transverse dispersion coefficient and dispersivity values for all components fell within the same range as previous continuous injection experiments. It should also be noted that the $\mathrm{AO}$ counts for these experiments were blurry and difficult to read, which could have increased the error in the bacteria counts.

Chemotactic

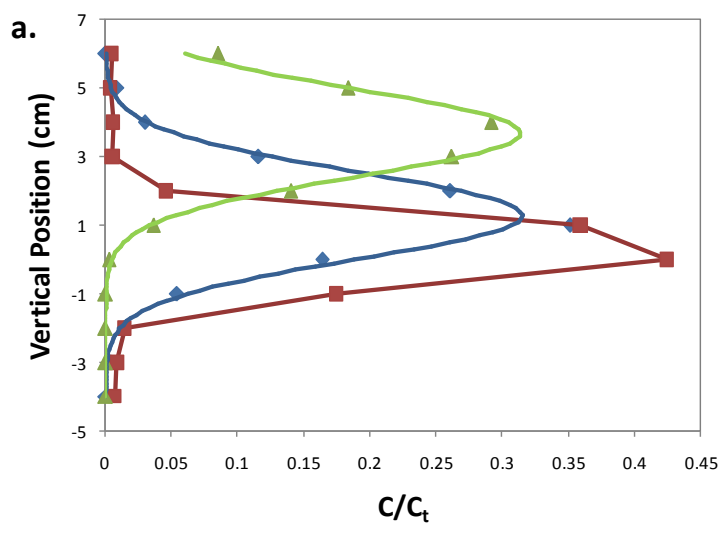

Nonchemotactic

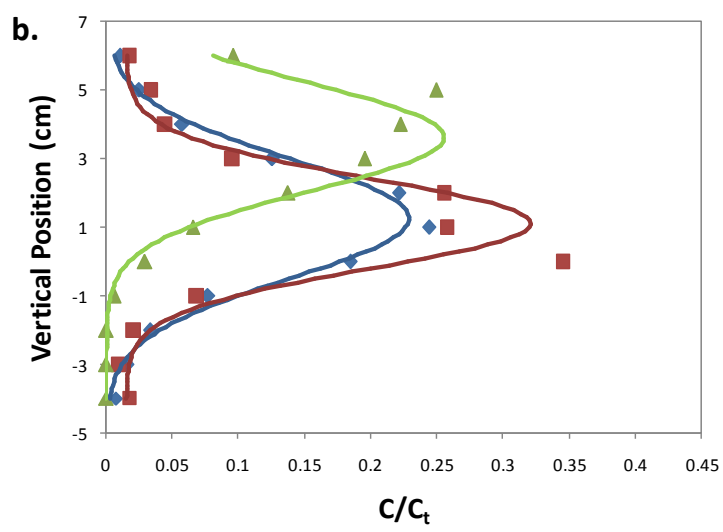

Figure 5.5 Transverse population distributions from 2-D microcosm experiments with continuous bacteria injections $3 \mathrm{~cm}$ below attractant plume using 10\% glycerol in AGW to increase media density. Chemotactic bacteria $P$. putida F1 are represented as red squares, $\square$, (a,) and nonchemotactic bacteria $P$. putida $\mathrm{F} 1 \mathrm{CheA}$ are represented as red squares, $\square$, (b). Concentration distributions for the uranine tracer are represented by blue diamonds, $\triangleleft$, and benzoate attractant concentration represented by green triangles, $\Delta$. All bacteria, uranine and 
benzoate distributions have been normalized by the sum of concentrations from each individual port. Normalized distribution curves have been fit to the nonchemotactic bacteria, uranine, and benzoate data using Equation 3.5.

\subsection{Conclusions}

Two-dimensional microcosm experiments with continuous bacteria injections below the attractant provided data to suggest that chemotactic bacteria can migrate transversely toward an attractant source. Statistical analysis of center of mass differences between bacteria and uranine tracer show that there is a difference between chemotactic and nonchemotactic values. Chemotactic bacteria are on average closer to the attractant source than the nonchemotactic control when compared to the fluorescent tracer for both $3 \mathrm{~cm}$ and $2 \mathrm{~cm}$ spacing.

Continuously injected bacteria experiments have aided in providing more reliable microcosm results. Continuous bacteria injections help with differentiating injected bacteria from background bacteria due to the larger population of those injected. The continuous injections appear to stabilize the bacteria injections and prevent some of the distortions that occur with pulse injections. Additionally, the continuous injection method reduces the variability associated with pulse injections administered by hand, which allows for the determination of more accurate transport parameters. These parameters can then be used to evaluate a twodimensional mathematical model to interpret the experimental results. The mathematical models are an important step towards understanding the processes that govern transport and mixing in the groundwater environment, and the effect of chemotaxis on these processes. 


\section{Results of Mathematical Modeling}

\subsection{Introduction}

A mathematical model of the two-dimensional advection-dispersion equations has been evaluated using experimentally determined transport parameters. The finite element solver, COMSOL, was used to solve the differential equations for attractant and bacteria transport in the two-dimensional microcosm. The model was evaluated at steady state conditions assuming continuously injected bacteria and attractant plumes. In this chapter the effects of changing the distance between the attractant injection and bacteria injection, the chemotactic sensitivity coefficient, $\chi_{0}$, and the chemotaxis receptor constant, $K_{c}$, were explored. The first goal of the mathematical modeling was to determine the range of $\chi_{0}$ values which match the shift in center of mass of the bacteria measured in experimental results. The second goal was to perform a sensitivity analysis for the $\chi_{0}$ and $K_{c}$ parameters under different experimental configurations to determine the effects of changing the parameter values. The final goal was to find an optimal operating condition which provided the largest shift in the center of mass for the chemotactic bacteria. Output from the mathematical model was evaluated for three different experimental configurations of $4 \mathrm{~cm}, 3 \mathrm{~cm}$, and $2 \mathrm{~cm}$ spacing between initial injections of bacteria and attractant. These were chosen to explore the relationship between the exposure time of the bacteria to attractant and the extent of the chemotactic response. Experiments were only performed with $3 \mathrm{~cm}$ and $2 \mathrm{~cm}$ spacing, however the effluent concentration distributions show that flow variations and sinking of bacteria may have caused the actual exposure of the bacteria to the attractant to resemble predictions for a larger spacing distance. For example, the average distance between the center of mass of chemotactic bacteria and attractant in the effluent samples from results of experiments with $3 \mathrm{~cm}$ spacing is $3.9 \mathrm{~cm}$, therefore a mathematical model 
evaluated with $4 \mathrm{~cm}$ spacing may more closely mimick the experimental results. Similarly, the average distance between the center of mass of chemotactic bacteria and attractant in the effluent samples from results of experiments with $2 \mathrm{~cm}$ spacing is $2.4 \mathrm{~cm}$, therefore the model results using $3 \mathrm{~cm}$ spacing may more closely resemble the experimental results. The chemotaxis number, $C h$, which estimates the contribution of chemotaxis relative to dispersion, has been calculated for various model configurations. The chemotaxis number is an important tool which can be used to relate the results from these smaller scale experiments to what may happen at the field scale.

\subsection{Effects of Chemotactic Sensitivity Coefficient}

\subsubsection{Results Using 4 cm Spacing}

Figure 6.1 below shows breakthrough curves for the attractant and bacteria at the microcosm exit for continuous injections of bacteria $4 \mathrm{~cm}$ below the attractant. The chemotactic sensitivity coefficient has been varied to explore its effect on the transverse migration of chemotactic bacteria. The chemotactic receptor constant was kept at a constant value of $1 \mathrm{mM}$, which was experimentally determined for $P$. putida F1 in a previous study (Brashear 2009). 


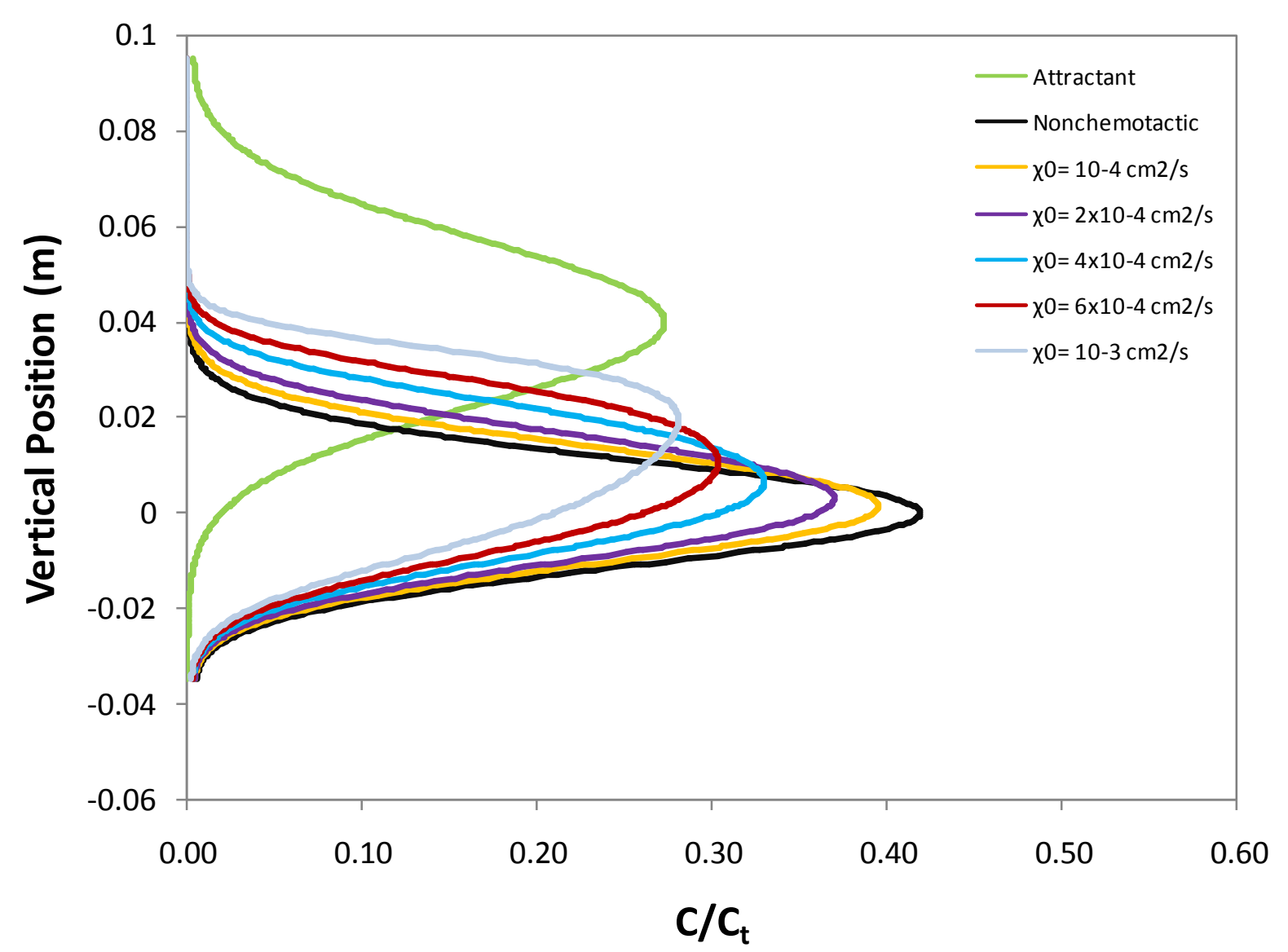

Figure 6.1 Transverse population distributions from two-dimensional mathematical modeling using different values of the chemotactic sensitivity coefficient with continuous bacteria injections $4 \mathrm{~cm}$ below attractant plume.

Table 6.1 below summarizes the values for the center of mass, transverse dispersion coefficient, and skewness from the moment analysis. Concentration values that were less than three orders of magnitude smaller than the peak attractant or bacteria concentration were not used in the moment analysis. The center of mass for the nonchemotactic bacteria profile is $0 \mathrm{~cm}$, as expected. The center of mass for the attractant is slightly above $0 \mathrm{~cm}$. This is most likely due to the inability to simulate data at a finer resolution, which has introduced uncertainties due to rounding of the data. The skewness for the nonchemotactic bacteria profile was expected to be zero, however the lower boundary condition has caused a shift in the shape of the distribution, 
and yielded a skewness value of 0.05 . The bacteria disperse past $3.5 \mathrm{~cm}$ in the positive vertical direction, and due to the symmetry of dispersion the bacteria would also be expected to disperse past $-3.5 \mathrm{~cm}$. The model however introduces a no flux boundary condition at $-3.5 \mathrm{~cm}$ at the bottom of the microcosm. The no flux boundary condition has also affected the skewness values for $\chi_{0}$ of $10^{-4} \mathrm{~cm}^{2} / \mathrm{s}$ and $2 \times 10^{-4} \mathrm{~cm}^{2} / \mathrm{s}$, which were expected to be negative.

Table 6.1 Moment analysis summary for mathematical modeling with continuous bacteria injections $4 \mathrm{~cm}$ below attractant plume and varying chemotactic sensitivity coefficient.

\begin{tabular}{|l|ccc|}
\hline \multicolumn{1}{|c|}{ Component/Parameter } & $\bar{y}(\mathrm{~cm})$ & $D_{T} \times 10^{5}\left(\mathrm{~cm}^{2} / \mathrm{s}\right)$ & $\gamma$ \\
\hline Attractant & 0.01 & 2.02 & 0.00 \\
Nonchemotactic/ $\chi_{0}=0 \mathrm{~cm}^{2} / \mathrm{s}$ & 0.00 & 0.78 & 0.05 \\
Chemotactic/ $\chi_{0}=10^{-4} \mathrm{~cm}^{2} / \mathrm{s}$ & 0.15 & 0.86 & 0.06 \\
Chemotactic/ $\chi_{0}=2 \times 10^{-4} \mathrm{~cm}^{2} / \mathrm{s}$ & 0.31 & 0.96 & 0.04 \\
Chemotactic/ $\chi_{0}=4 \times 10^{-4} \mathrm{~cm}^{2} / \mathrm{s}$ & 0.60 & 1.13 & -0.03 \\
Chemotactic/ $\chi_{0}=6 \times 10^{-4} \mathrm{~cm}^{2} / \mathrm{s}$ & 0.85 & 1.27 & -0.11 \\
Chemotactic/ $\chi_{0}=10^{-3} \mathrm{~cm}^{2} / \mathrm{s}$ & 1.20 & 1.47 & -0.24 \\
\hline
\end{tabular}

The center of mass for the chemotactic bacteria increases with increasing chemotactic sensitivity coefficient. This shows that the bacteria are migrating closer to the attractant plume as the chemotactic sensitivity coefficient increases. A chemotactic sensitivity value of $2 \times 10^{-4}$ $\mathrm{cm}^{2} / \mathrm{s}$ corresponds to the difference in center of mass of about $0.3 \mathrm{~cm}$ seen experimental results with $3 \mathrm{~cm}$ spacing. The chemotaxis number, $C h$, for this spacing and $\chi_{0}$ is 0.039 .

The transverse dispersion coefficient increases as the chemotactic sensitivity coefficient increases. This is because the fraction of the bacteria that are exposed to the concentration gradient tend to migrate in the transverse direction to higher attractant concentrations. However 
the bacteria at lower vertical positions are not exposed to the attractant gradient and therefore do not migrate towards higher concentration gradients. This effect pulls the bacteria in two different directions, increasing the spread of the bacteria which causes an increase in the transverse dispersion coefficient. This could also be due to the changing steepness of the concentration gradient, which produces different magnitudes of the chemotactic velocity at different locations.

The skewness values become more negative as the chemotactic sensitivity coefficient increases. This is consistent with what is expected, as a negative value of skewness represents a bias in the distribution towards the attractant.

\subsubsection{Results Using $3 \mathrm{~cm}$ Spacing}

Figure 6.2 below shows breakthrough curves for the attractant and bacteria at the microcosm exit for continuous injections of bacteria $3 \mathrm{~cm}$ below the attractant. The chemotactic sensitivity coefficient has been varied to explore its effect on the transverse migration of chemotactic bacteria. 


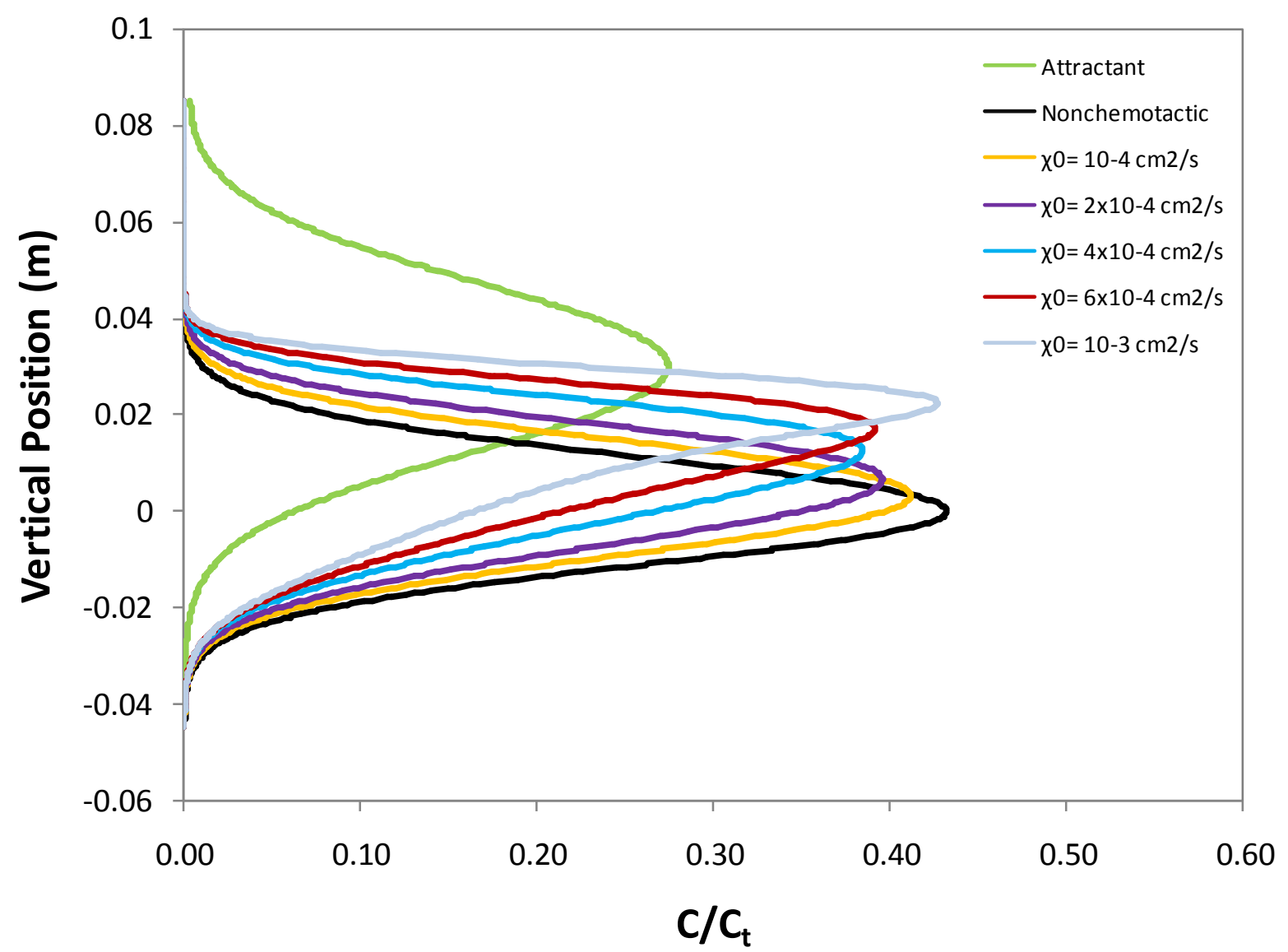

Figure 6.2 Transverse population distributions from two-dimensional mathematical modeling using different values of the chemotactic sensitivity coefficient with continuous bacteria injections $3 \mathrm{~cm}$ below attractant plume.

Table 6.2 below summarizes the values for the center of mass, transverse dispersion coefficient, and skewness from the moment analysis. Concentration values that were less than three orders of magnitude smaller than the peak attractant or bacteria concentration were not used in the moment analysis. The center of mass for nonchemotactic bacteria is slightly below 0 $\mathrm{cm}$, and the center of mass of the attractant is slightly above zero. The skewness for the attractant is slightly below zero. These small deviations from zero are most likely due to the inability to collect data at a finer resolution, which introduced uncertainties due to rounding of the data. 
Table 6.2 Moment analysis summary for mathematical modeling with continuous bacteria injections $3 \mathrm{~cm}$ below attractant plume and varying chemotactic sensitivity coefficient.

\begin{tabular}{|l|ccc|}
\hline \multicolumn{1}{|c|}{ Component/Parameter } & $\bar{y}(\mathrm{~cm})$ & $D_{T} \times 10^{5}\left(\mathrm{~cm}^{2} / \mathrm{s}\right)$ & $\gamma$ \\
\hline Attractant & 0.01 & 2.04 & -0.01 \\
Nonchemotactic/ $\chi_{0}=0 \mathrm{~cm}^{2} / \mathrm{s}$ & -0.01 & 0.81 & 0.00 \\
Chemotactic/ $\chi_{0}=10^{-4} \mathrm{~cm}^{2} / \mathrm{s}$ & 0.22 & 0.87 & -0.07 \\
Chemotactic/ $\chi_{0}=2 \times 10^{-4} \mathrm{~cm}^{2} / \mathrm{s}$ & 0.44 & 0.94 & -0.16 \\
Chemotactic/ $\chi_{0}=4 \times 10^{-4} \mathrm{~cm}^{2} / \mathrm{s}$ & 0.79 & 1.05 & -0.35 \\
Chemotactic/ $\chi_{0}=6 \times 10^{-4} \mathrm{~cm}^{2} / \mathrm{s}$ & 1.04 & 1.13 & -0.51 \\
Chemotactic/ $\chi_{0}=10^{-3} \mathrm{~cm}^{2} / \mathrm{s}$ & 1.33 & 1.23 & -0.73 \\
\hline
\end{tabular}

The center of mass for the chemotactic bacteria increases with increasing chemotactic sensitivity coefficient. This shows that the bacteria are migrating closer to the attractant plume as the chemotactic sensitivity coefficient increases. A chemotactic sensitivity value between 1-2 $\mathrm{x} 10^{-4} \mathrm{~cm}^{2} / \mathrm{s}$ captures the difference in center of mass of about $0.3 \mathrm{~cm}$ seen in experimental results with $3 \mathrm{~cm}$ spacing. Interpolation to determine the exact value is not warranted because of the degree of uncertainty associated with the experimental data. The chemotaxis number for 3 $\mathrm{cm}$ spacing and $\chi_{0}$ of $10^{-4} \mathrm{~cm}^{2} / \mathrm{s}$ is 0.0262 . A chemotactic sensitivity value of $10^{-4} \mathrm{~cm}^{2} / \mathrm{s} \mathrm{most}$ closely corresponds to the difference in center of mass of about $0.2 \mathrm{~cm}$ seen in experimental results with $2 \mathrm{~cm}$ spacing. A lower value of the chemotactic sensitivity coefficient is needed to match the center of mass values determined experimentally for the $3 \mathrm{~cm}$ spaced model results when compared to the $4 \mathrm{~cm}$ model results. The center of mass values are always higher for $3 \mathrm{~cm}$ spacing than $4 \mathrm{~cm}$ at constant $\chi_{0}$, which shows the chemotactic bacteria that have been exposed 
to the attractant for a longer period of time within the microcosm show a greater transverse migration of bacteria. This supports the exposure time argument discussed in Hypothesis 2.

The transverse dispersion coefficient increases as the chemotactic sensitivity coefficient increases. Again, this is because the portion of the bacteria that are exposed to the concentration gradient tend to migrate transverse to the flow toward higher attractant concentrations, whereas the bacteria at lower vertical positions are not exposed to the attractant gradient and do not migrate towards higher concentration gradients. The bacteria are pulled in two different directions, increasing the spread of the bacteria which subsequently increases in the transverse dispersion coefficient. The steepness of the concentration gradient is also changing with vertical position, which produces different magnitudes of the chemotactic velocity at different locations.

The skewness values become more negative as the chemotactic sensitivity coefficient increases. This is consistent with what is expected, as a negative value of skewness represents a bias in the distribution towards the attractant. It is difficult to compare the skewness parameter between the $4 \mathrm{~cm}$ spaced results and the $3 \mathrm{~cm}$ spaced results because the skewness values reported for $4 \mathrm{~cm}$ have been affected by the lower no-flux boundary condition. For the $3 \mathrm{~cm}$ model, the bacteria are injected far enough away from the bottom that this boundary condition does not affect the shape of the effluent concentration distributions.

\subsubsection{Results Using 2 cm Spacing}

Figure 6.3 below shows breakthrough curves for the attractant and bacteria at the microcosm exit for continuous injections of bacteria $2 \mathrm{~cm}$ below the attractant. The chemotactic sensitivity coefficient has been varied to explore its effect on the transverse migration of chemotactic bacteria. A smaller range of values have been used for the chemotactic sensitivity 
coefficient to help with the ability to clearly read the graph and also because the bacteria have spread beyond peak concentration of the attractant for the highest $\chi_{0}$ reported. Chemotactic bacteria migrate up attractant gradients, towards regions of higher attractant concentration, therefore when the bacteria reach the highest local attractant concentration they will tend to stay in that region. There is no longer an increasing attractant concentration for the bacteria to respond to.

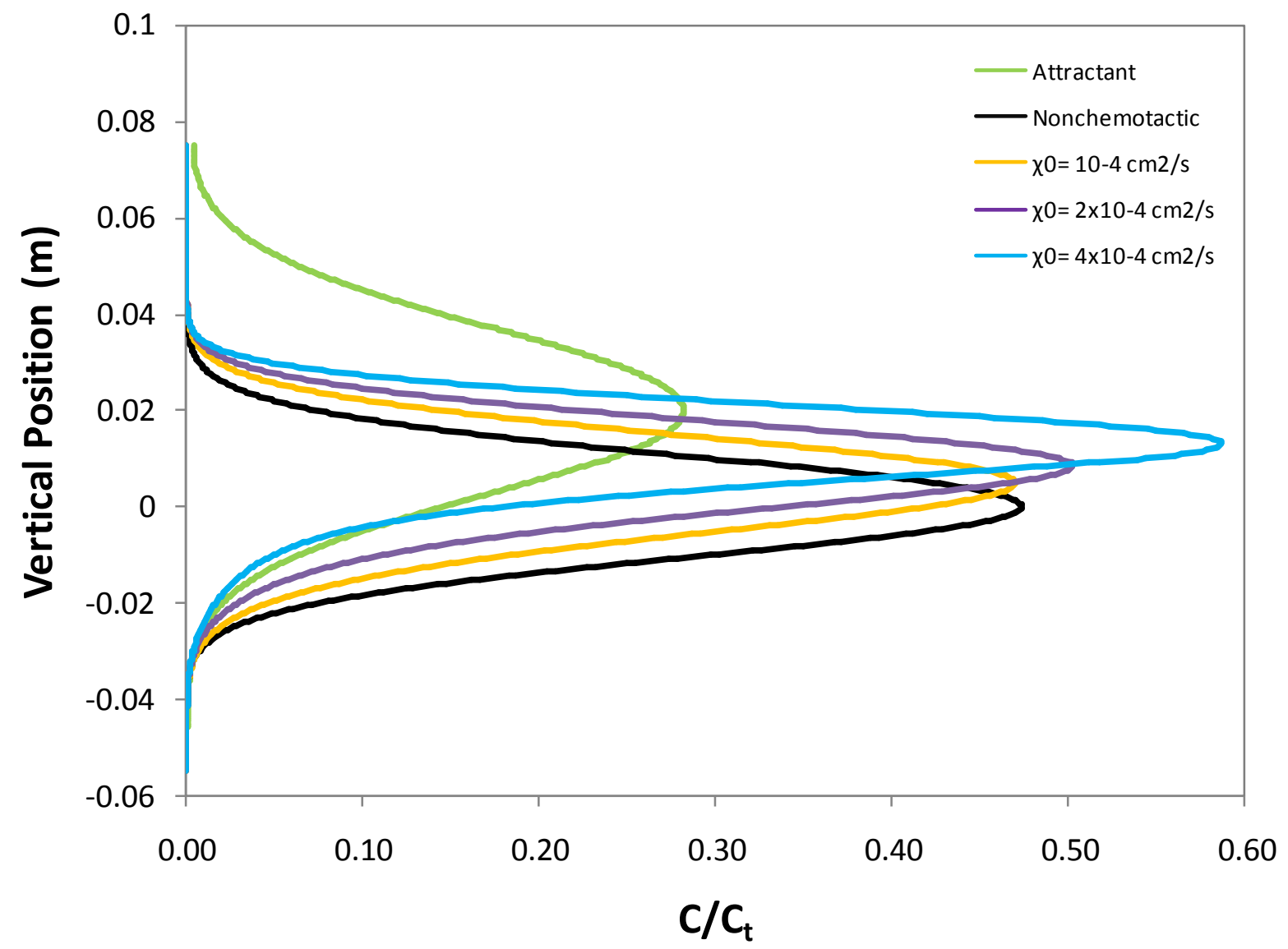

Figure 6.3 Transverse population distributions from two-dimensional mathematical modeling using different values of the chemotactic sensitivity coefficient with continuous bacteria injections $2 \mathrm{~cm}$ below attractant plume.

Table 6.3 below summarizes the values for the center of mass, transverse dispersion coefficient, and skewness from the moment analysis. Concentration values that were less than 
three orders of magnitude smaller than the peak attractant or bacteria concentration were not used in the moment analysis. The center of mass for the attractant is slightly below zero, which is most likely due to the inability to collect data at a finer resolution and rounding of the data.

Table 6.3 Moment analysis summary for mathematical modeling with continuous bacteria injections $2 \mathrm{~cm}$ below attractant plume and varying chemotactic sensitivity coefficient.

\begin{tabular}{|l|ccc|}
\hline \multicolumn{1}{|c|}{ Component/Parameter } & $\bar{y}(\mathrm{~cm})$ & $D_{T} \times 10^{5}\left(\mathrm{~cm}^{2} / \mathrm{s}\right)$ & $\gamma$ \\
\hline Attractant & 0.01 & 2.05 & 0.00 \\
Nonchemotactic/ $\chi_{0}=0 \mathrm{~cm}^{2} / \mathrm{s}$ & 0.00 & 0.72 & 0.00 \\
Chemotactic/ $\chi_{0}=10^{-4} \mathrm{~cm}^{2} / \mathrm{s}$ & 0.37 & 0.77 & -0.21 \\
Chemotactic/ $\chi_{0}=2 \times 10^{-4} \mathrm{~cm}^{2} / \mathrm{s}$ & 0.68 & 0.73 & -0.41 \\
Chemotactic/ $\chi_{0}=4 \times 10^{-4} \mathrm{~cm}^{2} / \mathrm{s}$ & 1.12 & 0.63 & -0.82 \\
\hline
\end{tabular}

The center of mass for the chemotactic bacteria increases with increasing chemotactic sensitivity coefficient. This shows that the bacteria are migrating closer to the attractant plume as the chemotactic sensitivity coefficient increases. A chemotactic sensitivity value less than $10^{4}$ $\mathrm{cm}^{2} / \mathrm{s}$ is required to match the difference in center of mass of about $0.2 \mathrm{~cm}$ seen in experimental results with $2 \mathrm{~cm}$ spacing. Values of $\chi_{0}$ less than $10^{4} \mathrm{~cm}^{2} / \mathrm{s}$ were not tested because the uncertainty associated with the experimental data did not warrant a more precise determination. The chemotaxis number for $2 \mathrm{~cm}$ spacing and $\chi_{0}$ of $10^{4} \mathrm{~cm}^{2} / \mathrm{s}$ is 0.039 . Center of mass values, at the same $\chi_{0}$, show that the center of mass for the chemotactic bacteria distributions are always higher for $2 \mathrm{~cm}$ spacing compared to $3 \mathrm{~cm}$ or $4 \mathrm{~cm}$. This shows the chemotactic bacteria that have been exposed to the attractant for a longer period of time within the microcosm exhibit a greater transverse migration of bacteria towards higher concentrations of attractant, which supports the exposure time argument discussed in Hypothesis 2. 
The transverse dispersion coefficient does not have a clear trend with the chemotactic sensitivity coefficient, and it does not change drastically over the range of chemotactic sensitivity coefficients tested. This may be because the entire bacteria population is exposed to the attractant. Therefore the whole population migrates in the same direction and the transverse dispersion coefficient does not change very much.

The skewness values become more negative as the chemotactic sensitivity coefficient increases. This is consistent with what is expected, as a negative value of skewness represents a bias in the distribution towards the attractant. When comparing the model results for $2 \mathrm{~cm}$ and 3 $\mathrm{cm}$ spacing, the exposure time argument is supported through the skewness values. At constant $\chi_{0}$, the change in skewness is always larger for $2 \mathrm{~cm}$ than for $3 \mathrm{~cm}$. This shows that the shape of the bacteria concentration distribution is impacted by the exposure time of the bacteria to the attractant for these two separation distances.

\subsection{Effects of Chemotactic Receptor Constant}

\subsubsection{Results Using $4 \mathrm{~cm}$ Spacing}

Figure 6.4 below shows breakthrough curves for the attractant and bacteria at the microcosm exit for continuous injections of bacteria $4 \mathrm{~cm}$ below the attractant. The chemotaxis receptor constant was varied to explore its effect on the transverse migration of chemotactic bacteria. The chemotactic sensitivity coefficient was held constant at $2 \times 10^{-4} \mathrm{~cm}^{2} / \mathrm{s}$, which is the value that best matched the experimental center of mass data. 


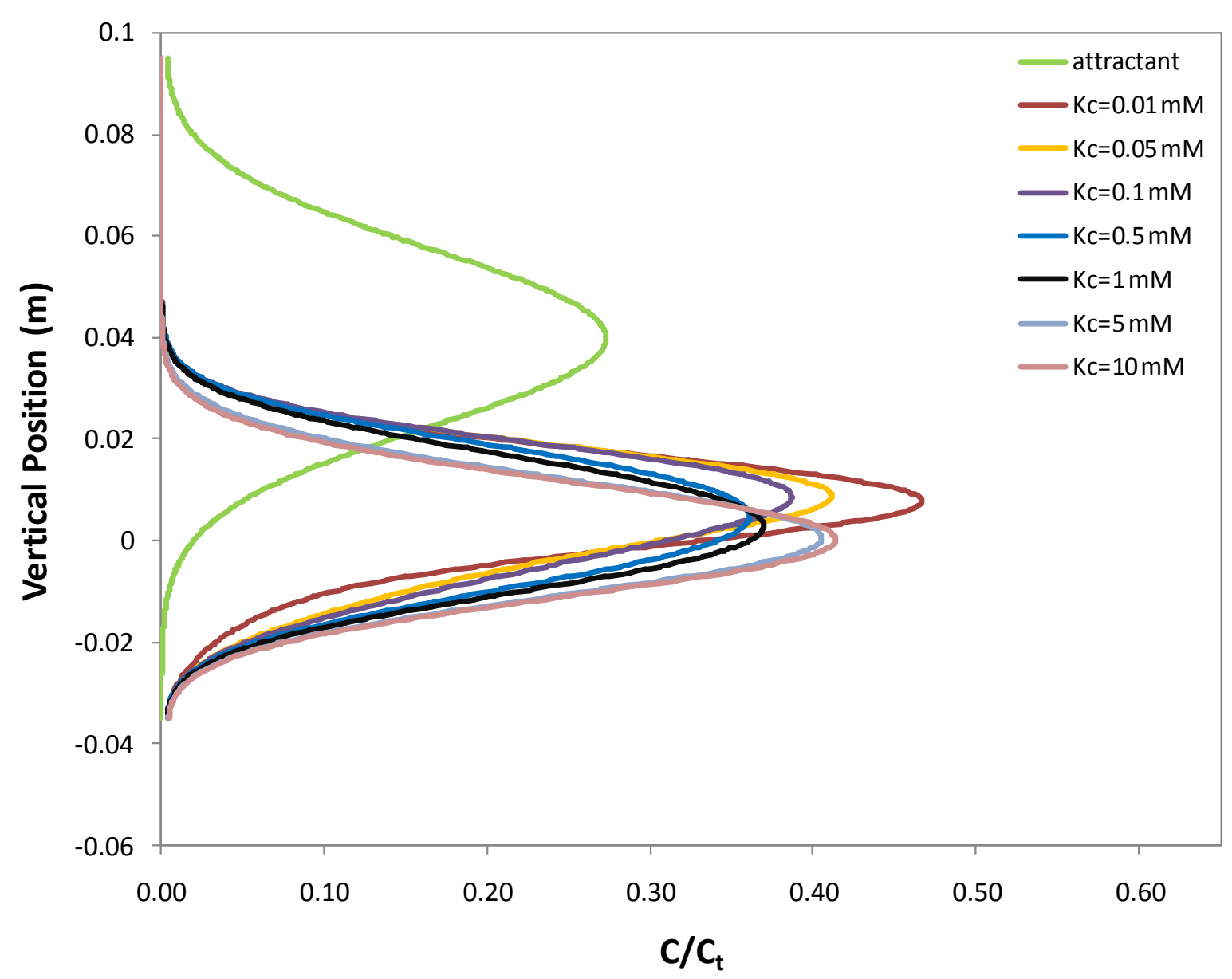

Figure 6.4 Transverse population distributions from two-dimensional mathematical modeling using different values of the chemotaxis receptor constant and constant $\chi_{0}$ of $2 \times 10^{-4} \mathrm{~cm}^{2} / \mathrm{s}$ with continuous bacteria injections $4 \mathrm{~cm}$ below attractant plume.

Table 6.4 below summarizes the values for the center of mass, transverse dispersion coefficient, and skewness from the moment analysis. Concentration values that were less than three orders of magnitude smaller than the peak attractant or bacteria concentration were not used in the moment analysis. The center of mass for all $K_{c}$ values are above $0 \mathrm{~cm}$, which is expected due to the transverse migration of the chemotactic bacteria toward the attractant. Skewness is expected to be negative for the chemotactic bacteria, however many of the curves exhibit a slightly positive skewness value. This discrepancy is due to the lower no flux boundary 
condition of the model at $-3.5 \mathrm{~cm}$. This boundary condition has affected the shape of the bacteria profiles.

Table 6.4 Moment analysis summary for mathematical modeling with continuous bacteria injections $4 \mathrm{~cm}$ below attractant plume and varying chemotaxis receptor constant with constant $\chi_{0}$ of $2 \times 10^{-4} \mathrm{~cm}^{2} / \mathrm{s}$.

\begin{tabular}{|c|ccc|}
\hline Component & $\bar{y}(\mathrm{~cm})$ & $D_{T} \times 10^{5}\left(\mathrm{~cm}^{2} / \mathrm{s}\right)$ & $\gamma$ \\
\hline Attractant & 0.01 & 2.02 & 0.00 \\
$\mathrm{~K}_{\mathrm{c}}=0.01 \mathrm{mM}$ & 0.66 & 0.80 & -0.32 \\
$\mathrm{~K}_{\mathrm{c}}=0.05 \mathrm{mM}$ & 0.57 & 0.94 & -0.26 \\
$\mathrm{~K}_{\mathrm{c}}=0.1 \mathrm{mM}$ & 0.54 & 0.97 & -0.19 \\
$\mathrm{~K}_{\mathrm{c}}=0.5 \mathrm{mM}$ & 0.40 & 0.98 & -0.02 \\
$\mathrm{~K}_{\mathrm{c}}=1 \mathrm{mM}$ & 0.31 & 0.96 & 0.04 \\
$\mathrm{~K}_{\mathrm{c}}=5 \mathrm{mM}$ & 0.09 & 0.83 & 0.08 \\
$\mathrm{~K}_{\mathrm{c}}=10 \mathrm{mM}$ & 0.04 & 0.80 & 0.07 \\
\hline
\end{tabular}

The moment analysis shows that the $K_{c}$ value does not greatly change the shape or location of the bacteria distributions for this spacing of $4 \mathrm{~cm}$ and $\chi_{0}$ of $2 \times 10^{-4} \mathrm{~cm}^{2} / \mathrm{s}$. A $K_{c}$ of $0.01 \mathrm{mM}$ provides the greatest transverse migration of chemotactic bacteria for this model configuration.

\subsubsection{Results Using $3 \mathrm{~cm}$ Spacing}

Figure 6.5 below shows breakthrough curves for the attractant and bacteria at the microcosm exit for continuous injections of bacteria $3 \mathrm{~cm}$ below the attractant. The chemotaxis receptor constant was varied to explore its effect on the transverse migration of chemotactic bacteria. The chemotactic sensitivity coefficient was held constant at $10^{-4} \mathrm{~cm}^{2} / \mathrm{s}$, which is the value that best matched the experimental center of mass data. 


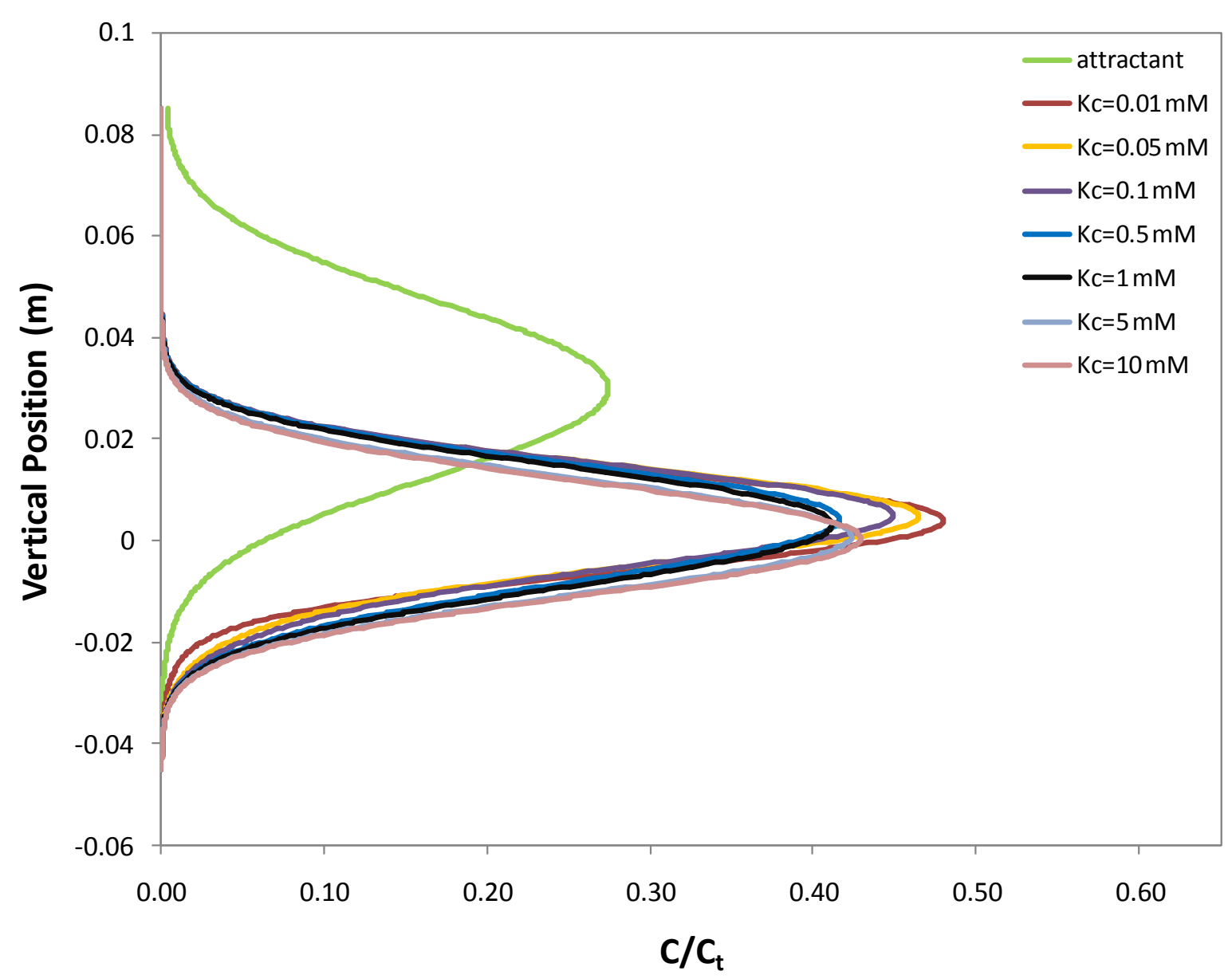

Figure 6.5 Transverse population distributions from two-dimensional mathematical modeling using different values of the chemotaxis receptor constant and constant $\chi_{0}$ of $10^{-4} \mathrm{~cm}^{2} / \mathrm{s} \mathrm{with}$ continuous bacteria injections $3 \mathrm{~cm}$ below attractant plume.

Table 6.5 summarizes the values for the center of mass, transverse dispersion coefficient, and skewness from the moment analysis. Concentration values that were less than three orders of magnitude smaller than the peak attractant or bacteria concentration were not used in the moment analysis. The center of mass values for all $K_{c}$ values are above $0 \mathrm{~cm}$, which demonstrates transverse migration of the chemotactic bacteria toward the attractant. A $K_{c}$ value of $0.01 \mathrm{mM}$ provides the largest shift in the center of mass of the bacteria. Skewness is expected to be negative for the chemotactic bacteria, which was true for most $K_{c}$ values. The skewness 
was 0 for a $K_{c}$ of $10 \mathrm{mM}$, and the center of mass was $0.04 \mathrm{~cm}$. This shows that when the chemotaxis receptor constant is much higher than the concentration of attractant, the bacteria do not respond. The skewness was 0.01 for a $K_{c}$ of $0.01 \mathrm{mM}$, however the center of mass shows that the bacteria migrated closer to the attractant. At this low value of $K_{c}$ the shape of the bacteria distribution curve was not greatly altered.

Table 6.5 Moment analysis summary for mathematical modeling with continuous bacteria injections $3 \mathrm{~cm}$ below attractant plume and varying chemotaxis receptor constant with constant $\chi_{0}$ of $10^{-4} \mathrm{~cm}^{2} / \mathrm{s}$.

\begin{tabular}{|c|ccc|}
\hline Component & $\bar{y}(\mathrm{~cm})$ & $D_{T} \times 10^{5}\left(\mathrm{~cm}^{2} / \mathrm{s}\right)$ & $\gamma$ \\
\hline Attractant & 0.01 & 2.04 & -0.01 \\
$\mathrm{~K}_{\mathrm{c}}=0.01 \mathrm{mM}$ & 0.41 & 0.68 & 0.01 \\
$\mathrm{~K}_{\mathrm{c}}=0.05 \mathrm{mM}$ & 0.40 & 0.78 & -0.17 \\
$\mathrm{~K}_{\mathrm{c}}=0.1 \mathrm{mM}$ & 0.37 & 0.82 & -0.18 \\
$\mathrm{~K}_{\mathrm{c}}=0.5 \mathrm{mM}$ & 0.28 & 0.87 & -0.11 \\
$\mathrm{~K}_{\mathrm{c}}=1 \mathrm{mM}$ & 0.22 & 0.87 & -0.07 \\
$\mathrm{~K}_{\mathrm{c}}=5 \mathrm{mM}$ & 0.07 & 0.83 & -0.01 \\
$\mathrm{~K}_{\mathrm{c}}=10 \mathrm{mM}$ & 0.04 & 0.81 & 0.00 \\
\hline
\end{tabular}

Figure 6.6 below shows breakthrough curves for the attractant and bacteria at the microcosm exit for continuous injections of bacteria $3 \mathrm{~cm}$ below the attractant. The chemotactic receptor constant has been varied to explore its effect on the transverse migration of chemotactic bacteria. The chemotactic receptor constant has been constant at $10^{-3} \mathrm{~cm}^{2} / \mathrm{s}$, which is a full order of magnitude greater than the $\chi_{0}$ used to match experimental results. This configuration was chosen to explore the effects of changing the $K_{c}$ value when the chemotactic sensitivity 
coefficient is relatively high. The curves in Figure 6.6 exhibit a wider range of shapes and locations than the curves shown in Figure 6.7. The curves for $K_{c}$ of $0.01 \mathrm{mM}, 0.05 \mathrm{mM}$, and 0.1 $\mathrm{mM}$ are all relatively symmetric, and all have peaks very close to the highest attractant concentration. The curves for $K_{c}$ of $0.5 \mathrm{mM}$ and $1 \mathrm{mM}$ have longer tails reaching towards the bottom of the microcosm. Finally the curve for $K_{c}$ of $10 \mathrm{mM}$ appears to be symmetric about the injection port, which suggests that migration has not occurred at this high value for chemotaxis receptor constant.

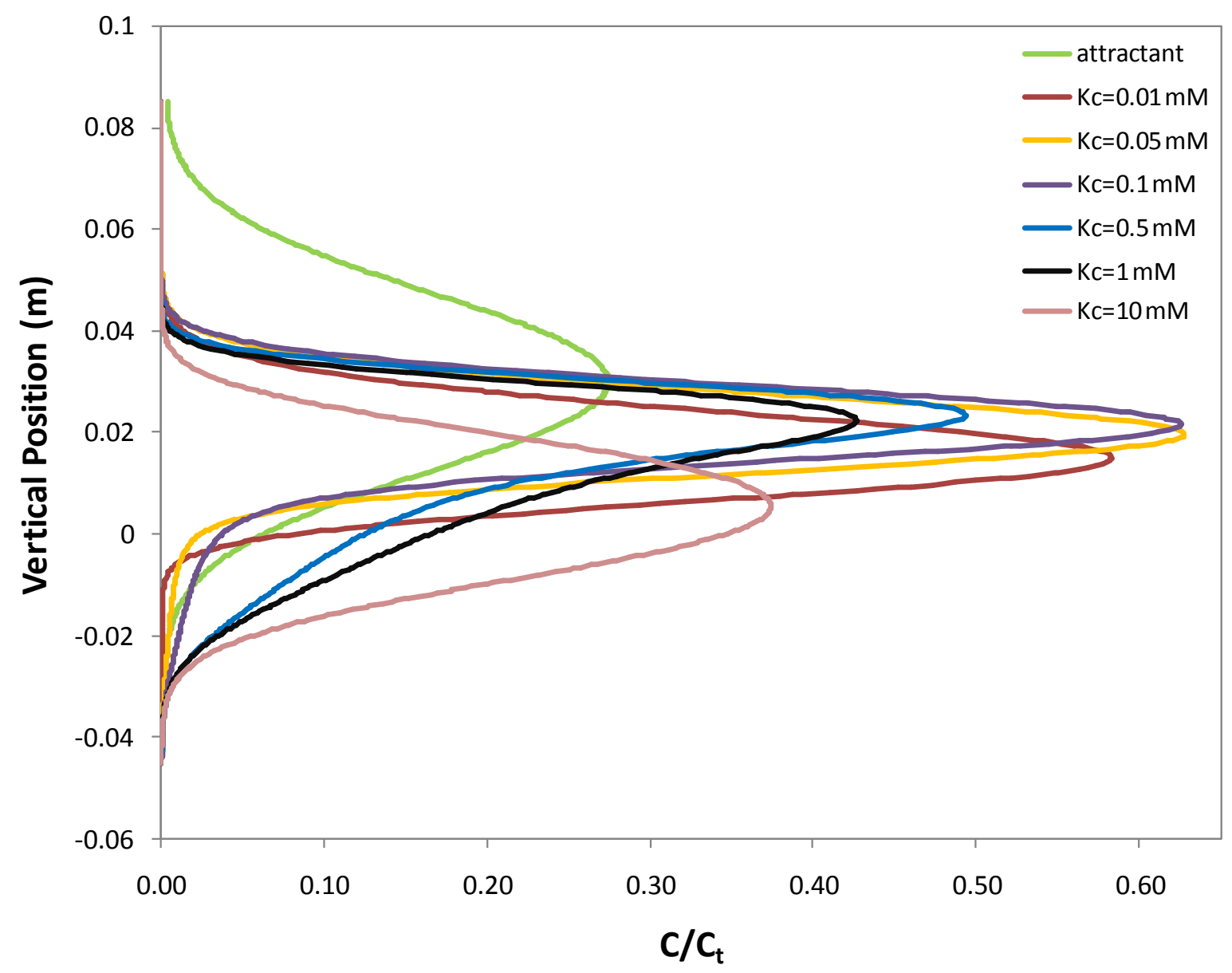

Figure 6.6 Transverse population distributions from two-dimensional mathematical modeling using different values of the chemotaxis receptor constant and constant $\chi_{0}$ of $10^{-3} \mathrm{~cm}^{2} / \mathrm{s}$ with continuous bacteria injections $3 \mathrm{~cm}$ below attractant plume. 
Table 6.6 summarizes the values for the center of mass, transverse dispersion coefficient, and skewness from the moment analysis. Concentration values that were less than three orders of magnitude smaller than the peak attractant or bacteria concentration were not used in the moment analysis. The center of mass values for all $K_{c}$ values are above $0 \mathrm{~cm}$, which demonstrates transverse migration of the chemotactic bacteria toward the attractant. A $K_{c}$ value of $0.1 \mathrm{mM}$ provides the largest shift in the center of mass of the bacteria. This is a higher value compared to the previous model configurations examined, which is most likely because the bacteria in this configuration are present at higher values of attractant concentration. The shift in center of mass of the bacteria was a full $2 \mathrm{~cm}$, which is the largest value reported in the range of configurations tested in this study. The chemotaxis number which corresponding to this large shift in center of mass at $3 \mathrm{~cm}$ spacing and relatively high $\chi_{0}$ is 0.26 .

The transverse dispersion coefficient decreases at low $K_{c}$ values. This may be due to the bacteria concentrating in regions of high attractant concentration. Skewness is expected to be negative for the chemotactic bacteria, which was true for all $K_{c}$ values except $0.01 \mathrm{mM}$. The skewness was 0.01 for a $K_{c}$ of $0.01 \mathrm{mM}$ which indicates that chemotactic migration has not altered the shape of the distribution, however the center of mass shows that the bacteria have migrated closer to the attractant. The skewness is most negative at a $K_{c}$ of $0.1 \mathrm{mM}$, which also corresponds to the largest shift in center of mass. The chemotaxis receptor constant affects the effluent chemotactic bacteria concentration distributions to a greater extent at a higher chemotactic sensitivity coefficient. 
Table 6.6 Moment analysis summary for mathematical modeling with continuous bacteria injections $3 \mathrm{~cm}$ below attractant plume and varying chemotaxis receptor constant with constant $\chi_{0}$ of $10^{-3} \mathrm{~cm}^{2} / \mathrm{s}$.

\begin{tabular}{|c|ccc|}
\hline Component & $\bar{y}(\mathrm{~cm})$ & $D_{T} \times 10^{5}\left(\mathrm{~cm}^{2} / \mathrm{s}\right)$ & $\gamma$ \\
\hline Attractant & 0.01 & 2.04 & -0.01 \\
$\mathrm{~K}_{\mathrm{c}}=0.01 \mathrm{mM}$ & 1.61 & 0.47 & 0.14 \\
$\mathrm{~K}_{\mathrm{c}}=0.05 \mathrm{mM}$ & 1.98 & 0.52 & -0.93 \\
$\mathrm{~K}_{\mathrm{c}}=0.1 \mathrm{mM}$ & 2.01 & 0.69 & -1.47 \\
$\mathrm{~K}_{\mathrm{c}}=0.5 \mathrm{mM}$ & 1.56 & 1.22 & -0.98 \\
$\mathrm{~K}_{\mathrm{c}}=1 \mathrm{mM}$ & 1.56 & 1.22 & -0.98 \\
$\mathrm{~K}_{\mathrm{c}}=10 \mathrm{mM}$ & 0.44 & 0.99 & -0.11 \\
\hline
\end{tabular}

\subsubsection{Results Using $2 \mathrm{~cm}$ Spacing}

Figure 6.7 below shows breakthrough curves for the attractant and bacteria at the microcosm exit for continuous injections of bacteria $2 \mathrm{~cm}$ below the attractant. The chemotaxis receptor constant was varied to explore its effect on the transverse migration of chemotactic bacteria. The chemotactic sensitivity coefficient was held constant at $10^{-4} \mathrm{~cm}^{2} / \mathrm{s}$, which is the value that best matched the experimental center of mass data. 


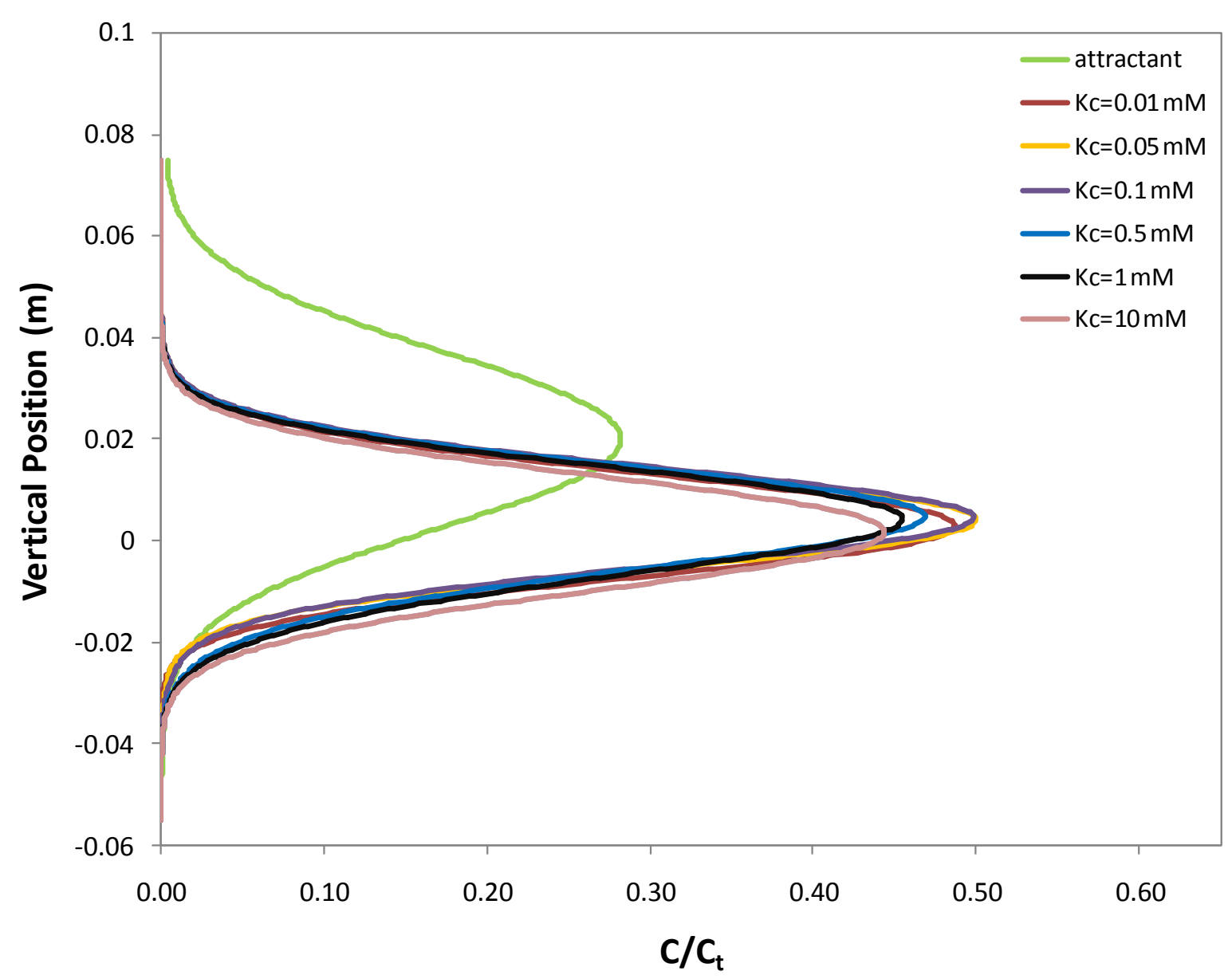

Figure 6.7 Transverse population distributions from two-dimensional mathematical modeling using different values of the chemotaxis receptor constant and constant $\chi_{0}$ of $10^{-4} \mathrm{~cm}^{2} / \mathrm{s}$ with continuous bacteria injections $2 \mathrm{~cm}$ below attractant plume.

Table 6.7 summarizes the values for the center of mass, transverse dispersion coefficient, and skewness from the moment analysis. Concentration values that were less than three orders of magnitude smaller than the peak attractant or bacteria concentration were not used in the moment analysis. The center of mass values for all $K_{c}$ values are above $0 \mathrm{~cm}$, which demonstrates transverse migration of the chemotactic bacteria toward the attractant. A $K_{c}$ value of $0.1 \mathrm{mM}$ provides the largest shift in the center of mass of the bacteria. The transverse dispersion coefficient decreases as $K_{c}$ decreases. Again, this may be due to the bacteria concentrating in regions of high attractant concentration. Skewness is expected to be negative 
for the chemotactic bacteria, which was true for most $K_{c}$ values. The skewness was positive for small values of $K_{c}, 0.01 \mathrm{mM}$ and $0.05 \mathrm{mM}$, however the center of mass shows that the bacteria have migrated closer to the attractant. This is consistent with results from previous model configurations. At low values of $K_{c}$ the shape of the bacteria distribution curve is not greatly altered.

Table 6.7 Moment analysis summary for mathematical modeling with continuous bacteria injections $2 \mathrm{~cm}$ below attractant plume and varying chemotaxis receptor constant with constant $\chi_{0}$ of $10^{-4} \mathrm{~cm}^{2} / \mathrm{s}$.

\begin{tabular}{|c|ccc|}
\hline Component & $\bar{y}(\mathrm{~cm})$ & $D_{T} \times 10^{5}\left(\mathrm{~cm}^{2} / \mathrm{s}\right)$ & $\gamma$ \\
\hline Attractant & 0.01 & 2.05 & 0.00 \\
$\mathrm{~K}_{\mathrm{c}}=0.01 \mathrm{mM}$ & 0.35 & 0.67 & 0.10 \\
$\mathrm{~K}_{\mathrm{c}}=0.05 \mathrm{mM}$ & 0.45 & 0.66 & 0.02 \\
$\mathrm{~K}_{\mathrm{c}}=0.1 \mathrm{mM}$ & 0.46 & 0.68 & -0.08 \\
$\mathrm{~K}_{\mathrm{c}}=0.5 \mathrm{mM}$ & 0.37 & 0.78 & -0.20 \\
$\mathrm{~K}_{\mathrm{c}}=1 \mathrm{mM}$ & 0.30 & 0.80 & -0.18 \\
$\mathrm{~K}_{\mathrm{c}}=10 \mathrm{mM}$ & 0.12 & 0.81 & -0.07 \\
\hline
\end{tabular}

\subsection{Conclusions}

Mathematical modeling has provided insight into the effects of changing the chemotactic sensitivity coefficient and the chemotaxis receptor constant. A lower value of the chemotactic sensitivity coefficient was needed to match the center of mass values determined experimentally for the $2 \mathrm{~cm}$ and $3 \mathrm{~cm}$ spaced model results when compared to the $4 \mathrm{~cm}$ model results. The change in center of mass is always highest for $2 \mathrm{~cm}$ spacing and lowest for $4 \mathrm{~cm}$ at constant $\chi_{0}$. This shows that increasing the exposure time of the bacteria to the attractant increases the transverse migration of bacteria. When the bacteria and the attractant are injected closer 
together, the bacteria are exposed to the attractant gradient for a longer period of time, and therefore migrate transverse to convective flow for a longer period, resulting in a larger overall distance travelled as indicated by the center of mass. The largest shift in the center of mass for the chemotactic bacteria for the range of values tested was found using $3 \mathrm{~cm}$ spacing, a $K_{c}$ value of $0.1 \mathrm{mM}$, and $\chi_{0}$ of $10^{-3} \mathrm{~cm}^{2} / \mathrm{s}$. This suggests that using bacteria with a high chemotactic sensitivity coefficient and a lower chemotaxis receptor constant would increase chemotactic migration to the attractant source. Changes in the chemotaxis receptor constant were more pronounced at relatively high values of the chemotactic sensitivity coefficient. The chemotaxis number was found to be on the order of $0.026-0.039$ for the experimental results, and was found to be 0.26 for the model configuration which provided the largest shift in center of mass.

Mathematical modeling is an important step in the design of future experiments and also allows for predictions of what will happen at a larger scale. The mathematical model evaluated in this study is a useful tool that can aid in the design of future two-dimensional microcosm experiments. 


\section{Conclusions and Recommendations}

\subsection{Conclusions}

Two-dimensional microcosm experiments with a pulse injection of bacteria below the attractant indicated that chemotactic bacteria migrated in a direction transverse to flow in response to an attractant source. The center of mass value for the chemotactic bacteria was 0.1 $\mathrm{cm}$ closer to the attractant plume than that of the uranine tracer whereas the nonchemotactic control was found $0.6 \mathrm{~cm}$ further away from the attractant than the uranine tracer, which supported Hypothesis 1. The transverse dispersion coefficient and transverse dispersivity values were larger for the chemotactic bacteria than for the nonchemotactic control or the uranine tracer. This suggested that biased swimming of the chemotactic bacteria enhanced the ability of the population to spread out within the porous media. Similarly, in experiments with a pulse injection of bacteria above the attractant chemotactic bacteria were $0.9 \mathrm{~cm}$ closer to the attractant than the uranine tracer, and nonchemotactic bacteria were $0.2 \mathrm{~cm}$ further away from the attractant than the tracer.

Many factors contributed to uncertainty in evaluating the center of mass from experiments using pulse injections. The presence of background bacteria coupled with low concentrations of injected bacteria in the effluent may have affected the moment analysis calculations. Another problem affecting the pulse injection results was the sinking of the bacteria. The sinking affects the values obtained from the moment analysis, causing the center of mass and the skewness parameters to shift. Finally, the inability to create an idealized flow within the microcosm may have affected the accuracy of the results.

Continuously injected bacteria experiments aided in providing more reliable microcosm results. In experiments using continuous bacteria injections the concentration of injected 
bacteria was much greater in magnitude than the background bacteria, which reduced the effect of background bacteria on the moment analysis. The continuous injections appeared to stabilize the bacteria injections and prevent some of the distortions that occurred with pulse injections. Finally, the continuous injection method reduced the human error associated with pulse injections, which yielded more accurate transport parameters. Chemotactic bacteria were on average $0.3 \mathrm{~cm}$ and $0.2 \mathrm{~cm}$ closer to the attractant source than the nonchemotactic control when compared to the fluorescent tracer for both $3 \mathrm{~cm}$ and $2 \mathrm{~cm}$ spacing, respectively. This supports Hypothesis 1 however it does not support Hypothesis 2. The transverse migration of chemotactic bacteria was expected to be greater for $2 \mathrm{~cm}$ spacing due to the increased exposure time of the bacteria to the attractant.

Transport parameters determined experimentally were used to evaluate a twodimensional mathematical model, as proposed in Hypothesis 3. Modeling was used to test the effects of changing the chemotactic sensitivity coefficient and the chemotaxis receptor constant at three different bacteria and attractant separation distances: $4 \mathrm{~cm}, 3 \mathrm{~cm}$, and $2 \mathrm{~cm}$. A chemotactic sensitivity coefficient of $10^{-4} \mathrm{~cm}^{2} / \mathrm{s}$ was found to match the change in center of mass determined experimentally for $3 \mathrm{~cm}$ and $2 \mathrm{~cm}$ separation distances. The experimentally determined change in center of mass for the $3 \mathrm{~cm}$ spacing was also compared to the model with 4 $\mathrm{cm}$ spacing because the sinking of bacteria in experiments may have caused the actual exposure of the bacteria and attractant to resemble that of a larger spacing distance. A chemotactic sensitivity coefficient of $2 \times 10^{-4} \mathrm{~cm}^{2} / \mathrm{s}$ was found to match the change in center of mass for the model with $4 \mathrm{~cm}$ spacing to the center of mass determined in experiments with $3 \mathrm{~cm}$ spacing. Model results showed the center of mass shift for chemotactic bacteria was greater for $3 \mathrm{~cm}$ and $2 \mathrm{~cm}$ spacing than $4 \mathrm{~cm}$ spacing at constant chemotactic sensitivity coefficient values, which 
shows that increasing the exposure time of the bacteria to the attractant can increase the transverse migration of bacteria. This shows that increasing the exposure time of the bacteria to the attractant can increase the transverse migration of bacteria.

Results from these bench scale experiments show that chemotaxis can enhance bacterial transport, potentially improving bacterial transport to contaminant sources in groundwater aquifers. The ability of the bacteria population to migrate towards the contaminant source, with the help of rapid growth and degrading ability, could improve biodegradation in both bench scale and field scale scenarios.

\subsection{Recommendations}

A major obstacle present in all two-dimensional microcosm experiments was the sinking of the bacteria. This made it difficult to assess the transverse migration of chemotactic bacteria towards the attractant source. Sinking also caused the center of mass of the nonchemotactic bacteria to shift downwards, which caused uncertainties in the control experiments to which the chemotactic experiments were compared. One possibly way to resolve the sinking of bacteria would be to turn the microcosm on its side, horizontally rather than vertically. The top of the tank would have to be sealed watertight beforehand. The bacteria would still experience sinking in the vertical direction, however they would no longer sink in the direction transverse to convective flow, allowing for a more reliable measurement of transverse migration due to chemotaxis. Another option would be to investigate the possibility to culture neutrally buoyant bacteria to prevent or lessen the sinking observed experimentally (Harvey et al. 1997).

Flow variations within the tank also added to the uncertainty associated with experimental results. One way to control for flow variations would be to use a two-dimensional 
microcosm with a smaller separation distance between injection ports. This would allow for a more uniform velocity profile within the microcosm and also data could be collected at a higher resolution. Controlling for the flow variations and sinking bacteria will allow for a more accurate experimental characterization of chemotaxis in a two-dimensional porous microcosm.

One possible way to directly compare the migration of chemotactic and nonchemotactic bacteria would be to inject them simultaneously into the microcosm. A different color stain would be required to distinguish between types of bacteria, as well as microscopes capable of distinguishing between the two colors. A major concern when using bacteria stains is that the stains often reduce motility of the bacteria (Toepfer et al. 2012). Chemotactic bacteria labeled with green fluorescent protein and nonchemotactic bacteria labeled with red fluorescent protein would be a possible combination. Simultaneous injection of chemotactic and nonchemotactic bacteria was not performed in this study because the green fluorescent protein labeled chemotactic bacteria exhibited low fluorescence which made it difficult to accurately count all chemotactic bacteria. DAPI staining is an option for the nonchemotactic bacteria, but not for the chemotactic bacteria, because it impairs chemotaxis and the motility of chemotactic bacteria (Toepfer et al. 2012). DAPI stained nonchemotactic bacteria could be injected with unlabeled chemotactic bacteria, however there is not yet an effective way to count the chemotactic bacteria in the effluent sample. AO staining of the effluent sample might mask the blue color exhibited by the DAPI stain. The Ford research group is currently investigating whether it is possible to differentiate between AO stained bacteria and DAPI labeled bacteria that have been counterstained with AO.

It is valuable to explore different combinations of bacteria and attractant separation distances both experimentally and through mathematical modeling. The results from this study 
showed that increasing the exposure time by placing the bacteria too close to the attractant may not increase the transverse migration of chemotactic bacteria. Larger separation distances should be tested to determine a clear trend between exposure time and chemotactic response. It would be useful to explore how the exposure time changes over larger length scales in the microcosm. Additionally, an experiment utilizing the parameters which exhibited the largest shift in the center of mass for the chemotactic bacteria according to the mathematical model should be tested. This corresponds to $3 \mathrm{~cm}$ spacing, a $K_{c}$ value of $0.1 \mathrm{mM}$, and $\chi_{0}$ of $10^{-3} \mathrm{~cm}^{2} / \mathrm{s}$.

Once the transport of chemotactic bacteria to a contaminant source is better understood, the next step involves determining if chemotaxis can improve degradation of contaminants. The chemotactic bacteria are expected to enhance transport to the contaminant plume, resulting in increased contaminant removal. Degradation rates can be assessed by a contaminant mass balance between the inlet and effluent samples. Transport and degradation parameters from the bench scale microcosm experiments and modeling can allow for reliable predictions at the field scale. Field experiments can then be executed with a strong conceptual understanding of the bacterial migration and degradation. The enhancement of biodegradation due to bacteria chemotaxis at the field scale can be assessed. 


\section{References}

Barton, J.W. \& Ford, R.M., 1995. Determination of effective transport coefficients for bacterial migration in sand columns. Applied and environmental microbiology, 61(9), pp.3329-35. Available at:

http://www.pubmedcentral.nih.gov/articlerender.fcgi?artid=1388575\&tool=pmcentrez\&ren dertype $=$ abstract.

Bauer, R.D. et al., 2008. Mixing-controlled biodegradation in a toluene plume--results from twodimensional laboratory experiments. Journal of contaminant hydrology, 96(1-4), pp.150-68. Available at: http://dx.doi.org/10.1016/j.jconhyd.2007.10.008 [Accessed December 23, 2010].

Bauer, R.D., Rolle, M., Bauer, S., et al., 2009. Enhanced biodegradation by hydraulic heterogeneities in petroleum hydrocarbon plumes. Journal of contaminant hydrology, 105(1-2), pp.56-68. Available at: http://dx.doi.org/10.1016/j.jconhyd.2008.11.004 [Accessed December 23, 2010].

Bauer, R.D., Rolle, M., Kürzinger, P., et al., 2009. Two-dimensional flow-through microcosms Versatile test systems to study biodegradation processes in porous aquifers. Journal of Hydrology, 369(3-4), pp.284-295. Available at: http://dx.doi.org/10.1016/j.jhydrol.2009.02.037 [Accessed December 23, 2010].

Berg, H.C. \& Brown, D.A., 1972. Chemotaxis in Escherichia coli analysed by Threedimensional Tracking. Nature, 239(5374), pp.500-504. Available at: http://dx.doi.org/10.1038/239500a0 [Accessed June 16, 2011].

Boopathy, R., 2000. Factors limiting bioremediation technologies. Bioresource Technology, 74(1), pp.63-67. Available at: http://linkinghub.elsevier.com/retrieve/pii/S0960852499001443 [Accessed May 3, 2011 ].

Bouwer, E.J. \& Rittmann, B.E., 1992. Comment on "Use of colloid filtration theory in modeling movement of bacteria through a contaminated sandy aquifer." Environmental Science \& Technology, 26(1), pp.400-401. Available at: http://pubs.acs.org/doi/abs/10.1021/es00013a021.

Brashear, L., 2009. No Title. University of Virginia.

Chen, K.C., Ford, R.M. \& Cummings, P.T., 1998. Mathematical models for motile bacterial transport in cylindrical tubes. Journal of theoretical biology, 195(4), pp.481-504. Available at: http://dx.doi.org/10.1006/jtbi.1998.0808 [Accessed December 6, 2011].

Cirpka, O.A. et al., 2006. Determination of transverse dispersion coefficients from reactive plume lengths. Ground water, 44(2), pp.212-21. Available at:

http://www.ncbi.nlm.nih.gov/pubmed/16556203 [Accessed January 7, 2011]. 
Cussler, E.L., 1997. Diffusion: Mass Transfer in Fluid Systems, 2nd edition, New York: Cambridge University Press.

Environmental Protection Agency, 2001. Groundwater Pump and Treat Systems: Summary of Selected Cost and Performance Information at Superfund-financed Sites. , p.7. Available at: http://www.epa.gov/tio/download/remed/542r01021b.pdf [Accessed November 2, 2011].

Ford, R.M. \& Harvey, R.W., 2007. Role of chemotaxis in the transport of bacteria through saturated porous media. Advances in Water Resources, 30(6-7), pp.1608-1617. Available at: http://dx.doi.org/10.1016/j.advwatres.2006.05.019 [Accessed March 30, 2011].

Ford, R.M. et al., 1991. Measurement of bacterial random motility and chemotaxis coefficients: I. Stopped-flow diffusion chamber assay. Biotechnology and bioengineering, 37(7), pp.64760. Available at: http://www.ncbi.nlm.nih.gov/pubmed/18600656.

Groundwater Foundation, T., 2011. How much do we depend on groundwater? Available at: http://www.groundwater.org/gi/depend.html [Accessed November 2, 2011].

Harvey, R.W. et al., 1997. Physiological Considerations in Applying Laboratory-Determined Buoyant Densities to Predictions of Bacterial and Protozoan Transport in Groundwater: Results of In-Situ and Laboratory Tests. Environmental Science \& Technology, 31(1), pp.289-295. Available at: http://dx.doi.org/10.1021/es960461d [Accessed May 18, 2012].

Harwood, C.S., Fosnaugh, K. \& Dispensa, M., 1989. Flagellation of Pseudomonas putida and analysis of its motile behavior. Journal of bacteriology, 171(7), p.4063. Available at: http://jb.asm.org/cgi/content/abstract/171/7/4063 [Accessed July 13, 2011].

Harwood, C.S., Parales, R E \& Dispensa, M., 1990. Chemotaxis of Pseudomonas putida toward chlorinated benzoates. Applied and environmental microbiology, 56(5), pp.1501-3. Available at:

http://www.pubmedcentral.nih.gov/articlerender.fcgi?artid=184439\&tool=pmcentrez\&rend ertype $=$ abstract.

Head, I.M., 1998. Bioremediation: towards a credible technology. Microbiology, 144(3), p.599. Available at: http://mic.sgmjournals.org/cgi/content/abstract/144/3/599 [Accessed May 3, 2011].

Hobbie, J.E., Daley, R.J. \& Jasper, S., 1977. Use of nuclepore filters for counting bacteria by fluorescence microscopy. Appl. Envir. Microbiol., 33(5), pp.1225-1228. Available at: http://aem.asm.org/cgi/content/abstract/33/5/1225 [Accessed August 19, 2011].

Huang, W.E. et al., 2003. Dissolved Oxygen Imaging in a Porous Medium to Investigate Biodegradation in a Plume with Limited Electron Acceptor Supply. Environmental Science \& Technology, 37(9), pp.1905-1911. Available at: http://dx.doi.org/10.1021/es020128b [Accessed April 25, 2011]. 
Kusy, K., 2005. Bacterial migration within heterogeneous porous media. University of Virginia.

Lanning, L., 2004. Application of a microfluidic T-sensor assay for the study of chemotaxis perpendicular to convective flow. University of Virginia.

Liu, C. \& Ball, W.P., 2002. Back Diffusion of Chlorinated Solvent Contaminants from a Natural Aquitard to a Remediated Aquifer Under Well-Controlled Field Conditions: Predictions and Measurements. Ground Water, 40(2), pp.175-184. Available at: http://doi.wiley.com/10.1111/j.1745-6584.2002.tb02502.x [Accessed November 1, 2011].

Liu, J., 2011. Multi-scale evaluation of bacterial transport and chemotaxis in porous media. The University of Virginia.

Liu, X. et al., 2009. Chemotaxis to pyrimidines and identification of a cytosine chemoreceptor in Pseudomonas putida. Journal of bacteriology, 191(9), pp.2909-16. Available at:

http://www.pubmedcentral.nih.gov/articlerender.fcgi?artid=2681813\&tool=pmcentrez\&ren dertype $=$ abstract [Accessed August 30, 2011].

Long, T. \& Ford, R.M., 2009. Enhanced Transverse Migration of Bacteria by Chemotaxis in a Porous T-Sensor. Environmental Science \& Technology, 43(5), pp.1546-1552. Available at: http://dx.doi.org/10.1021/es802558j [Accessed March 30, 2011].

Lovely, P.S. \& Dahlquist, F.W., 1975. Statistical measures of bacterial motility and chemotaxis. Journal of Theoretical Biology, 50(2), pp.477-496. Available at: http://dx.doi.org/10.1016/0022-5193(75)90094-6 [Accessed April 16, 2012].

Marx, R.B. \& Aitken, M.D., 2000. Bacterial Chemotaxis Enhances Naphthalene Degradation in a Heterogeneous Aqueous System. Environmental Science \& Technology, 34(16), pp.33793383. Available at: http://pubs.acs.org/doi/abs/10.1021/es000904k.

McClaine, J.W., 2001. Influence of flagellar rotation on cell transport and adsorption kinetics for various fluid conditions. University of Virginia.

Olson, M.S. et al., 2005. Analysis of column tortuosity for $\mathrm{MnCl} 2$ and bacteria diffusion using magnetic resonance imaging. Environmental Science \& Technology, 39(1), pp.149-154.

Olson, M.S. et al., 2004. Quantification of Bacterial Chemotaxis in Porous Media Using Magnetic Resonance Imaging. Environmental Science \& Technology, 38(14), pp.38643870. Available at: http://dx.doi.org/10.1021/es035236s [Accessed December 6, 2011].

Olsson, A. \& Grathwohl, P., 2007. Transverse dispersion of non-reactive tracers in porous media: a new nonlinear relationship to predict dispersion coefficients. Journal of contaminant hydrology, 92(3-4), pp.149-61. Available at:

http://www.ncbi.nlm.nih.gov/pubmed/17601523 [Accessed June 30, 2011]. 
Pandey, G. \& Jain, R.K., 2002. Bacterial Chemotaxis toward Environmental Pollutants : Role in Bioremediation. Applied and Environmental Microbiology, 68(12), pp.5789-5795.

Pedit, J.A. et al., 2002. Quantitative analysis of experiments on bacterial chemotaxis to naphthalene. Biotechnology and bioengineering, 78(6), pp.626-34. Available at: http://www.ncbi.nlm.nih.gov/pubmed/11992528 [Accessed March 10, 2012].

Porter, M.L., Valdes, F.J. \& Wood, B.D., 2010. Multiscale modeling of chemotaxis in homogeneous porous media. Water Resources, pp.1-38.

Prommer, H. et al., 2009. Biogeochemical and isotopic gradients in a BTEX/PAH contaminant plume: model-based interpretation of a high-resolution field data set. Environmental science \& technology, 43(21), pp.8206-12. Available at: http://www.ncbi.nlm.nih.gov/pubmed/19924945.

Ptak, T., Piepenbrink, M. \& Martac, E., 2004. Tracer tests for the investigation of heterogeneous porous media and stochastic modelling of flow and transport - a review of some recent developments. Journal of Hydrology, 294(1-3), pp.122-163. Available at: http://dx.doi.org/10.1016/j.jhydrol.2004.01.020 [Accessed April 25, 2011].

Rahman, M.A. et al., 2005. Experiments on vertical transverse mixing in a large-scale heterogeneous model aquifer. Journal of contaminant hydrology, 80(3-4), pp.130-48. Available at: http://dx.doi.org/10.1016/j.jconhyd.2005.06.010 [Accessed July 22, 2010].

Rice, J.A., 2007. Mathematical Statistics and Data Analysis, Duxbury: India.

Roush, C.J., Lastoskie, C.M. \& Worden, R.M., 2006. Denitrification and chemotaxis of Pseudomonas stutzeri $\mathrm{KC}$ in porous media. Journal of environmental science and health. Part A, Toxic/hazardous substances \& environmental engineering, 41(6), pp.967-83. Available at: http://www.tandfonline.com/doi/abs/10.1080/10934520600689258 [Accessed May 20, 2012].

Strobel, K.L. et al., 2011. Chemotaxis increases vertical migration and apparent transverse dispersion of bacteria in a bench-scale microcosm. Biotechnology and bioengineering. Available at: http://www.ncbi.nlm.nih.gov/pubmed/21495010 [Accessed May 9, 2011].

Thornton, S.F. et al., 2001. Processes controlling the distribution and natural attenuation of dissolved phenolic compounds in a deep sandstone aquifer. Journal of Contaminant Hydrology, 53(3-4), pp.233-267. Available at: http://dx.doi.org/10.1016/S01697722(01)00168-1 [Accessed April 26, 2011].

Thullner, M. et al., 2004. Modeling of a microbial growth experiment with bioclogging in a twodimensional saturated porous media flow field. Journal of contaminant hydrology, 70(1-2), pp.37-62. Available at: http://dx.doi.org/10.1016/j.jconhyd.2003.08.008 [Accessed September 2, 2010]. 
Toepfer, A.J. et al., 2012. Impact of Fluorochrome Stains used to Study Bacterial Transport in Shallow Aquifers on Motility and Chemotaxis of Pseudomonas species. FEMS microbiology ecology, 81(1), pp.163-71. Available at:

http://www.ncbi.nlm.nih.gov/pubmed/22404159 [Accessed March 28, 2012].

Wang, M. \& Ford, R.M., 2009. Transverse Bacterial Migration Induced by Chemotaxis in a Packed Column with Structured Physical Heterogeneity. Environmental Science \& Technology, 43(15), pp.5921-5927.

Wang, X., 2010. Bacterial Chemotaxis to NAPL Residual in Microfluidic Device. University of Virginia. 


\section{Appendices}

\section{A.1 Pulse Injection Graphs}
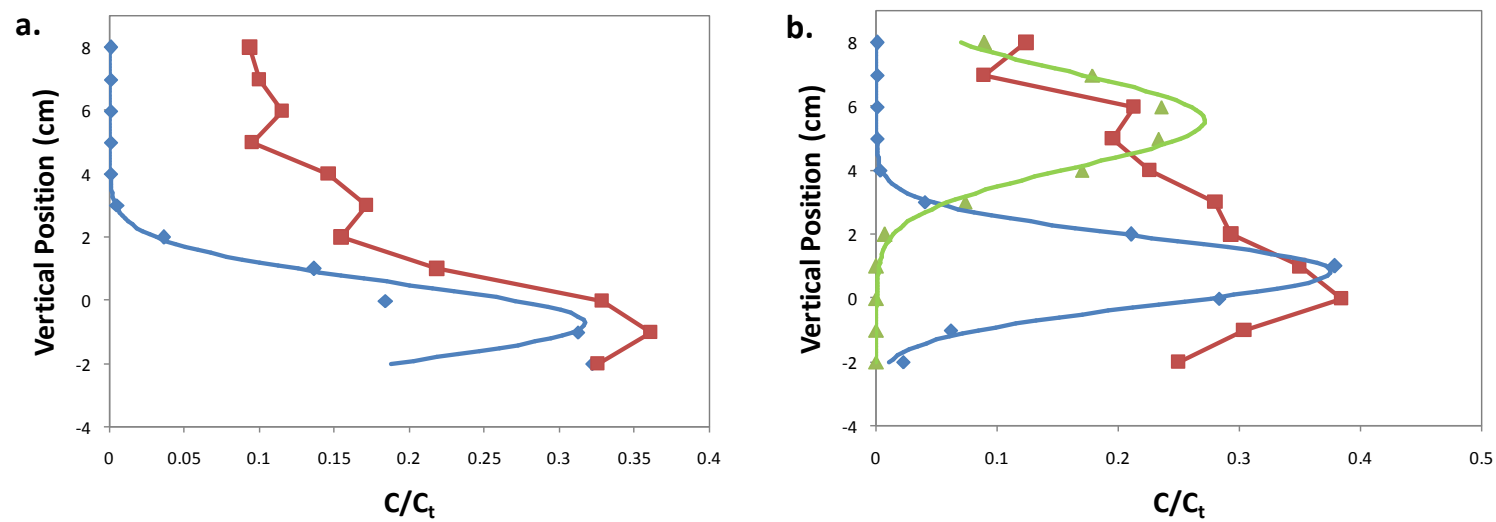

Figure A.1 Transverse population distributions from 2-D microcosm experiments with bacteria pulse injections below attractant plume in port 10. Chemotactic bacteria P. putida F1 are represented as red squares, $\square$, (a) and nonchemotactic bacteria $P$. putida F1 CheA are represented as red squares, $\square$, (b). Concentration distributions for the uranine tracer are represented by blue diamonds, $\diamond$, and benzoate attractant concentration represented by green triangles, $\triangle$. All bacteria, uranine and benzoate distributions have been normalized by the sum of concentrations from each individual port. Normalized distribution curves have been fit to the nonchemotactic bacteria, uranine, and benzoate data using Equation 3.5.

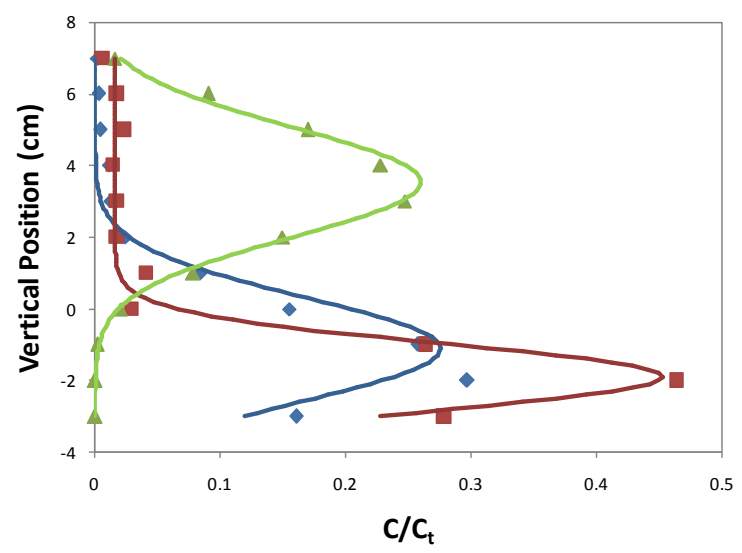

Figure A.2 Transverse population distributions from 2-D microcosm experiments with bacteria pulse injections below attractant plume in port 9. Chemotactic bacteria $P$. putida $\mathrm{F} 1$ are represented as red squares, $\square$, (a) and nonchemotactic bacteria $P$. putida F1 CheA are represented as red squares, $\square$, (b). Concentration distributions for the uranine tracer are represented by blue diamonds, $\diamond$, and benzoate attractant concentration represented by green triangles, $\triangle$. Bacteria, uranine and benzoate distributions have been normalized by the sum of 
concentrations from each individual port. Normalized distribution curves have been fit to the nonchemotactic bacteria, uranine, and benzoate data using Equation 3.5.
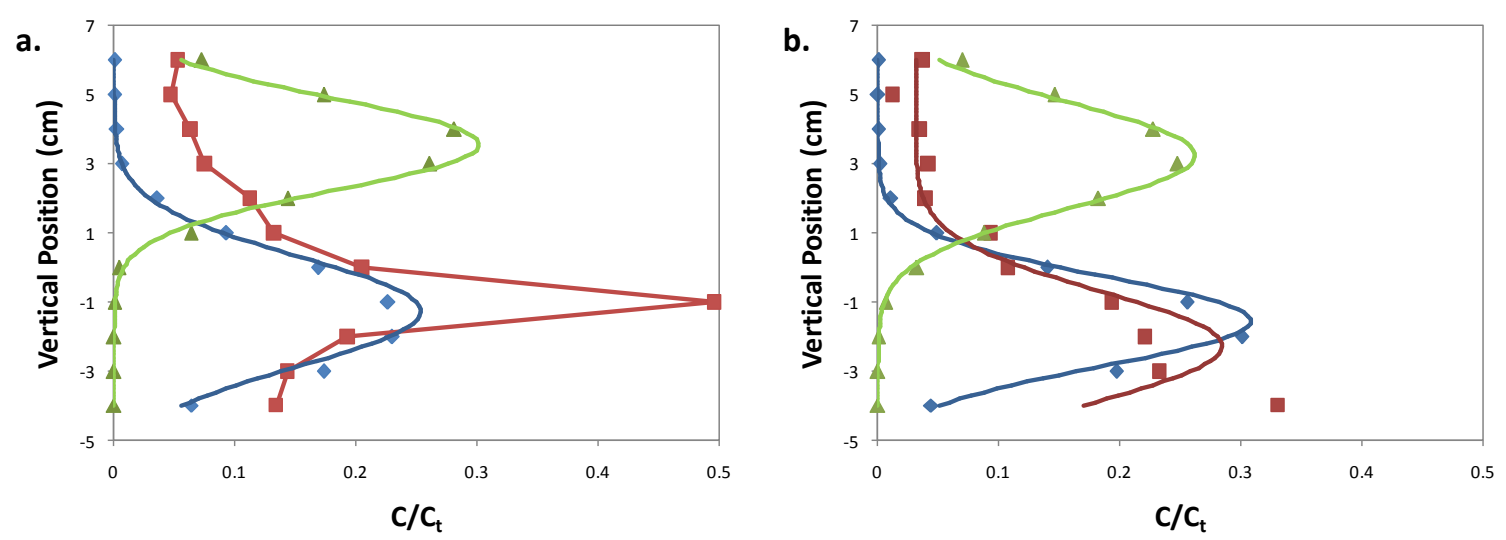

Figure A.3 Transverse population distributions from 2-D microcosm experiments with bacteria pulse injections below attractant plume in port 8. Chemotactic bacteria $P$. putida $\mathrm{F} 1$ are represented as red squares, $\square$, (a) and nonchemotactic bacteria $P$. putida F1 CheA are represented as red squares, $\square,(b)$. Concentration distributions for the uranine tracer are represented by blue diamonds, $\diamond$, and benzoate attractant concentration represented by green triangles, $\Delta$. All bacteria, uranine and benzoate distributions have been normalized by the sum of concentrations from each individual port. Normalized distribution curves have been fit to the nonchemotactic bacteria, uranine, and benzoate data using Equation 3.5. 

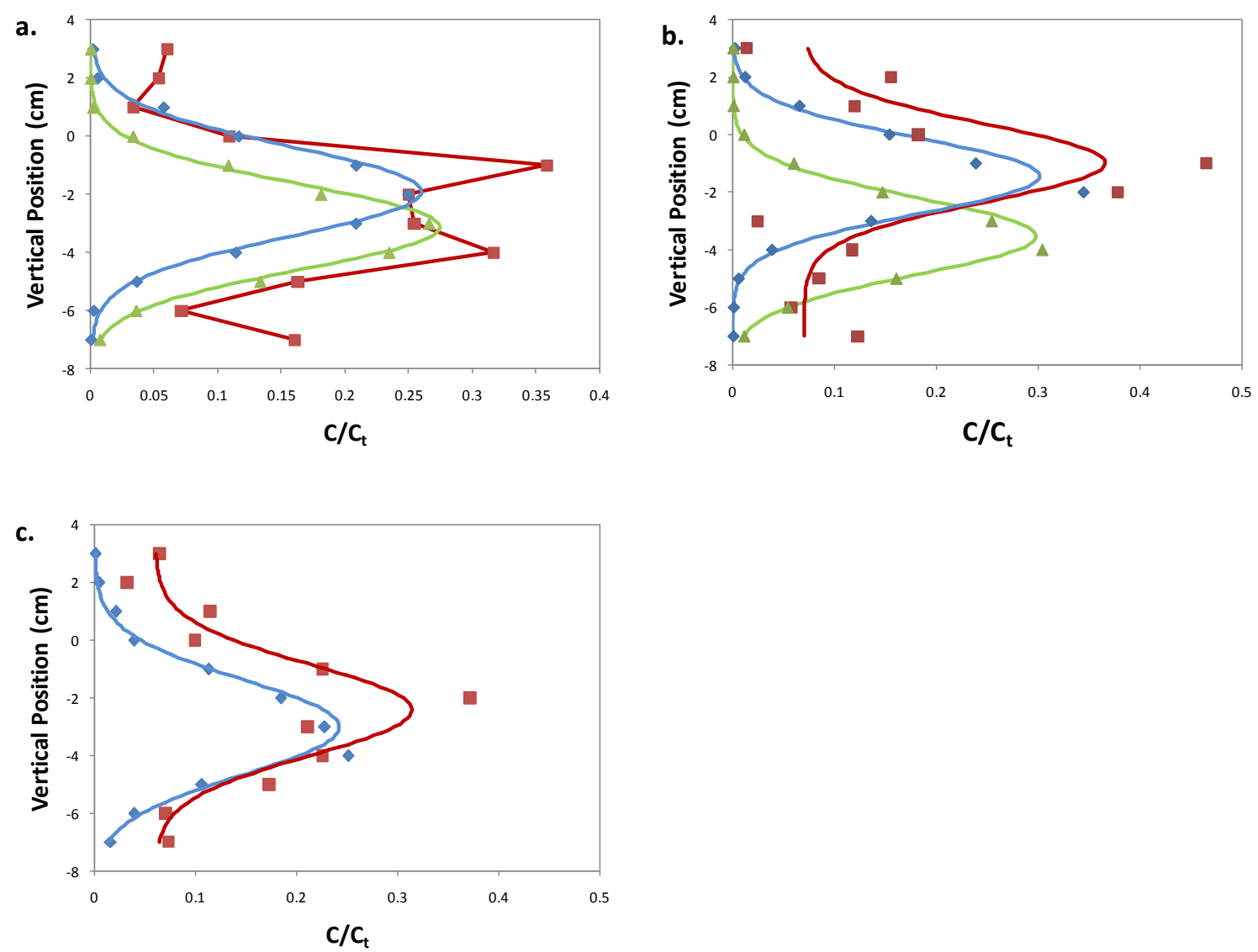

Figure A.4 Transverse population distributions from 2-D microcosm experiments with bacteria pulse injections above attractant plume. Chemotactic bacteria $P$. putida $\mathrm{F} 1$ are represented as red squares, $\square,(\mathrm{a}, \mathrm{c})$ and nonchemotactic bacteria $P$. putida $\mathrm{F} 1 \mathrm{CheA}$ are represented as red squares, $\square$, (b). Concentration distributions for the uranine tracer are represented by blue diamonds, $\bullet$, and benzoate attractant concentration represented by green triangles, $\triangle$. Benzoate attractant was not present in (c). All bacteria, uranine and benzoate distributions have been normalized by the sum of concentrations from each individual port. Normalized distribution curves have been fit to the nonchemotactic bacteria, uranine, and benzoate data using Equation 3.5. 


\section{A.2 Effect of Background Bacteria Selection on Moment Analysis}

Figure A.5 below shows breakthrough curves for an experiment where a pulse of bacteria has been injected $3 \mathrm{~cm}$ below attractant. The bacteria data points have been labeled by their corresponding y-axis location. Table A.1 below summarizes the values for the center of mass, transverse dispersion coefficient, transverse dispersivity, and skewness from the moment analysis. The moment analysis has been performed using different combinations of bacteria data points. The data analysis for experiments in this study relies on accurately choosing which bacteria data points are part of the background bacteria and which are part of the injected bacteria breakthrough curve. Table A.1 shows how the values calculated from the moment analysis change when different points from the bacteria distribution are included. Data points that are not included in the moment analysis are considered background bacteria. The average background bacteria concentrations were subtracted from each of the ports before performing the moment analysis. Differences in the center of mass calculation can vary up to $0.84 \mathrm{~cm}$ depending on the combination of point chosen, which is larger than differences seen between the experimentally determined differences in center of mass of chemotactic and nonchemotactic bacteria. The transverse dispersion coefficient differs up to $2.5 \times 10^{-5} \mathrm{~cm}^{2} / \mathrm{s}$, which is larger than the average experimentally calculated transverse dispersion coefficients in all experiments. Finally the skewness value differs over the range of 0.22 , which is on the order of calculated skewness values from experimental data. This shows the importance of correctly choosing which bacteria data points to include in the moment analysis. This analysis also shows the large uncertainty of calculated transport parameters introduced by the presence of background bacteria. 


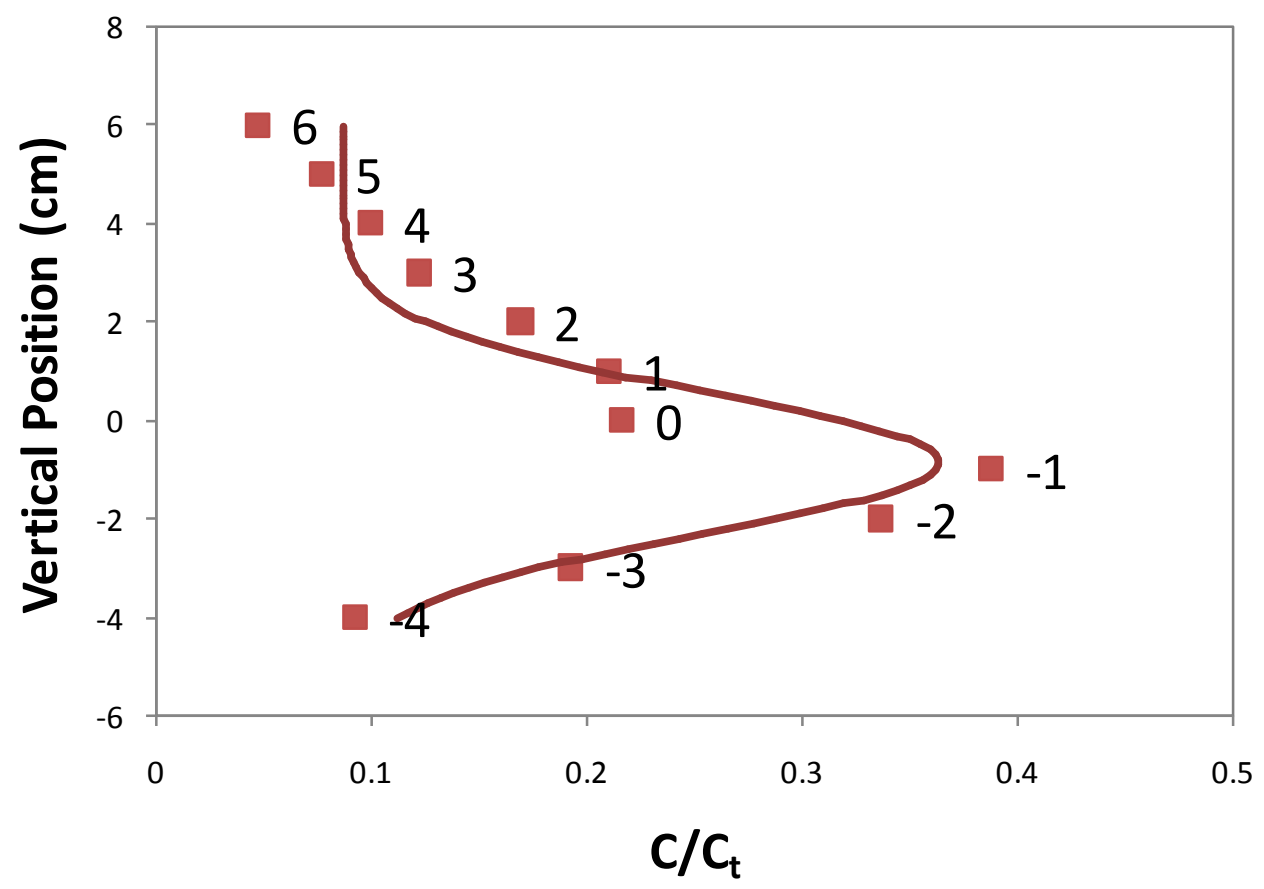

Figure A.5 Transverse population distributions from 2-D microcosm experiments with bacteria pulse injections below attractant plume. Nonchemotactic bacteria $P$. putida F1 CheA are represented as red squares, $\square$. The bacteria distribution has been normalized by the sum of concentrations from each individual port. A normalized distribution curve has been fit to the nonchemotactic bacteria data using Equation 3.5. Bacteria points have been labeled by their location on the y-axis.

Table A.1 Moment Analysis Summary Table for various points selected from the bacteria distribution shown in Figure A.5.

\begin{tabular}{|c|ccc|}
\hline Points Selected & $\bar{y}(\mathrm{~cm})$ & $D_{T} \times 10^{5}\left(\mathrm{~cm}^{2} / \mathrm{s}\right)$ & $\gamma$ \\
\hline$-4: 6$ & -0.01 & 3.49 & 0.57 \\
$-4: 5$ & -0.38 & 2.44 & 0.62 \\
$-4: 4$ & -0.55 & 1.95 & 0.55 \\
$-4: 3$ & -0.70 & 1.53 & 0.46 \\
$-4: 2$ & -0.85 & 1.16 & 0.40 \\
$-3: 3$ & -0.67 & 1.43 & 0.55 \\
$-3: 2$ & -0.84 & 1.13 & 0.44 \\
\hline
\end{tabular}




\section{A.3 Comparison of Methods to Calculate Transverse Dispersion}

Transverse dispersion coefficients were calculated using two different methods for all components for experiments with continuously injected bacteria. One method uses Equation 2.9 which accounts for the width of the injectate plume along with two-dimensional dispersion in porous media. The alternative method is to use a moment analysis in conjunction with the Einstein relationship (Equation 2.5) to find the transverse dispersion coefficient. The moment analysis assumes a point source. The results from the calculations are found below in Tables A.1-A.4. Two tailed t-tests $(\alpha=0.05)$ were performed for each component for each experimental configuration. The t-tests failed to prove a difference between the two methods for all cases except for the uranine component in the chemotactic experiments at $3 \mathrm{~cm}$ spacing. These results show that both methods yield dispersion coefficients that fall within the range of experimental uncertainty, and that the moment analysis gives a reasonable approximation of the transverse dispersion coefficient, despite its failure to account for the width of the injection zone.

Table A.2 Transverse dispersion coefficient values for chemotactic experiments at $3 \mathrm{~cm}$ spacing. Results have been calculated using two different methods: Equation 2.9 and a moment analysis.

\begin{tabular}{|c|c|c|c|c|c|c|}
\hline \multirow[b]{2}{*}{ Run } & \multicolumn{3}{|c|}{$D_{T} \times 10^{5}\left(\mathrm{~cm}^{2} / \mathrm{s}\right)-E q .2 .9$} & \multicolumn{3}{|c|}{$D_{T} \times 10^{5}\left(\mathrm{~cm}^{2} / \mathrm{s}\right)$-Moment Analysis } \\
\hline & Benzoate & Uranine & Bacteria & Benzoate & Uranine & Bacteria \\
\hline 1 & 1.29 & 0.92 & 0.54 & 1.26 & 0.98 & 0.46 \\
\hline 2 & 1.85 & 0.97 & 0.74 & 1.38 & 1.05 & 1.05 \\
\hline 3 & 2.42 & 0.92 & 0.77 & 1.57 & 1.07 & 0.60 \\
\hline Average & 1.85 & 0.94 & 0.69 & 1.40 & 1.03 & 0.70 \\
\hline \multirow{2}{*}{\multicolumn{2}{|c|}{$\Delta D_{T} \times 10^{5}\left(\mathrm{~cm}^{2} / \mathrm{s}\right)$}} & Benzoate & \multicolumn{2}{|c|}{ Uranine } & Bacteria & \\
\hline & & -0.45 & \multicolumn{2}{|c|}{0.10} & 0.02 & \\
\hline
\end{tabular}


Table A.3 Transverse dispersion coefficient values for nonchemotactic experiments at $3 \mathrm{~cm}$ spacing. Results have been calculated using two different methods: Equation 2.9 and a moment analysis.

\begin{tabular}{|c|c|c|c|c|c|c|}
\hline \multirow[b]{2}{*}{ Run } & \multicolumn{3}{|c|}{$D_{T} \times 10^{5}\left(\mathrm{~cm}^{2} / \mathrm{s}\right)-E q .2 .9$} & \multicolumn{3}{|c|}{$D_{T} \times 10^{5}\left(\mathrm{~cm}^{2} / \mathrm{s}\right)-$ Moment Analysis } \\
\hline & Benzoate & Uranine & Bacteria & Benzoate & Uranine & Bacteria \\
\hline 4 & 1.22 & 1.11 & 0.81 & 1.15 & 1.19 & 0.46 \\
\hline 5 & 1.74 & 1.09 & 0.66 & 1.24 & 1.17 & 0.77 \\
\hline 6 & 1.43 & 1.54 & 0.64 & 1.09 & 1.57 & 0.66 \\
\hline Average & 1.46 & 1.25 & 0.70 & 1.16 & 1.31 & 0.63 \\
\hline \multirow{2}{*}{\multicolumn{2}{|c|}{$\Delta D_{T} \times 10^{5}\left(\mathrm{~cm}^{2} / \mathrm{s}\right)$}} & Benzoate & \multicolumn{2}{|c|}{ Uranine } & Bacteria & \\
\hline & & -0.30 & \multicolumn{2}{|c|}{0.07} & -0.06 & \\
\hline
\end{tabular}

Table A.4 Transverse dispersion coefficient values for chemotactic experiments at $2 \mathrm{~cm}$ spacing. Results have been calculated using two different methods: Equation 2.9 and a moment analysis.

\begin{tabular}{|c|c|c|c|c|c|c|}
\hline \multirow[b]{2}{*}{ Run } & \multicolumn{3}{|c|}{$D_{T} \times 10^{5}\left(\mathrm{~cm}^{2} / \mathrm{s}\right)-E q .2 .9$} & \multicolumn{3}{|c|}{$D_{T} \times 10^{5}\left(\mathrm{~cm}^{2} / \mathrm{s}\right)$-Moment Analysis } \\
\hline & Benzoate & Uranine & Bacteria & Benzoate & Uranine & Bacteria \\
\hline 7 & 3.28 & 2.07 & 0.74 & 1.46 & 1.75 & 0.52 \\
\hline 8 & 3.01 & 0.93 & 0.75 & 1.41 & 1.65 & 0.61 \\
\hline 9 & 2.41 & 1.38 & 0.39 & 1.86 & 1.65 & 0.48 \\
\hline Average & 2.90 & 1.46 & 0.62 & 1.58 & 1.69 & 0.53 \\
\hline \multirow{2}{*}{\multicolumn{2}{|c|}{$\Delta D_{T} \times 10^{5}\left(\mathrm{~cm}^{2} / \mathrm{s}\right)$}} & Benzoate & \multicolumn{2}{|c|}{ Uranine } & Bacteria & \\
\hline & & -1.32 & \multicolumn{2}{|c|}{0.23} & -0.09 & \\
\hline
\end{tabular}


Table A.5 Transverse dispersion coefficient values for nonchemotactic experiments at $2 \mathrm{~cm}$ spacing. Results have been calculated using two different methods: Equation 2.9 and a moment analysis.

\begin{tabular}{|c|c|c|c|c|c|c|}
\hline \multirow[b]{2}{*}{ Run } & \multicolumn{3}{|c|}{$D_{T} \times 10^{5}\left(\mathrm{~cm}^{2} / \mathrm{s}\right)-E q .2 .9$} & \multicolumn{3}{|c|}{$D_{T} \times 10^{5}\left(\mathrm{~cm}^{2} / \mathrm{s}\right)-$ Moment Analysis } \\
\hline & Benzoate & Uranine & Bacteria & Benzoate & Uranine & Bacteria \\
\hline 10 & 2.37 & 1.01 & 0.73 & 1.17 & 1.13 & 0.65 \\
\hline 11 & 2.21 & 1.11 & 0.75 & 1.53 & 1.31 & 0.69 \\
\hline 12 & 2.38 & 1.56 & 0.51 & 1.83 & 1.81 & 0.39 \\
\hline Average & 2.32 & 1.23 & 0.67 & 1.51 & 1.42 & 0.58 \\
\hline \multirow{2}{*}{\multicolumn{2}{|c|}{$\Delta D_{T} \times 10^{5}\left(\mathrm{~cm}^{2} / \mathrm{s}\right)$}} & Benzoate & \multicolumn{2}{|c|}{ Uranine } & Bacteria & \\
\hline & & -0.81 & \multicolumn{2}{|c|}{0.19} & -0.09 & \\
\hline
\end{tabular}




\section{A.4 Images from Mathematical Modeling}

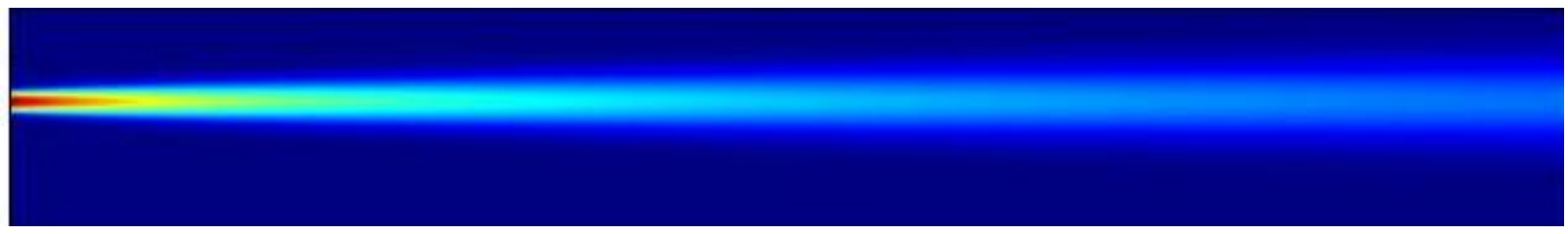

Figure A.6 Attractant concentration distribution image from COMSOL. Red represents a benzoate concentration of $5 \mathrm{mM}$, yellow represents $3 \mathrm{mM}$, and dark blue represent $0 \mathrm{mM}$.

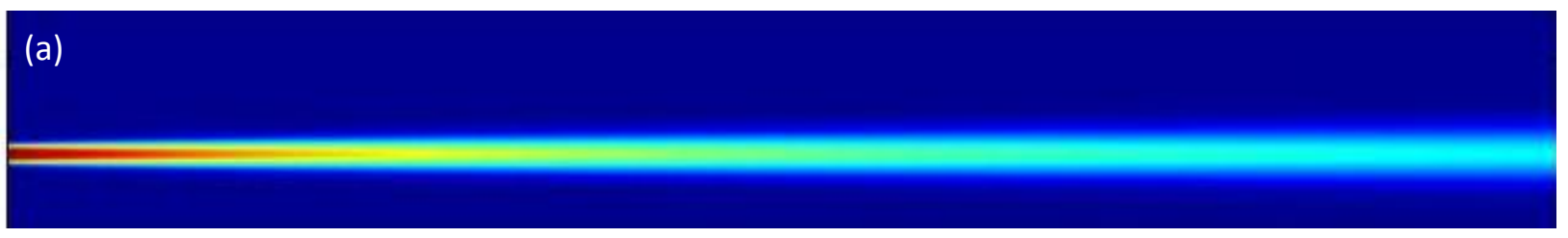

(b)

Figure A.7 (a) Nonchemotactic and (b) chemotactic bacteria concentration distribution images from COMSOL. Red represents a bacteria concentration of $10^{9}$ cells $/ \mathrm{mL}$, yellow represents $6 \times 10^{8}$ cells $/ \mathrm{mL}$, and dark blue represent 0 cells $/ \mathrm{mL}$. 